Modelagem e Análise de Requisitos de Sistemas Automatizados Usando UML e Redes de Petri 

SERVIÇO DE PÓS-GRADUAÇÃO DA POLI-USP

Data de Depósito: 22/03/2017

Assinatura:

\section{Modelagem e Análise de Requisitos de Sistemas Automatizados Usando UML e Redes de Petri}

\section{Arianna Zoila Olivera Salmon}

Orientador: Prof. Dr. José Reinaldo Silva

Tese apresentada à Escola Politécnica da Universidade de São Paulo, para obtenção do título de Doutor em Ciências. Área de Concentração: Engenharia de Controle e Automação Mecânica.

\section{USP - Escola Politécnica}

Março de 2017 
Este exemplar foi revisado e corrigido em relação à versão original, sob responsabilidade única do autor e com a anuência de seu orientador.

São Paulo, de de

Assinatura do autor:

Assinatura do orientador:

Salmon, Arianna Zoila Olivera

Modelagem e Análise de Requisitos de Sistemas Automatizados Usando UML e Redes de Petri / A. Z. O. Salmon -- versão corr. -- São Paulo, 2017.

$162 \mathrm{p}$.

Tese (Doutorado) - Escola Politécnica da Universidade de São Paulo. Departamento de Engenharia Mecatrônica e de Sistemas Mecânicos.

1.modelagem de sistemas automatizados 2.modelagem e análise de requisitos 3.redes de Petri 4.verificação formal I.Universidade de São Paulo. Escola Politécnica. Departamento de Engenharia Mecatrônica e de Sistemas Mecânicos II.t. 
Primeiramente, gostaria de agradecer ao meu orientador Prof. Dr. José Reinaldo Silva, pela sua orientação, apoio, dedicação e compreensão durante todos estes anos de pesquisa e trabalho. Seus ensinamentos, conselhos, críticas e discussões foram essenciais para minha superação acadêmica.

A todos meus professores da USP, por terem contribuído na minha formação. Em especial agradeço ao professor Dr. Diolino José dos Santos, suas conversas e sugestões sempre foram de grande ajuda e enriqueceram meus conhecimentos.

Agradeço também a todos meus colegas de Dlab, a convivência e troca constante de conhecimentos contribuíram muito na pesquisa.

Não posso deixar de agradecer aos meus amigos Ariagna Ramon, Daniel Mendoza, Helena Castro, José Ruben Sichar, Margarita Gonzalez, Michael Prieto, Oscar Rodriguez e Yahilina Silveira, por todo o apoio incondicional e incentivos.

Ao meu esposo Pedro M. González, por sua amizade, ensinamentos, e por acompanhar e criticar cada detalhe deste trabalho.

Agradeço à Coordenação de Aperfeiçoamento de Pessoal de Nível Superior (Capes), e à Agência Nacional do Petróleo, Gás Natural e Biocombustíveis- ANP - da Financiadora de Estudos e Projetos - FINEP- e do Ministério da Ciência, Tecnologia e Inovação -MCTI por meio do Programa de Recursos Humanos da ANP para o Setor Petróleo e Gás- PRH-ANP/MCTI, pelo suporte através de bolsas de estudo.

Por fim, um agradecimento especial à minha família, em especial aos meus país, irmãs e avós, que mesmo desde muito longe sempre estiveram presentes para me incentivar e dar todo seu apoio emocional. 



\section{RESUMO}

OLIVERA SAlMON, A. Z.. Modelagem e Análise de Requisitos de Sistemas Automatizados Usando UML e Redes de Petri. 2017. 162 f. Tese (Doutorado em Ciências. Área de Concentração: Engenharia de Controle e Automação Mecânica) - Escola Politécnica (POLI/USP), São Paulo.

Resumo

A fase inicial de projeto de sistemas, baseada na elicitação, modelagem e análise dos requisitos é considerada a mais complexa e a mais estratégica para obtenção de bons resultados. Por conseguinte, erros precisam ser detectados durante esta fase inicial, antes de começar a implementação, evitando assim o desperdício de tempo e recursos.

Este trabalho propõe um método formal de modelagem, análise e verificação de requisitos, partindo de uma representação semi-formal de requisitos em UML, e utilizando o formalismo das Redes de Petri para proceder à modelagem, análise e verificação. Propriedades das redes de Petri, tais como invariantes, são usadas para analisar os requisitos, permitindo uma validação antecipada dos requisitos no processo de design.

O objetivo deste trabalho é estender a aplicação das redes de Petri como representação formal para a modelagem e análise de requisitos, endereçando assim a fase anterior às especificações. Pressupõe-se a existência de uma disciplina de projeto baseada em modelos (model driven) que abrange a fase inicial do projeto e se propaga para a modelagem e verificação de soluções. Assim, a abordagem proposta nesta tese se encaixa plenamente em um processo orientado a modelos que use a mesma linguagem: as redes de Petri.

Palavras-chave: modelagem de sistemas automatizados, modelagem e análise de requisitos, Redes de Petri, verificação formal. 



\section{ABSTRACT}

OLIVERA SALMON, A. Z.. Modelagem e Análise de Requisitos de Sistemas Automatizados Usando UML e Redes de Petri. 2017. 162 f. Tese (Doutorado em Ciências. Área de Concentração: Engenharia de Controle e Automação Mecânica) - Escola Politécnica (POLI/USP), São Paulo.

\section{Abastract}

The first stage of system design, which includes elicitation, modeling, and analysis of requirements is considered at the same time, very complex and very strategic to achieve proper results.Therefore it is important to detect mistakes both, conceptual and in requirements, before implementation begins, avoiding the waste of time and resources.

This work proposes a formal method for modeling, analysis and verification of requirements, starting with a semi-formal representation of requirements in UML. Petri net and its properties such as invariants are used to analyze requirements, thereby allowing that requirements can be validated earlier.

The main objective of this work is to extend the application of Petri Nets, as a formal representation, to requirements phase, addressing specification building. It is assumed that there is a model driven design approach that encompass the initial (requirements) phase and goes through the modeling and verification of solutions. Therefore the approach proposed in this work fits a model driven general approach which could use the same formal language: Petri Nets.

Key-words: automated systems modeling, modeling and analysis of requirements, Petri nets, formal verification. 



\section{RESUMEN}

OLIVERA SALMON, A. Z.. Modelagem e Análise de Requisitos de Sistemas Automatizados Usando UML e Redes de Petri. 2017. 162 f. Tese (Doutorado em Ciências. Área de Concentração: Engenharia de Controle e Automação Mecânica) - Escola Politécnica (POLI/USP), São Paulo.

La fase inicial de proyecto de sistemas, basada en la elicitación, modelaje y análisis de requisitos, es considerada la más complexa, por lo que debe ser realizada de forma precisa, para conseguir detectar posibles errores. Es importante que, en esta fase inicial del proyecto, sean detectados los errores antes de comenzar la fase de implementación, evitando de esta manera, el desperdicio de tiempo y recursos.

En este trabajo se propone un método formal de modelaje, análisis y verificación de requisitos, que parte de una representación semi-formal en UML, y usa el formalismo de las redes de Petri para proceder a las fases de modelaje, análisis e verificación. Propiedades de las redes de Petri, como invariantes, son usadas para analizar los requisitos, permitiendo que estos requisitos sean validados anticipadamente de dentro del proceso de design.

El objetivo de este trabajo es extender la aplicación de las redes de Petri como representación formal para modelar y analizar requisitos, direccionando de esta forma la fase anterior a las especificaciones. Se asume la existencia de una disciplina de proyectos model driven que abarca la fase inicial del proyecto e se extiende hasta las fases de modelado y verificación de soluciones. Por consiguiente, el método propuesto en esta tesis se adapta completamente a un proceso orientado a modelos que use la misma lenguaje: redes de Petri.

Palabras clave: modelaje de sistemas, modelaje de requisitos, redes de Petri, verificación formal. 



\section{LISTA DE ILUSTRAÇÕES}

Figura 1 - Visão geral dos pacotes UML de PNML . . . . . . . . . . . . . . . 42

Figura 2 - Rede de Petri Colorida do sistema . . . . . . . . . . . . . 59

Figura 3 - Simulção do sistema em CPN-Tools(a) . . . . . . . . . . . . . . . 63

Figura 4 - Simulção sistema em CPN-Tools (b) . . . . . . . . . . . . . . 63

Figura 5 - Rede de Petri clássica obtida a partir da figura $2 \ldots \ldots$. . . . . . . . 64

Figura 6 - Matriz de incidência da rede da figura $5 \ldots \ldots$. . . . . . . . 65

Figura 7 - Invariantes de lugar da rede da figura $5 \ldots \ldots 5$

Figura 8 - Hierarquia dos diagramas da UML $2.5 \ldots \ldots \ldots$

Figura 9 - Rede de Petri do sistemas readers-writers modelada em GHENeSys . . . . 84

Figura 10 - Matriz de incidência do sistemas readers-writers calculada por GHENeSys . 84

Figura 11 - Invariantes de lugar e transição do sistemas readers-writers obtidos por GHENeSys ............................... 87

Figura 12 - Elementos do diagrama de Máquina de Estados . . . . . . . . . . . . . 91

Figura 13 - Diagrama de Integração Geral . . . . . . . . . . . . . . . . . . . . . . . 91

Figura 14 - Esquema da proposta $\ldots \ldots \ldots \ldots$. . . . . . . . . . . . 94

Figura 15 - Mapeamento dos elementos do diagrma de estados de UML e os elementos da rede

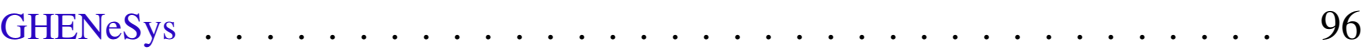

Figura 16 - Mapeamento das relações entre elementos do diagrama de estados de UML e a rede GHENeSys . . . . . . . . . . . . . . . . . . . . . 97

Figura 17 - Estrutura de clases que representam os diagramas de estados da UML _ . . . . . 98

Figura 18 - Estrutura de clases que representam a rede GHENeSys . . . . . . . . . . . . . 98

Figura 19 - Diagrama de classes . . . . . . . . . . . . . . . . . 108

Figura 20 - Diagrama de objetos correspondena à classe CCarro . . . . . . . . . . . . . 109 
Figura 21 - Diagramas de estados: (a) Diagrama de estados correspondente à classe CFabrica, (b) Diagrama de estados correspondente à classe CLinhaProdução, (c) Diagrama de estados correspondente à classe CPintura . . . . . . . . . 110

Figura 22 - Diagrama de estados correspondente à classe CLinhaProdução, considerando os diferentes objetos da classe . . . . . . . . . . . . . . . . 111

Figura 23 - Modelagem em GHENeSys da Linha de Produção . . . . . . . . . . . . . . 111

Figura 24 - Modelagem em GHENeSys da Linha de Produção com os novos lugares . 113

Figura 25 - Invariantes de lugar obtidos por GHENeSys . . . . . . . . . . . . . . 113

Figura 26 - Modelagem em GHENeSys do sistema completo . . . . . . . . . . . . 115

Figura 27 - Sistema de Evaporação . . . . . . . . . . . . . . . . . 116

Figura 28 - Diagrama de classes do Sistema . . . . . . . . . . . . . . 117

Figura 29 - Diagrama de classes da planta . . . . . . . . . . . . . . 118

Figura 30 - Diagrama de classes do controlador . . . . . . . . . . . . . . . . . 119

Figura 31 - Diagrama de estados da Planta:(a)Tank1, (b)Tank2, (c)Condensador . . . . 120

Figura 32 - Diagrama de estados do Controlador . . . . . . . . . . . . . . . . 121

Figura 33 - Modelagem em rede de Petri da planta . . . . . . . . . . . . . . 123

Figura 34 - Modelagem em rede de Petri do controlador . . . . . . . . . . . . . . . 124

Figura 35 - Invariantes da rede de Petri da Planta . . . . . . . . . . . . . 127

Figura 36 - Invariantes da rede de Petri do controlador . . . . . . . . . . . . . . 127

Figura 37 - Esquema das faixas e a posição dos portos na costa brasileira. . . . . . . . . 129

Figura 38 - Diagrama de classes do sistema geral . . . . . . . . . . . . . . . 130

Figura 39 - Diagrama de objetos correspondente as classes: (a) WaitingAreas, (b) Ports, (c) Platforms. . . . . . . . . . . . . . . . . . . . . 131

Figura 40 - Diagrama de estados da classe Ship . . . . . . . . . . . . . . . . 132

Figura 41 - Hirarquía dos diagramas de estados:(a) Diagrama de estado Geral, (b) Diagrama de estado correspondentes aos portos, (c) Diagrama de estados correspondentes as plataformas, (d) Diagrama de estados correspondentes as plataformas de reabastecimento . . . . . . . . . . . . . 133

Figura 42 - Diagrama de estado correspondentes aos portos. . . . . . . . . . . . . . 134 
Figura 43 - Diagrama de estado correspondentes as plataformas: (a) Plataformas sem abastacimento, (b) plataformas com abastecimiento . . . . . . . . . . . . 135

Figura 44 - Diagrama de tempo para operações do navio nos portos . . . . . . . . . . 136

Figura 45 - Diagrama de tempo para operações do navio nas plataformas . . . . . . . . 136

Figura 46 - Modelagem hierárquica do sistema na rede GHENeSys. (a) Rede geral do sistema,

(b) Rede correspondentes aos portos, (c) Rede correspondentes as plataformas, (d)

Rede correspondentes as plataformas de reabastecimento . . . . . . . . . . . . . 137

Figura 47 - Rede GHENeSys do sistema geral . . . . . . . . . . . . . . . . . . 139

Figura 48 - (a): Invariantes de lugar da rede que modela as ações nos portos (figura 46(b)). (b): Invariantes de lugar da rede que modela as ações nas plataformas (figura 46(c)). . 140

Figura 49 - Invariantes de lugar da rede principal (figura 47). A cor laranja pertence ao navio N1, a cor azul ao navio N2, e a cor vermelha ao navio N3. . . . . . . . . . . . 141

Figura 50 - Rede de Petri alto nível. . . . . . . . . . . . . . . . . . . . . . . 142

Figura 51 - Novo Diagrama de Classes da rede GHENeSys . . . . . . . . . . . . . . 158

Figura 52 - Teorema de Rouche-Frobenius . . . . . . . . . . . . . . . . . . . 161 

Algoritmo $1-$ Calculo Invariantes . . . . . . . . . . . . . . . 81

Algoritmo 2 - Calculo Invariantes de Transição . . . . . . . . . . . . . . . 81

Algoritmo 3 - Calculo Invariantes de Lugar . . . . . . . . . . . . . . . . 81

Algoritmo 4 - Calculo da solução básica . . . . . . . . . . . . . 82

Algoritmo 5 - Transformação UML-GHENeSys . . . . . . . . . . . . . . . . . 99

Algoritmo 6 - Criar arcos simples Part $1 \ldots \ldots \ldots$. . . . . . . . . 100

Algoritmo 7 - Criar arcos simples Part $2 \ldots \ldots \ldots 10 \ldots$

Algoritmo $8-$ Criar arcos multiples Part $1 \ldots \ldots \ldots 2$

Algoritmo $9-$ Criar $\operatorname{arcos}$ multiples Part $2 \ldots \ldots \ldots$ 

Tabela 1 - Condições algebraicas das propriedades estruturais . . . . . . . . . 82

Tabela 2 - Transformando o diagrama de estados da linha de produção em rede de Petri 109

Tabela 3 - Sinais do controlador presentes no modelo da planta . . . . . . . . . . 122

Tabela 4 - Descrição dos lugares da rede de Petri, correspondentes aos estados dos diagramas de estados da UML. . . . . . . . . . . . . . . . . . 122

Tabela 5 - Especificação em OCL correspondente ao funcionamento da Planta . . . . . 125

Tabela 6 - Definição das inequações que representam invariantes de lugar da Planta . . 125

Tabela 7 - Especificação em OCL correspondente ao funcionamento do Controlador . . 126

Tabela 8 - Definição das inequações que representam invariantes de lugar do Controlador 126

Tabela 9 - Equivalência entre os estados no diagrama de estados e os lugares na rede GHENeSys. 138

Tabela 10 - Especificação descritas em OCL correspondente as operações dos navios nos portos. 139

Tabela 11 - Especificação descritas em OCL correspondente as operações dos navios nas plataformas. . . . . . . . . . . . . . . . . . 139

Tabela 12 - Invariantes do sistema geral. . . . . . . . . . . . . . . . . . . . 140 

RdP ..... Redes de Petri

Post ..... Condição posterior

Pre ...... Condição prévia

CP-nets ... Rede de Petri Colorida

GHENeSys General Hierarchical Enhanced Net System

HLPNGs . High-Level Petri Net Graphs

IEC ..... International Electrotechnical Commission

ISO ..... International Organization for Standardization

MOF .... Modeling Objects Framework

OCL .... Object Constraint Language

OMG .... Object Management Group

PNML ... Petri Net Markup Language

PrT-nets .. Rede Predicado/Transição

RdP ...... Rede de Petri

RdP-AN .. Rede de Petri de alto nível

ROADEF . Société française de Recherche Opérationnelle et d'Aide à la Décision

SI ....... International System

Timed PNs Rede de Petri com tempo

UML .... Unified Modeling Language

XML ..... EXtensible Markup Language 

$\subseteq-$ Contido

$\rightarrow$ - Mapeamento

$\bullet \delta$ - Pré-elementos do elemento $\delta$

$\delta^{\bullet}$ — Pós-elementos do elemento $\delta$

$\Sigma$ - Somatória

$\leq-$ Menor ou igual que

$\in$ - Pertence

$\neq-$ Diferente

$\geq-$ Maior ou igual que;

$A^{T}$ — Transposta da matriz A

$\exists$ Existe

$\forall$ - Qualquer, para todos

$\wedge$ - "e"logico

$\equiv$ - Relação de equivalencia

$\vee —$ "ou"logico

$N$ - Conjunto dos números naturais

$N^{+}$— Conjunto dos números naturais sem o zero

$Q^{+}$— Conjunto dos números racionais positivos

$Q^{+} \cup\{\infty\}$ - Conjunto dos números racionais positivos incluindo innito

$\downarrow$ - operador que devolve o limite inferior de um intervalo 
$\uparrow —$ operador que devolve o limite superior de um intervalo

$\infty-$ Infinito 

INTRODUÇÃO $\ldots \ldots \ldots \ldots \ldots \ldots \ldots \ldots$

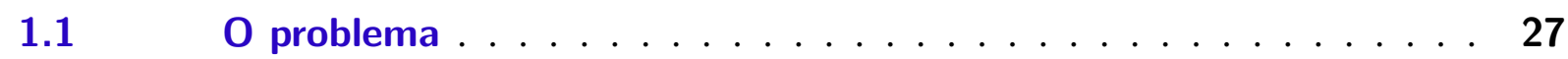

$1.2 \quad$ Justificativa . . . . . . . . . . . . . . . . . 29

$1.3 \quad$ Objetivos da tese $\ldots \ldots \ldots \ldots \ldots \ldots$

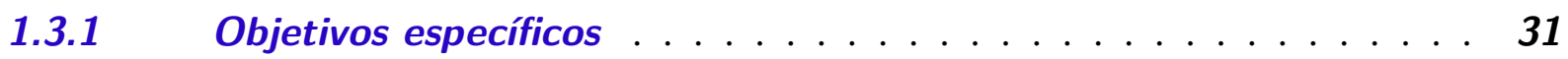

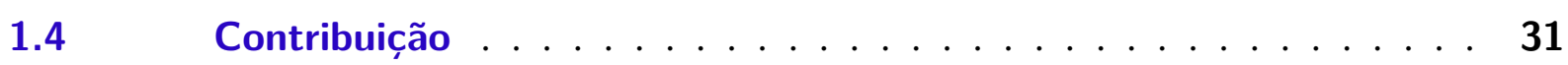

$1.5 \quad$ Metodologia $\ldots \ldots \ldots \ldots \ldots \ldots \ldots \ldots \ldots \ldots \ldots$

1.6 Organização do trabalho $\ldots \ldots \ldots \ldots \ldots \ldots \ldots \ldots \ldots \ldots$

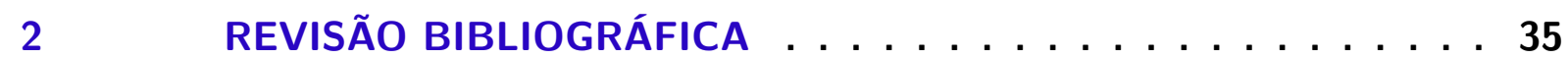

$2.1 \quad$ Redes de Petri: conceitos fundamentais . . . . . . . . . . 35

2.1.1 Definição formal . . . . . . . . . . . . . . . . . . 36

2.1.1.1 Definição dos lugares de entrada e saída . . . . . . . . . . . . . . . 37

2.1.2 Matriz de incidência e Equação de estado . . . . . . . . . . . 37

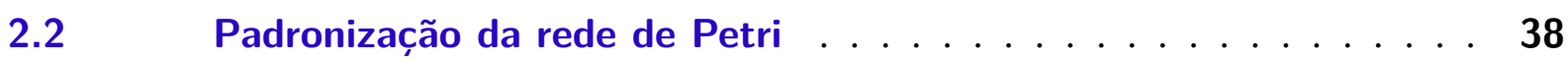

2.2.1 Norma ISO/IEC 15909-1 . . . . . . . . . . . . . . . 39

2.2.1.1 Rede de Petri clássica . . . . . . . . . . . . . . . . . . . . . 39

2.2.1.2 Redes de Petri de alto nível . . . . . . . . . . . . . . . . . 40

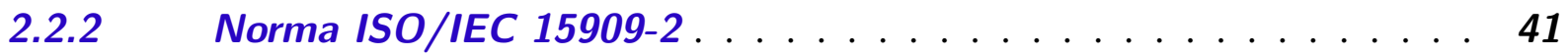

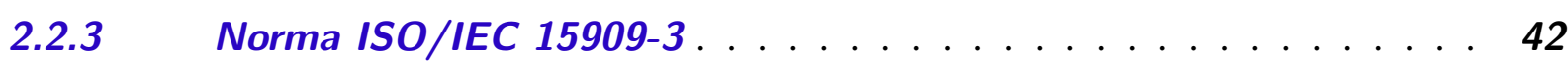

2.2.3.1 Rede de Petri estendidas . . . . . . . . . . . . . . . . . 42

$2.3 \quad$ Técnicas de análise em rede de Petri $\ldots \ldots \ldots \ldots$

$2.4 \quad$ Propriedades das redes de Petri $\ldots \ldots \ldots \ldots \ldots$

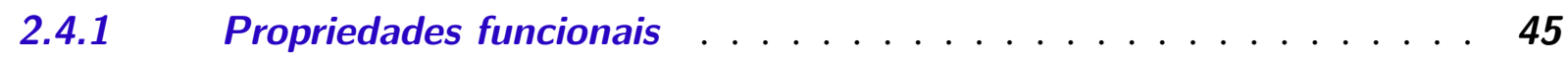

2.4.1.1 Alcançabilidade . . . . . . . . . . . . . . . . 45 
2.4.1.2 Limitação. . . . . . . . . . . . . . . . . . . 46

2.4.1.3 Vivacidade ...................... 46

2.4.1.4 Reversibilidade . . . . . . . . . . . . . . . . 47

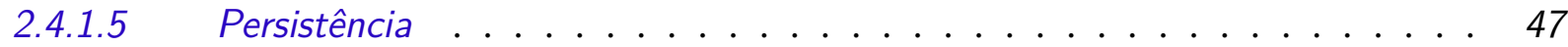

2.4.2 Propriedades estruturais . . . . . . . . . . . . . . 47

2.4.2.1 Limitação Estrutural . . . . . . . . . . . . . . . . . . . . 47

2.4.2.2 Conservatividade . . . . . . . . . . . . . . . . 47

2.4.2.3 Repetitividade ..................... 48

2.4.2.4 Consistência . . . . . . . . . . . . . . . . . . 48

2.4.2.5 Vivacidade estrutural . . . . . . . . . . . . . . 48

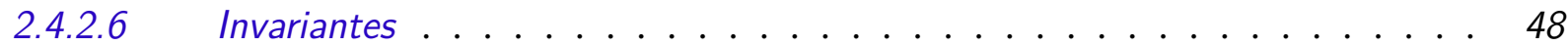

$2.5 \quad$ Teoria dos Invariantes $\ldots \ldots \ldots \ldots$

2.5.1 Invariantes algébricos: definições . . . . . . . . . . . 51

2.5.2 Invariantes na ciência da computação . . . . . . . . . . . . . . 52

$2.6 \quad$ Análise dos Invariantes nas redes de Petri . . . . . . . . . . 53

2.6.1 Análise dos invariantes em redes clássicas . . . . . . . . . . . . . 54

2.6.2 Análise dos invariantes em redes de alto nível . . . . . . . . . 55

2.6.2.1 Métodos para calcular os invariantes em CP-nets . . . . . . . . . . . 56

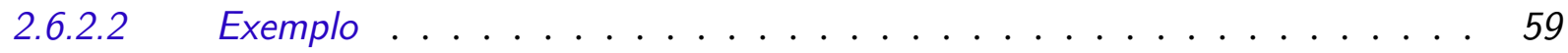

2.6.3 Considerações finais . . . . . . . . . . . . . . . . 65

$2.7 \quad$ Engenharia de requisitos: Visão Geral . . . . . . . . . . . . . . 67

2.7.1 Definição de requisitos . . . . . . . . . . . . . . . 68

2.7.2 Classificação dos requisitos . . . . . . . . . . . . . . . 69

2.7.3 Atividades envolvidas na Engenharia de Requisitos . . . . . . . . . 69

2.7.4 Engenharia de Requisitos Orientada a Objetivos . . . . . . . . . . . . 71

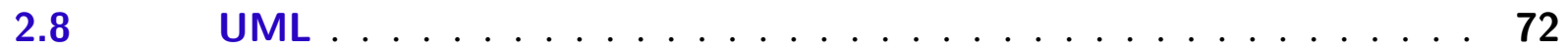

$2.8 .1 \quad O C L \ldots \ldots \ldots \ldots \ldots \ldots \ldots \ldots$

2.8.2 UML e redes de Petri na modelagem de sistemas . . . . . . . . . 75

$3 \quad$ PROPOSTA $\ldots \ldots \ldots \ldots \ldots \ldots \ldots$

3.1 Análise de propriedades estruturais usando os invariantes . . . . . 78 
3.1.1 Cálculo dos invariantes . . . . . . . . . . . . . . . . 79

3.1.1.1 Método para obter a solução básica do sistema de equações lineares homogêneos 80

3.1.2 Método para analisar outras propriedades partindo dos invariantes . 82

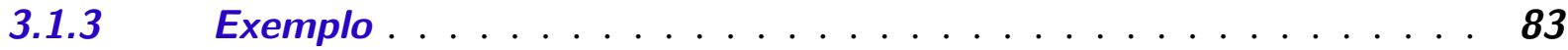

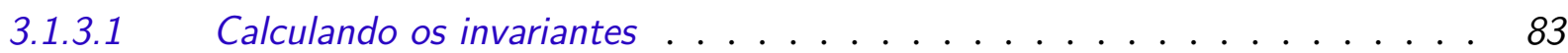

3.1.3.2 Analisando outras propriedades estruturais . . . . . . . . . . . . . . 87

3.2 Método de modelagem: UML- GHENeSys . . . . . . . . . . . 87

3.2.1 Proposta de um conjunto mínimo de diagramas para modelar sistemas a eventos discretos . . . . . . . . . . . . . . . . 88

3.2.1.1 Diagrama de classes . . . . . . . . . . . . . . . 88

3.2.1.2 Diagrama de Pacote (Package Diagram) . . . . . . . . . . . . . . 89

3.2.1.3 Diagrama de Objeto . . . . . . . . . . . . . . . . . . 89

3.2.1.4 Diagramas comportamentais . . . . . . . . . . . . . . . 89

3.2.1.5 Diagrama de tempo . . . . . . . . . . . . . . . 89

3.2.1.6 Diagrama de máquina de estados . . . . . . . . . . . . . . . . 90

3.2.1.7 Diagrama de interação geral . . . . . . . . . . . . . . . . 90

3.3 Disciplina de Projeto UML- GHENeSys . . . . . . . . . . . . . 92

3.3.1 Método para transformar os diagramas de estado de UML em redes de Petri . . . . . . . . . . . . . . . . . . . . . 94

3.3.2 Algoritmo de transformação UML- GHENeSys . . . . . . . . . . . . 97

3.3.3 Transformação de restrições em equações . . . . . . . . . . . . . 103

3.3.3.1 Restrições lógicas . . . . . . . . . . . . . . . . . . . 103

3.3.3.2 Restrições como inequações (menor que, ou igual a) . . . . . . . . . . . 104

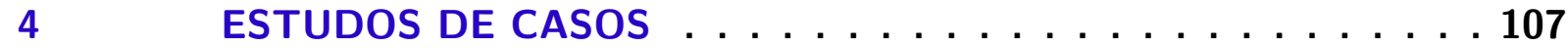

$4.1 \quad$ Problema proposto pelo ROADEF $2005 \ldots \ldots$. . . . . . . . 107

4.1.1 Modelagem usando a linguagem UML . . . . . . . . . . . . 108

4.1.2 Transformando os diagramas de estados em redes de Petri . . . . . 109

4.1.3 Representação das restrições em forma de regras . . . . . . . . . . . 110

4.1.4 Definição das equações (invariantes) . . . . . . . . . . . . 112

4.1.5 Verificação dos requisitos usando os invariantes . . . . . . . . . 112 
4.2 Sistema de evaporação . . . . . . . . . . . . . . . . . . 115

4.2.1 Modelando o sistema em UML . . . . . . . . . . . . . . . . . 117

4.2.2 Transformando os diagramas UML em rede de Petri . . . . . . . . 121

4.2.3 Definindo os invariantes . . . . . . . . . . . . . . . . . . . 124

4.2.4 Verificando os requisitos . . . . . . . . . . . . . . . 125

4.3 Planejamento de operações de navios em plataformas e portos de petróleo . . . . . . . . . . . . . . . . . . . 128

4.3.1 Especificações do sistema . . . . . . . . . . . . . . . . . 128

4.3.2 Restrições do sistema a ser consideradas neste trabalho . . . . . . 129

4.3.3 Modelagem do sistema de planejamento . . . . . . . . . . . . . 130

4.3.4 Transformando os diagramas UML em rede de Petri . . . . . . . 136

4.3.5 Verificação dos modelos . . . . . . . . . . . . . . . . 138

5 CONCLUSÕES E TRABALHOS FUTUROS $\ldots \ldots \ldots$

$5.1 \quad$ Conclusões $\ldots \ldots \ldots \ldots \ldots \ldots \ldots \ldots \ldots \ldots \ldots$

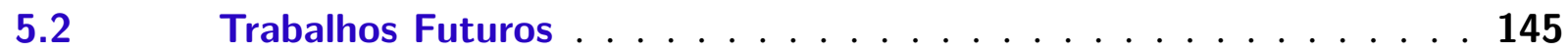

Referências Bibliográficas . . . . . . . . . . . . . . . 146

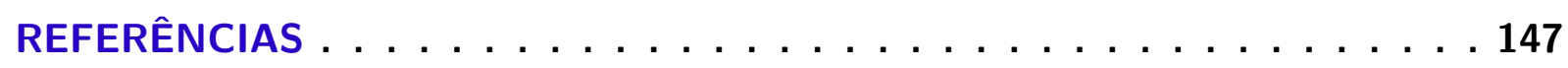

ANEXO A REDE DE PETRI GHENESYS $\ldots \ldots \ldots \ldots$

A.1 Diagrama de classes da rede GHENeSys $\ldots \ldots \ldots \ldots$

ANEXO B SISTEMAS DE EQUAÇÕES LINEARES $\ldots \ldots \ldots 159$

B.1 Sistemas de equações lineares homogêneos . . . . . . . . . . . . 161

B.2 Conjunto solução de um sistema de equações lineares homogêneos 162 


\subsection{O problema}

Existe uma tendência atual de produzir e utilizar sistemas cada vez mais complexos, o que implica que o custo para projetá-los também aumenta, levando pesquisadores e desenvolvedores a procurar novas abordagens que garantam mais confiabilidade e escalabilidade ao processo de desenvolvimento de projetos. Neste contexto, novos métodos de análise, modelagem, desenvolvimento e implementação foram sugeridos e testados em várias fases do processo de projeto. Especificamente, a fase inicial de projeto, baseada na obtenção, especificação e análise de requisitos, é considerada a fase estrategicamente mais sensível, dado que uma formalização completa do processo é inviável nesta fase. Por outro lado, as pesquisas mais recentes vão na direção da antecipação da formalização, aproximando-a cada vez mais da fase inicial de elicitação de requisitos (LIU; YU; MYLOPOULOS, 2002).

Entretanto, independentemente de como se faz a especificação final, o sucesso de qualquer projeto depende em grande parte da correta e completa definição dos requisitos, e a especificação dos requisitos serve como um balizador, cuja qualidade se reflete nas demais fases de desenvolvimento. A identificação inadequada dos requisitos é uma das principais causas de falhas nos sistemas, e portanto, a eliminação de erros durante esta fase é de vital importância no ciclo de desenvolvimento dos projetos. 
Muitos pesquisadores têm usado técnicas de modelagem semi formais (GOGUEN; LINDE, 1993) para capturar requisitos seguido de uma fase de análise e verificação. O questionamento que se faz a estes trabalhos reside justamente na análise, dado que tudo repousa sobre uma base informal e portanto depende muito da habilidade do designer. Por conseguinte, resultados diferentes podem surgir de um mesmo processo realizado por equipes distintas. Assim, uma boa parte dos trabalhos em Engenharia de Requisitos têm como foco reduzir a fase informal do processo de análise de requisitos (BARESI; PEZZÈ, 2001), (GUERRA; LARA, 2003).

Existem três desafios fundamentais na análise de requisitos que ainda não foram resolvidos, e são frequentemente mencionados em pesquisas recentes:

- A detecção e análise de requisitos, geralmente imprecisos e incompletos (LIU; YEN, 1996);

- A detecção de inconsistências e o estabelecimento de métodos para gerenciá-las;

- A criação de um processo sistemático que leve dos requisitos especificados informalmente, mesmo que imprecisos, a uma especificação formal.

A estes desafios é possível acrescentar ainda a volatilidade dos requisitos, isto é, o fato de que requisitos inseridos na fase de elicitação e análise podem perder validade ou até mudar de conteúdo e abrangência, durante o próprio processo de design, ou ainda, podem desaparecer ou se fundir com outros. Um grande desafio seria a detecção prévia, isto é, durante a fase de análise de requisitos, desta volatilidade (SANTOS; SILVA, 2005). Outro desafio importante é garantir o mapeamento entre os requisitos e os "features" do sistema, de modo a garantir, por um lado, que todos os requisitos tenham sido atendidos, e por outro, orientar a manutenção da sua validade (VAQUERO; SILVA, 2011). Estes desafios estão no entanto fora do escopo do presente trabalho.

O escopo desta tese é justamente o processo de análise de requisitos eliciados, especialmente quando se trata de sistemas automatizados, isto é, que possuem uma dinâmica, e esta dinâmica é um das propriedades principais do sistema a ser desenvolvido. Um formalismo esquemático basedo em grafos, as redes de Petri, é apresentado como base para a análise e também para a verificação formal dos requisitos, minorando as possibilidades de erros e omissões que afetem a descrição do sistema a ser desenvolvido. 


\subsection{Justificativa}

As Redes de Petri (RdP) constituem o formalismo mais usado na academia e na prática para a modelagem e análise de sistemas discretos concorrentes. Trata-se de um método relativamente recente, introduzido em 1962, com a tese de doutorado de Carl Adam Petri, cujo objetivo principal era a modelagem de processos com troca de mensagens. A base formal do método sempre foi a teoria de Grafos e a base conceitual a representação de relações entre um conjunto de elementos que pode ser associada ao paradigma estado/transição, usado no design de sistemas dinâmicos discretos. Assim, as redes de Petri passaram a compor a base teórica dos sistemas automatizados, que na sua grande maioria são sistemas discretos, dinâmicos e concorrentes.

Nestes anos, as redes de Petri passaram por um ciclo evolutivo que acompanha de perto a sofisticação dos sistemas automatizados e a exigência cada vez maior por sistemas com baixo índice de falhas. Um dos traços predominantes neste ciclo é o aumento do escopo de aplicação e a abrangência das Redes de Petri, que passaram rapidamente a ser estudadas como uma representação formal independente do domínio de aplicação, isto é, como um esquema que pode ser usado em sistemas de grande porte.

A evolução destes sistemas, mesmo quando não dependem funcionalmente do tempo, apresenta propriedades típicas dos sistemas dinâmicos que precisam ser previstas na fase inicial do processo de design, validadas, modeladas e posteriormente verificadas antes da fase seguinte onde se buscariam as soluções do problema. Este processo pode se tornar bastante difícil, especialmente quando os sistemas são grandes (no sentido de possuírem um número elevado de componentes) e complexos (no sentido de terem um número elevado de relações entre os seus componentes, ou quando o número de componentes não se conserva).

Assim, o grande interesse para o desenvolvimento destes sistemas é o estudo de propriedades que se apresentam em qualquer fase do processo de design, mesmo que de forma diferente (polimórfica), mas preservam o seu significado básico. Tursky e Maibaum denominaram extensão conservativa à capacidade de certas propriedades evoluírem mantendo a consistência e o seu conteúdo básico, e descreveram formalmente este processo. No caso o objeto de estudo para estes autores era o processo de desenvolvimento de software. Curiosamente, uma das áreas para onde evoluíram as aplicações das redes de Petri, desde os anos 80, foi a Engenharia de Software. 
Neste trabalho são analisadas as propriedades dos modelos em redes de Petri para dar suporte ao matching destas com as propriedades relevantes do sistema. Por exemplo, invariantes são propriedades que se preservam ao longo do processo de design, evoluem de forma conservativa, e possuem representação formal em Redes de Petri. São discutidos os métodos clássicos para a análise de invariantes para sistemas de grande porte e complexidade média fora do escopo dos sistemas complexos, onde se aplica a teoria do Caos - sempre apontando as vantagens e desvantagens de cada método ou algoritmo. Introduz- se então a possibilidade de aplicar a análise de invariantes às redes hierárquicas, onde se pode também ter a vantagem de controlar e representar as extensões conservativas do sistema em desenvolvimento. Esta parte do trabalho é baseada nas redes GHENeSys(General Hierarchical Enhanced Net System), criada pela equipe do Design Lab. Estas redes têm a vantagem de definir um ambiente de modelagem e design em Redes de Petri (clássicas e de alto nível) aderente à norma ISO/IEC 15.909, que são denominadas redes unificadas.

\subsection{Objetivos da tese}

Este trabalho tem como objetivo principal propôr um método para a análise, modelagem e verificação de requisitos, partindo da sua representação semi-formal em UML (Unified Modeling Language), e utilizando métodos formais baseados em Rede de Petri. Propriedades da rede de Petri, tais como invariantes, são usadas para analisar os requisitos e validá-los utilizando este mesmo formalismo.

Para cumprir este objetivo foi revisto o formalismo de invariantes de lugar e transição nas redes de Petri clássicas e estendidas, e foram analisadas as extensões conservativas utilizando redes hierárquicas. Também foi estudado o uso de invariantes na analise e verificação das propriedades desejadas dos sistemas, o que permitiu desenvolver uma disciplina de projeto, que possibilita representar e verificar requisitos de sistemas usando invariantes. Esta disciplina foi aplicada em sistemas automatizados de grande porte. 


\subsubsection{Objetivos específicos}

- Análise crítica dos métodos formais existentes, revisão dos algoritmos mais eficientes e estudo da sua inserção em um ambiente moderno de modelagem em Redes de Petri, no caso, o sistema GHENeSys ${ }^{1}$;

- Formalização do processo de extensão dos invariantes em uma rede hierárquica generalizada (que agrega extensões);

- Proposição de algoritmos de análise e verificação dos requisitos de projeto usando invariantes;

- Proposta de uma disciplina de projeto usando como linguagem de especificação de requisitos a UML (versão 2.5), e utilizando métodos formais baseados em Rede de Petri para proceder à modelagem, análise e verificação destes requisitos.

- Aplicação prática dos métodos propostos em sistemas automatizados de grande porte.

\subsection{Contribuição}

A principal contribuição deste trabalho é melhorar o processo de projeto de sistemas automatizados através da análise das propriedades de invariantes de lugar e transição (ou outras propriedades que possam ser deduzidas desta), em redes unificadas e que satisfaçam a norma ISO/IEC 15.909 que define a rede de Petri. Introduzir uma nova disciplina de projeto automatizável (parcialmente) e de base formal que facilite a análise de requisitos. Espera-se com isso cobrir uma lacuna na fase inicial dos projetos que leva a um tratamento superficial dos requisitos.

\subsection{Metodologia}

A tese foi desenvolvida pelo método exploratório, onde, a partir da hipótese inicial - a de que seria possível propor um método formal e semi-automatizado para análise de requisitos foram explorados os métodos atuais para propor um novo método compatível com os métodos formais existentes.

1 GHENeSys é um ambiente computacional orientado à modelagem de Sistemas Discretos e distribuídos que utiliza as Redes de Petri unificadas, incluindo extensões e orientação a objetos 
O objetivo é o de ter um método sound e também aplicável na prática. Por isso foi escolhido o tratamento em um ambiente que satisfizesse a norma vigente (ISO/IEC 15.909) para uso das rede Petri, que fosse definido formalmente, e que também admitisse extensões (de acordo com a norma) sugeridas por razões práticas, seja para análise de sitemas de manufatura, engenharia de software, ou outra área. Assim, o sistema GHENeSys foi escolhido como base.

GHENeSys é um ambiente de redes de Petri que admite, além das extensõs básicas (como gates) outras extensões como a hierárquia, orientação a objetos e a inserção do tempo como parâmetro ou como varíável. Portanto possui os elementos básicos para analisar propriedades seguindo a abordagem clássica, e também incluir elementos macro, lugares especiais para conexão entre o sistema estudado e o contexto (pseudo- lugares), e até elementos temporizados e temporais.

A validação dos resultados se dá, primeiramente pela aderência da base formal da norma ISO/IEC 15.909, pela aderência ao ambiente formalmente definido do GHENeSys, e pela aplicação prática, primeiro em estudos de caso modelo e depois em aplicações realísticas, como a modelagem do sistema de controle de navios de abastecimento para as plataformas do pre-sal.

Estes resultados foram apresentados em artigos publicados em congressos (SALMON et al., 2011), (SALMON; SILVA, 2012), (SALMON et al., 2014), (SALMON et al., 2016) e um artigo enviado para o IEEE Systems Journal, entitulado Modeling, Analysis and Verification of Requirements for Automated Systems Using UML/Petri Nets.

\subsection{Organização do trabalho}

O trabalho está organizado como segue:

No capítulo 2 é apresentado o estado da arte, que inclui as definições fundamentais das redes de Petri, suas propriedades funcionais e estruturais. Também é apresentado uma breve revisão teórica sobre invariantes. São descritos alguns dos principais métodos para analisar invariantes, tanto nas redes clássicas como nas redes de alto nível. Este capítulo também apresenta uma visão geral da engenharia dos requisitos, e da linguagem UML.

O capítulo 3 apresenta os métodos propostos para a análise e verificação de requisitos, usando UML e invariantes. Serão apresentados algoritmos para o cálculo dos invariantes nas redes 
GHENeSys, assim como o uso destes invariantes na análise de outras propriedades estruturais presentes nos sistemas. Além disto, neste capítulo será apresentada uma proposta de metodología de projeto usando invariantes na representação e análise de requisitos de sistemas, ainda na fase inicial do projeto (de elicitação e pré-análise dos requisitos).

Três estudos de caso são mostrados no capítulo 4, a fim de mostrar os resultados obtidos no desenvolvimento dos métodos propostos no capítulo 3.

Finalmente no capitulo 5 são apresentadas as conclusões e recomendações para trabalhos futuros. 



\section{REVISÃO BIBLIOGRÁFICA}

Nesta seção é apresentada uma sínteses dos principais conceitos, características, propriedades e aplicações do formalismo da rede de Petri.

\subsection{Redes de Petri: conceitos fundamentais}

A rede de Petri foi criada pelo matemático e cientista da computação Carl Adam Petri, em sua tese de doutorado intitulada Kommunikation mit Automaten (Comunicação com Autômata). O objetivo principal deste trabalho era a modelagem de processos com troca de mensagens. A base formal do método foi a teoria de Grafos e a base conceitual a representação de relações entre um conjunto de elementos que pode ser associado a uma representação estado/transição, característica dos sistemas dinâmicos discretos (SILVA, 2013). A característica principal do modelo desenvolvido por Petri foi a possibilidade de representar concorrência, um dos problemas candentes na segunda metade do século passado, e este modelo recebeu o nome de Rede de Petri em homenagem ao seu criador. Atualmente existem muitas variações do modelo original, possibilitando a aplicação destas redes em diversas áreas da ciência. A rede de Petri passou a compor a base teórica dos sistemas automatizados, que na sua grande maioria são sistemas discretos, dinâmicos e concorrentes.

A rede de Petri constitui hoje uma potente ferramenta de modelagem gráfica e formal que 
permite a descrição e o estudo de sistemas dinâmicos discretos. Além disto possui uma sólida base matemática que facilita a análise e a verificação de um número grande de propriedades presentes nos sistemas. A análise destas propriedades permite a verificação dos requisitos funcionais dos sistemas modelados, o que facilita a detecção de possíveis erros e facilita a correção destes, antes de iniciar a fase de implementação, aderindo assim, às técnicas de design orientadas a modelos e à prototipagem virtual.

A rede de Petri também pode ser vista como um formalismo visual que pode explicar o comportamento físico de um sistema e seus componentes, pelo menos no que se refere à evolução dos estados. Esta rede é usada tanto para modelar sistemas de software como hardware, podendo ser aplicada em diferentes níveis da engenharia de sistemas. Comparado com outros formalismos, a rede de Petri é mais adequada para ser uma "running specification"de sistemas discretos distribuídos.

Como ferramenta gráfica, a rede de Petri é usada como suporte para a comunicação visual, da mesma forma que os diagramas de fluxos. A diferença em favor das Redes de Petri é que é possível usar os tokens para simular as atividades dinâmicas e concorrentes dos sistemas. Matematicamente, têm uma representação algébrica perfeitamente aderente à representação gráfica, o que permite uma alternância entre métodos formais e semi-formais. Esta característica vai permitir uma aderência maior ao processo de análise de requisitos.

\subsubsection{Definição formal}

A seguir uma definição formal da rede Place/Tranistion (P/T) (MURATA, 1989) é apresentada.

Uma rede de Petri P/T é uma 5-tuple, $P N=(P, T, F, W, M o)$ onde:

$P=\left\{p_{1}, p_{2}, \cdots, p_{m}\right\}$ é um conjunto finito de lugares,

$T=\left\{t_{1}, t_{2}, \cdots, t_{n}\right\}$ é um conjunto finito de transições,

$F \subseteq(P X T) \cup(T X P)$ é um conjunto de arcos (relação de fluxo),

$W: F \rightarrow\{1,2,3, \cdots\}$ é uma função de peso,

$M_{0}: P \rightarrow\{0,1,2,3, \cdots\}$ é a marcação inicial, 
A estrutura de uma rede de Petri $N=(P, T, F, W)$ sem a especificação da marcação inicial é denotada por $N$. Uma rede de Petri onde é especificada a marcação inicial é denotada por $\left(N, M_{0}\right)$.

Para simular o comportamento dinâmico de um sistema, um estado ou marcação da rede de Petri muda de acordo com as seguintes regras de disparo de uma transição:

- Uma transição $t$ está habilitada se cada lugar de entrada $p$ da transição $t$ está marcado com pelo menos $w(p, t)$ token, onde $w(p, t)$ é o peso do arco desde $p$ até $t$.

- Uma transição habilitada pode ou não ser disparada, se os eventos de que dependem acontecem ou não nesse momento.

- Uma transição habilitada $t$ elimina $w(p, t)$ token de cada lugar de entrada $p$ de $t$, e adiciona $w(t, p)$ token a cada lugar de saída $p$ de $t$, onde $w(t, p)$ é o peso do arco de $t$ a $p$.

\subsubsection{Definição dos lugares de entrada e saída}

A notação $I\left(t_{j}\right)$ representa o conjunto dos lugares de entrada à transição $t_{j}$, enquanto $O\left(t_{j}\right)$ representa o conjunto dos lugares de saída da transição $t_{j}$. Formalmente:

$$
I\left(t_{j}\right)=\left\{p_{i} \in P:\left(p_{i}, t_{j}\right) \in F\right\}, \quad O\left(t_{j}\right)=\left\{p_{i} \in P:\left(t_{j}, p_{i}\right) \in F\right\}
$$

Outra notação muito utilizada para definir elementos (aplica-se tanto a lugares quanto a transições) de entrada e saída é a seguinte: Seja $\delta \in \Delta=P \cup T$ um elemento da rede $N=$ $(P, T, F, w)$

$$
\bullet \boldsymbol{\delta}=\{x \in \Delta:(x, \boldsymbol{\delta}) \in F\}, \quad \boldsymbol{\delta}^{\bullet}=\{y \in \Delta:(\boldsymbol{\delta}, y) \in F\}
$$

\subsubsection{Matriz de incidência e Equação de estado}

Uma rede de Petri $N$ pode ser representada por duas matrizes, uma indicando os conjuntos de lugares que servem de entrada para cada uma das transições da rede, onde $\left(\right.$ Pre $\left._{N}\right)$ denota as pré-condições de uma localidade, $\left(\operatorname{Pos}_{N}\right)$ que denota as pós-condições.

A matriz de indidência $C$ é dada pela soma $\operatorname{Pre}_{N}+\operatorname{Pos}_{N}$ onde cada elemento $\left[c_{i j}\right]=$ $w(i, j)^{+}+w(i, j)^{-}$, isto é, é igual à soma dos pessos dos arcos incidentes e dos arcos emergentes. 
Para usar estas matrizes na análise das redes de Petri, é preciso usar um vetor que indique quais as transições deverão disparar, chamado vetor de habilitação. Existem algorítmos para calcular o vetor de habilitação, a partir estrutura da rede, dada pela matriz de incidência e da marcação corrente.

Assim, a marcação no estado $k$ é dada por um vetor coluna $M_{k}$, onde a j-ésima entrada de $M_{k}$ denota o número de tokens no lugar $j$. Neste estado o vetor de habilitação $u_{k}$ é um vetor coluna $n x 1$ unimodular, onde um elemento genérico $j$ indica se a $i$-ésima transição está habilitada $\left[u_{k}\right]_{j}=1$ ou não $\left[u_{k}\right]_{j}=0$.

A equação de estado é então dada por $M_{k}+1=M_{k}+C^{T} u_{k}$ onde $k$ é um inteiro positivo.

\subsection{Padronização da rede de Petri}

Desde o início deste século, surgiram duas grandes tendências no tratamento das Redes de Petri:

- a primeira ampliava o uso da Rede de Petri como formalismo para modelar vários sistemas discretos em diferentes áreas do conhecimento, desde os sistemas biológicos e químicos até os sistemas de controle aplicado a procesos de fabricação e sistemas automatizados em geral, bem como a extrapolação do seu uso para várias fases do processo de design, desde a análise de requisitos até a definição das soluções - o que por outro lado ampliava também o número de redes e elementos especiais definidos por usuários;

- a segunda propunha a introdução de uma abordagem unificada para as Redes de Petri onde as redes $\mathrm{P} / \mathrm{T}$ e de alto nível são vistas como a abordagem de referência única. Esta corrente leva à proposição de ambientes unificados de modelagem e design (como o sistema GHENeSys), à possibilidade de ter uma linguagem de transferência, a PNML, que permite passar modelos de um ambiente para outro, e disciplina a introdução das extensões, obrigando-as a obedecer ao formalismo das redes de referência.

A normatização da rede de Petri pode ser vista como o maior esforço da comunidade acadêmica para unificar o estado atual e o futuro das pesquisa e desenvolvimento na área. O principal objetivo da norma ISO/IEC 15.909 é definir as características que permitem uma 
proposta de formalismo de rede a ser considerado uma rede de Petri. Este esforço de padronização convergiu para a norma ISO/IEC 15.909, e foi concebido em três etapas: a etapa 1, designada por High level Petri Nets-Concepts, Definitions and Graphical Notation; a parte 2, designada por High level Petri Nets-Transfer Format; e a parte 3, designada por High level Petri Nets-Extensions.

A seguir descrevem-se brevemente as característica destas normas, que são de grande importância para este trabalho, justamente pelo deslocamento do foco no uso das rede de Petri, dos aspectos de representação gráfica e executabilidade para aspectos mais gerais do formalismo (sem excluir os anteriores), o que leva necessariamente à valorização da análise de propriedades, que é o tema central desta tese.

\subsubsection{Norma ISO/IEC 15909-1}

A primeira parte da norma foi publicada como uma Norma Internacional (SI), em dezembro de 2004 e fornece uma documentação completa da terminologia, do modelo semântico e das notações gráficas para redes de Petri de alto nível (RdP-AN). Tecnicamente, a parte 1 da norma fornece as definições matemáticas da rede de Petri de alto nível (BILLINGTON et al., 2002), partindo da definição clássica das redes P/T aceita pela comunidade acadêmica.

Um glossário apresenta os diferentes termos a serem utilizados no contexto das redes de Petri. Sendo assim, existe um significado preciso para cada termo, o qual é detalhado utilizando notações matemáticas. O documento é, portanto, auto-suficiente e evita qualquer ambiguidade.

O modelo semântico da RdP-AN é definido usando notações matemáticas precisas. Todos os elementos básicos necessários para trabalhar com a RdP-AN são: marcação, habilitação das transições e as regras de transição.

Estes conceitos definidos matematicamente são redefinidos usando uma linguagem natural, e relacionados com as notações gráficas que são mais comumente utilizados na prática. Por isso, os gráficos que representam a rede estão definidos formalmente.

\subsubsection{Rede de Petri clássica}

Na rede de Petri clássica, a interpretação das marcas não é diferenciável a não ser pela estrutura da rede à qual estão associadas. Ela ainda pode ser subdividida em elementar 
(ROZENBERG, 1998) e Lugar/transição (DESEL, 1998).

A rede elementar conserva as características da rede proposta por Petri em sua tese de doutorado. Ela é extremamente restritiva do ponto de vista de modelagem, pois permite a existência de apenas uma marca em cada elemento da rede.

A rede lugar/transição busca minimizar este esforço de modelagem relaxando as restrições impostas à rede elementar, fundamentalmente, permitindo a utilização de mais de uma marca em cada elemento da rede, e assim, pode ter a rede Elementar como um caso especial, tornando-se uma rede de referência.

\subsubsection{Redes de Petri de alto nível}

A rede de Petri de alto nível surge primeiramente com a rede Predicado/Transição (PrTnets), desenvolvida por H.J. Genrich e K. Lautenbach (GENRICH, 1987). Pouco tempo depois foi definida a rede de Petri colorida (CP-nets) por K. Jensen (JENSEN, 1989). As principais ideias da rede CP-nets foram tomadas da rede PrT-nets, e a nova classe de rede foi introduzida para melhorar os métodos de análise dos invariantes. Logo depois outras classes de rede de alto nível foram desenvolvidas.

A característica fundamental que distingue a rede de Petri de alto nível da Rede de Petri clássica é a possibilidade das marcas serem distinguíveis, correspondendo a elementos de um domínio, e podendo representar diferentes tipos de dados e informação. As transições podem ter regras complexas de disparo que correspondem com o conjunto das marcas. Estas regras podem ser programadas usando alguma linguagem (Standard ML ou lógica de predicados). Os arcos também podem conter restrições especiais.

A norma ISO/IEC 15.909-1 (BILLINGTON et al., 2002) introduziu a rede de Alto Nível que herda boa parte da semântica da rede Colorida, e onde os modelos de RdP-AN são essencialmente uma representação concisa da rede de Petri clássicas, obtidas através de operações de dobramento (folding-operation), e vice-versa.

Uma vez que se tem vários tipos de marcas circulando em um processo macro, é preciso ter filtros associados aos lugares e arcos para, na iminência da passagem de marcas de tipos diferentes, poder selecionar aqueles que são pertinentes à transição em questão. Outra 
possibilidade é mapear comportamento diferente de uma transição "dobrada", dependendo do tipo de marca que recebe.

Naturalmente esta rede dobrada também deve ter uma declaração de tipo "sort", que é expressa, no caso das redes coloridas, em Standard-ML, ou em lógica de predicados e Teoria de Tipos, no caso mais geral das redes de Alto Nível.

Mais detalhes da rede de Alto Nível são abordados na seção 2.6.2. Neste capítulo este tópico é tratado apenas de forma conceitual, para embasar argumentos sobre a complexidade do tratamento de propriedades.

\subsubsection{Norma ISO/IEC 15909-2}

A segunda parte da norma ISO/IEC 15909-2, define o formato de intercâmbio para modelos de rede de Petri, denominado Petri Net Markup Language (PNML), baseado na linguagem XML. Esta parte da norma foi publicada em fevereiro de 2011. Ela foi criada devido à necessidade de um formato normalizado para especificação de rede de Petri de forma a permitir o intercâmbio de redes entre diferentes ferramentas de software. Esta segunda parte da norma permite a especificação de todos os tipos de rede de Petri existentes, e foi desenvolvido de forma a ser extensível e aberto a futuras variantes das redes de Petri.

O principal objetivo do formato PNML é permitir compatibilidade e interoperabilidade entre as ferramentas de redes de Petri. Assim, este formato deve suportar diferentes tipos de redes de Petri e ser extensível para permitir a definição de extensões.

O PNML define a sintaxe exata de três versões de redes de Petri: Place/Transition Net, Symmetric Nets e High-Level Petri Nets (HLPNGs), como definido na Parte 1 desta norma internacional. Neste trabalho são consideradas apenas as redes P/T e HLPNG.

A fim de lidar com todos os tipos de redes de Petri, assim como representar a definição exata delas em XML, PNML usa meta-modelos UML. O PNML Core Model (KINDLER, 2005) define os conceitos compartilhados por todos os tipos de rede de Petri. Além disto, o PNML possui meta-modelos UML para especificar os principais tipos de redes de Petri: Place/Transition-Nets e High-level Petri Nets.

A Figura 1 mostra os diferentes packages do PNML e as suas dependências. 
Figura 1 - Visão geral dos pacotes UML de PNML

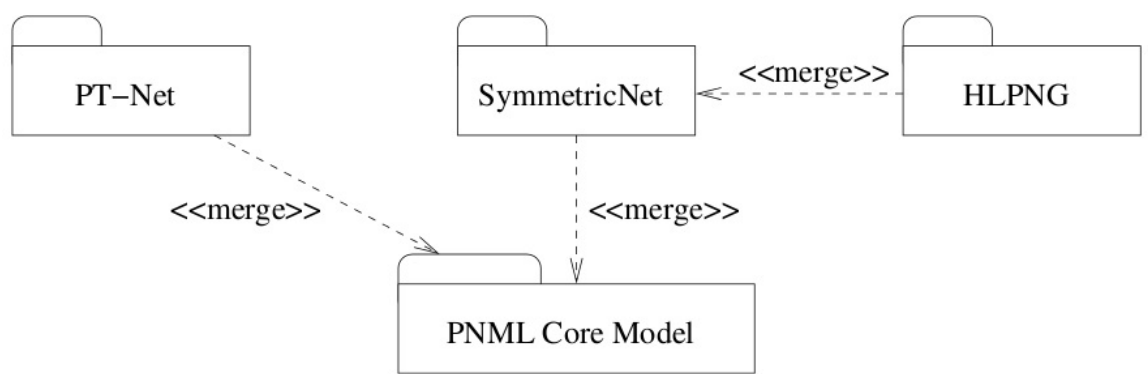

Fonte: (KINDLER, 2005).

\subsubsection{Norma ISO/IEC 15909-3}

A terceira parte da norma é dedicada à padronização das extensões das redes de Petri, incluindo hierarquias, tempo e recursos estocásticos. Estas extensões serão implementadas sobre o Core Model. A definição desta parte na norma se encontra ainda em desenvolvimento.

\subsubsection{Rede de Petri estendidas}

Existem várias extensões que na verdade podem ser obtidas por um arranjo das extensões normatizadas, tais como gates inibidores, hierarquia, com elementos pré-definidos pelos usuários e eventualmente aderentes às aplicações. Para os objetivos deste trabalho o escopo de redes estendidas é reduzido às extensões temporais e hierárquicas. A seguir descrevem-se brevemente cada uma delas:

- Extensão com tempo: As redes com tempo permitem representar os sistemas de tempo real, sincronismo e paralelismo entre processos de forma direta. Os tempos podem estar associados às marcas, lugares e/ou às transições. As extensões temporizadas referem-se àquelas que incorporam aspectos temporais determinísticos aos modelos, enquanto as extensões estocásticas incorporam aspectos temporais não determinísticos (SILVA J. R. ; DEL FOYO, 2012). A rede de Petri temporizada surge com o objetivo de solucionar o problema da escolha determinística. Esse tipo de rede possibilita a representação do comportamento dinâmico de sistemas que possuam atividades concorrentes, assíncronas e não-determinísticas, através da adição do conceito de tempo no modelo. Existem diferentes formas de representar as restrições de tempo na rede de Petri. Estas formas são:

- Com intervalos de tempo associados às transições: Esta abordagem foi introduzida 
por (MERLIN, 1974). Neste caso a referida transição poderia ocorrer entre um tempo $t_{\min }$ e $t_{\max }$ incluindo estes (intervalo fechado). Esta abordagem mais geral foi precedida por uma proposta anterior (RAMCHANDANI, 1974), onde cada transição (ou eventualmente lugar) poderia ocorrer depois de um intervalo fixo de tempo.

- O tempo pode ser usado de maneira probabilística: significa que o disparo de transições está associado a distribuições de probabilidade. Essas redes são denominadas rede de Petri estocásticas, pois seus comportamentos podem ser descritos por processos estocásticos.

- Com tempo fuzzy: conjuntos de tempo fuzzy também foram inseridos nas redes de Petri (TADAO, 1996). Existem alguns trabalhos que lidam com problemas de incerteza temporal, onde é introduzida o tempo fuzzy nas redes de alto nível.

O tempo na rede de Petri também pode estar associado aos lugares a as marcas. Quando é associado a lugares, as marcas (após o disparo de uma transição) só estarão disponíveis para disparar uma nova transição após um determinado intervalo de tempo. No caso de estar associado às transições, as marcas indicam o tempo necessário para encerrar a transição, isto é, para liberar a marca para os lugares sucessores.

- Extensões com hierarquias: A rede de Petri hierárquica permite a inclusão da abstração na modelagem em redes de Petri e o uso de sub-redes pre definidas, o que facilita a modelagem de sistemas de grande porte, e a reutilização de sub-redes específicas ao domínio de aplicação.

\subsection{Técnicas de análise em rede de Petri}

A principal vantagem da rede de Petri é a possibilidade de analisar e verificar os requisitos funcionais e não-funcionais dos sistemas. Neste sentido existem vários métodos de análise, que podem ser classificados em três grupos (SILVA, 2013), (MURATA, 1989):

1. Enumeração: Este método consiste na enumeração de todas as marcações que podem ser alcançadas desde a marcação inicial. O método é baseado na analise do grafo de alcançabilidade e consiste em construir um grafo direcionado atribuindo um nó para cada 
estado alcançável pelo sistema e um arco para cada possível transição. Estes grafos podem ser de tamanho considerável, inclusive para sistemas pequenos, o que torna o método ineficiente, especialmente quando se deseja analisar sistemas de grande porte. Assim, o principal problema deste método é estar limitado a redes mais simples, onde é pequeno o risco da explosão combinatória. No entanto, existem diversas técnicas alternativas para este tipo de análise, onde não se constrói o espaço de estados do sistema completo e sim um modelo resumido. Isto permite analisar classes de equivalência do grafo original(SILVA, 2013).

2. Transformação: Este método tem como objetivo reduzir o sistema modelado preservando as propriedades que se desejam analisar (MURATA, 1989).

3. Análise estrutural: O objetivo deste método é obter informações matemáticas da estrutura da rede ou da equação de estado. Existem duas estruturas formais que têm sido amplamente usadas: teoria de grafos e a álgebra linear. Este último tipo de abordagem foi introduzido por Lautenbach (LAUTENBACH, 1987).

A principal limitação do método baseado na equação de estado para a análise de redes de Petri é que este tipo de abordagem depende da resolução da equação em situações onde o número de variáveis e de equações é diferente (sistema não-Krameriano), o que pode originar soluções espúrias. No caso da análise estrutural não se considera a marcação inicial, portanto estados que nunca seriam alcançados pelo sistema fazem parte do processo.

A existência destes três tipos de análise de propriedades significa que nenhuma delas fornece resultados satisfatórios quando usadas de forma isolada. No entanto, o uso combinado de enumeração, transformação e das técnicas de análise estrutural, frequentemente leva a resultados satisfatórios na prática (SILVA, 2013). As regras de transformação têm baixo custo computacional e são frequentemente muito eficiente. Assim uma espécie de "meta-regra" de redução poderia ser aplicada em qualquer estratégia de análise de sistemas.

Outra técnica usada na análise de propriedades é a simulação dos modelos. Esta técnica serve de ajuda na compreensão dos modelos, ou na busca de alguns contra-exemplos ou erros de funcionamento; mas não podem ser usadas para provar propriedades, o que é às vezes necessário no projeto de sistemas, especialmente de sistemas críticos. 


\subsection{Propriedades das redes de Petri}

Para o projeto e análise de modelos baseados em rede de Petri, são analisadas várias propriedades (MURATA, 1989) que podem ser classificadas em: dependentes da marcação ou propriedades funcionais, e propriedades estruturais. A análise do comportamento de sistemas concorrentes geralmente não admite tratamento analítico e portanto depende do conhecimento de algumas propriedades desejáveis nestes sistemas. A seguir se descrevem algumas destas propriedades:

\subsubsection{Propriedades funcionais}

As propriedades funcionais são as que dependem da marcação inicial da rede. A seguir se descrevem algumas destas propriedades.

\subsubsection{Alcançabilidade}

Esta propriedade é a base fundamental para o estudo das propriedades dinâmicas de qualquer sistema. A alcançabilidade pode ser definida como segue:

Uma marcação $M_{n}$ é alcançável se existe uma sequência de disparos que leva de $M_{0}$ a $M_{n}$

O problema da alcançabilidade consiste em determinar se uma marcação $M_{n}$ pertence ou não ao conjunto de todas as marcações que podem ser alcançadas desde a marcação inicial $R\left(M_{0}\right)$. Embora o estudo da alcançabilidade seja um problema decidível, a complexidade do cálculo é muito elevada, podendo atingir o limite exponencial.

Condição algébrica necessária para a alcançabilidade:

Supondo que uma marcação $M_{d}$ é alcançável a partir de $M_{0}$ através de uma sequência de disparos $u_{1}, u_{2}, \ldots, u_{d}$, é possivel escrever a equação de estados após os $k=1,2, \ldots, d-1$ disparos como: $M_{d}=M_{0}+A^{T} x$

Esta equação pode ainda ser re-escrita da seguinte forma: supondo que a somatória dos vetores de disparo $\Sigma_{k=1}^{d-1} u_{k}$ esteja definida, temos que $A^{T} x=M_{d}-M_{0}$, onde $x=\Sigma_{k=1}^{d-1} u_{k}$ é um vetor coluna de inteiros não negativos, e a $i$-ésima entrada do vetor $x$ denota o número de vezes 
que a transição $i$ tem que disparar no processo que leva $M_{0}$ em $M_{d}$.

Sendo assim se pode afirmar que em uma rede de Petri, para que uma marcação $M_{d}$ seja atingível a partir de $M_{0}$ é necessário que exista uma solução inteira não negativa para o seguinte sistemas de equações: $A^{T} x=M_{d}-M_{0}$. Entretanto, a existência de solução não é condição suficiente para garantir a solução, uma vez que o vetor de habilitação é resultado de uma soma onde a ordem das parcelas indicam caminhos sobre a rede Petri, que eventualmente podem não existir ou não se verificarem na prática.

\subsubsection{Limitação}

Uma rede de Petri é limitada ou k-limitada se o número de marcas em cada lugar não excede um número finito $\mathrm{k}$ para qualquer marcação alcançável a partir de $M_{0}$, isto significa que $M(p) \leq k$ para todo lugar $p$ e para toda marcação $M_{n} \in R\left(M_{0}\right)$. Se a rede de Petri é 1 -limitada, então se diz que a rede é segura (safe).

Em aplicações que lidam com recursos, os lugares na rede de Petri são usados geralmente para representar buffers e registros que armazenam dados intermediários. Nesse caso a exigência que se tenha uma rede limitada pode garantir que não aconteçam overflows nos buffers ou registros, seja qual for a sequência de disparos executada. Na iminência de um overflow, as transições que antecedem o respectivo lugar são bloqueadas, se uma condição de disparo estrita é utilizada. Se, ao contrário, a proposta é detectar a tendência de overflow nos processos, então deve-se monitorar a marcação e liberar a capacidade dos lugares, usando uma condição de disparo mais branda, que não verifica as pós-condições.

\subsubsection{Vivacidade}

O conceito de vivacidade tem relação com a ausência de bloqueios (deadloks). Uma rede de Petri é dita viva, ou que $M_{0}$ é uma marcação viva, se para toda marcação atingível a partir de $M_{0}$ for possível disparar uma transição. A vivacidade é uma propriedade desejável para qualquer sistema, mas, a verificação direta de deadlocks é combinatoriamente explosiva. Existem no entanto vários algoritmos dedicados à verificação de deadlock que lidam apenas com condições necessárias e têm um desempenho computacional mais aceitável (CAMPOS; SILVA, 1990). 


\subsubsection{Reversibilidade}

Uma rede de Petri é reversível, se para cada marcação $M$ em $R\left(M_{0}\right), M_{0}$ é alcançável desde $M$. Em uma rede reversível, sempre é possível voltar ao estado inicial.

\subsubsection{Persistência}

Uma rede de Petri é persistente, se para qualquer par de transições, o disparo de uma delas não desabilita a outra. Em uma rede persistente, quando uma transição se habilita, permanece habilitada até ser disparada. A persistência é uma propriedade que está relacionada com as redes livres de conflitos.

\subsubsection{Propriedades estruturais}

As propriedades estruturais são as que dependem da estrutura da rede (MURATA, 1989), e não da marcação inicial. Podem ser caracterizadas em termos da matriz de incidência e estão associadas a sistemas de equações homogêneos ou inequações. A seguir se descrevem algumas destas propriedades.

\subsubsection{Limitação Estrutural}

Uma rede de Petri é estruturalmente limitada se está limitada para qualquer marcação inicial finita $M_{0}$. Nesse caso é possível enunciar o seguinte teorema (MURATA, 1989):

Teorema 2.1. Uma rede de Petri é estruturalmente limitada se existe um m-vetor $x$ de inteiros positivos tal que: $A^{T} x \leq 0$, onde $A$ é a matriz de incidência.

Uma demonstração deste teorema pode ser encontrada em (MURATA, 1989).

\subsubsection{Conservatividade}

Uma rede de Petri é conservativa se existe um vetor de ponderação (da mesma dimensão do vetor de marcação) de marcas $x$, onde $x(p)$ é um número inteiro positivo para todo lugar $p$, de modo que para cada marcação o produto escalar do vetor de marcação pelo vetor de ponderação é constante, isto é, $\forall M, M^{T} x=M_{0}^{T} x$. 
Se a propriedade acima se verifica apenas para alguns lugares, então a rede é dita parcialmente conservativa.

No caso da conservatividade é possível enunciar (MURATA, 1989) uma condição necessária e suficiente para que uma rede seja estruturalmente conservativa:

Uma rede de Petri é conservativa, se e somente se, existe um $m$-vetor $x$ de inteiros positivos tal que: $A^{T} x=0$, onde $A$ é a matriz de incidência e $x \neq 0$.

\subsubsection{Repetitividade}

Uma rede de Petri é repetitiva se existe uma marcação $M_{0}$ e uma sequência de disparos $\sigma$ a partir de $M_{0}$, tal que cada transição acontece infinitas vezes em $\sigma$.

Uma rede de Petri é repetitiva, se e somente se, existir um n-vetor y de inteiros positivos, tal que: $A y \geq 0$, onde A é a matriz de incidência e $y \neq 0$.

\subsubsection{Consistência}

Uma rede de Petri é consistente se existe uma marcação $M_{0}$, e uma sequência de disparos $\sigma$ de $M_{0}$ a $M_{d}$, tal que cada transição acontece pelo menos uma vez em $\sigma$.

Uma rede é consistente, se e somente se, existe um $n$-vetor $y$ de inteiros positivos tal que se cumpra que: $A y=0$, onde A é a matriz de incidência e $y \neq 0$.

\subsubsection{Vivacidade estrutural}

Uma rede de Petri é estruturalmente viva se existe uma marcação inicial viva para a rede. Não se conhece uma caracterização geral de vivacidade estrutural envolvendo outros estados de marcas.

\subsubsection{Invariantes}

Invariantes são uma das propriedades estruturais das redes de Petri. Estas propriedades representam os componentes conservativos e repetitivos da rede. Existem dois tipos de invariantes: invariantes de lugar(representam os componentes conservativos) e invariantes de transição (representam os componentes repetitivos). 
Definição 2.1. Um invariante de lugar é um vetor $x$ de dimensão $m$ (onde $m$ é o número de lugares da rede) que satisfaz o seguinte sistemas de equações:

$$
A^{T} \cdot x=0
$$

Cada vetor inteiro $x$ satisfaz a seguinte equação:

$$
M^{T} \cdot x=M_{0}^{T} \cdot x
$$

onde $M_{0}$ é a marcação inicial e $M$ pertence a $R\left(M_{0}\right)$.

A equação (2.2) significa, como foi visto acima, que a soma (ponderada) dos tokens nos lugares invariantes permanece constante em todas as marcações e esta soma está determinada pela marcação inicial.

Definição 2.2. Um vetor $y$ de dimensão $m$ (onde $m$ é o número de transições), é um invariante de transição, se:

$$
A \cdot y=0
$$

Um invariante de transição pode ser interpretado fisicamente como uma sequência de disparo de transições que não modifica a marcação da rede. Tal invariante corresponde a uma sequência cíclica de eventos que pode ser repetida indefinidamente.

$\mathrm{O}$ vetor $y$ é tal que cada componente é instanciada com um número inteiro nas posições que pertencem às transições invariantes, e instanciada com o valor zero nos outros casos. Os números inteiros representam a quantidade de vezes que a transição correspondente pode ser disparada para que a rede volte ao seu estado inicial.

A análise dos invariantes permite investigar propriedades das redes de Petri e dos sistemas modelado por elas. Através deles é possível investigar a estrutura da rede independentemente dos processos dinâmicos. Os invariantes também podem ser usados para a verificação de sistemas, já que oferecem uma importante recursos formal para a análise de outras propriedades importantes.

A análise de invariantes pode ainda ser inserida em uma rede estruturada hierárquica e podem ser calculados em qualquer nível de abstração. Trabalhos anteriores (FOYO, 2001), 
(SONG, 1997) mostram que os invariantes não são muito afetados pelos refinamentos da rede e o seu cálculo se mostra consistente exceto pela dimensão do vetor (que é proporcional ao número de lugares ou transições) (FOYO, 2001), (SALMON et al., 2011). Portanto, enquanto a Rede de Petri for tratada como um formalismo esquemático, a análise de propriedades é uma boa opção para os métodos de análise. No entanto algumas dificuldades semânticas podem surgir se a interpretação da rede for inserida como parte da representação.

\subsection{Teoria dos Invariantes}

Nos processos de representação formal se entende por invariante uma propriedade de que permanece inalterada quando transformações de um certo tipo são aplicadas. Invariantes são utilizados em diversas representações formais, como a geometria, topologia e álgebra (incluindo a álgebra de processos).

A teoria dos invariantes algébricos é considerada uma das áreas de pesquisas mais ativas durante a segunda metade do século XIX. O trabalho de Gauss sobre as formas quadráticas binárias, publicado no inicio do século XIX, em Disquisitiones Arithmeticae, apresentou as primeiras definições relacionadas aos invariantes algébricos ${ }^{1}$. Porém, o verdadeiro desenvolvimento da teoria dos invariantes só começou em 1840 em dois contextos diferentes: com os trabalhos de George Boole na Inglaterra, e Otto Hesse na Alemanha. O artigo de George Boole, publicado em 1841, intitulado "Exposition of a General Theory of Linear Transformations", foi o que motivou Cayley e Sylvester a desenvolver a teoria dos invariantes (CRILLY, 1986) (PARSHALL, 2006). Foram precisamente os matemáticos Arthur Cayley (1821-1895) e James Joseph Sylvester (1814-1897) os que mais contribuiriam para a teoria dos invariantes. Em 1854, Cayley publicou “An Introductory Memoir on Quantics”, que marcou o início de uma série de publicações referentes à Teoria dos Invariantes na Philosophical Transaction of Royal Society of London. Neste período, o tema dos invariantes esteve presente com grande frequência em inúmeras revistas de matemática da Europa. A movimentação em torno do assunto envolveu vários matemáticos em um propósito comum: provar "a finitude do número de invariantes fundamentais"(OLVER, 1999).

1 Este livro foi escrito por Gaus em 1778, quando tinha 21 anos e publicado somente em 1801, portanto no início do século XIX. 
Os maiores resultados em invariantes na Alemanha foram obtidos dos trabalhos de Hesse em geometria. No entanto, um pouco antes de Hesse, foram desenvolvidas idéias similares por Gotthold Eisenstein no âmbito da teoria dos números. Estas idéias surgiram com o objetivo de generalizar a teoria das formas quadráticas de Gauss. Além disto, Gauss propôs um procedimento que permitiu associar uma classe de formas cúbicas a uma classes de formas quadráticas.

Depois de 1860, um dos resultados mais importantes obtidos na teoria dos invariantes foi a prova do "teorema da finitude"para formas binárias. Esta prova foi publicada em 1868 por Paul Albert Gordan. Uma generalização do teorema de Gordan permaneceu como um problema aberto durante vários anos: demonstrar a existência de uma base finita de invariantes para qualquer sistema invariante de grau e número de variáveis indeterminadas arbitrárias. Este problema da geração finita dos invariantes foi abordado por David Hilbert, em vários trabalhos, os quais resultaram na criação de uma nova disciplina chamada "álgebra abstrata". Um tema importante nesta nova disciplina foi a teoria dos invariantes para grupos finitos, onde as bases de Gröbner têm um papel fundamental, já que permitem o estudo de polinômios invariantes sob a ação de algum grupo finito de matrizes, o que significa que é possível calcular todos os polinômios que não se modificam quando ocorre uma mudança de variáveis em algum grupo finito de matrizes dadas.

\subsubsection{Invariantes algébricos: definições}

Se define como invariante algébrico uma função polinômial dos componentes da matriz de uma aplicação linear, que não depende da base vetorial escolhida, para representar a aplicação linear. Significa que um invariante algébrico é uma combinação dos componentes de uma matriz cujo valor numérico não é alterado quando se aplica alguma mudança de base. Os invariantes algébricos mais comuns são: determinante de uma matriz, e os invariantes quadráticos.

Na teoria das matrizes, um invariante algébrico é uma função polinômial dos componentes da matriz cujo valor não varia se é calculado sobre matrizes (quadradas) semelhantes (que representam a mesma aplicação linear).

A seguir, se descrevem algumas definições importantes da teoria dos invariantes, mais especificamente aquelas relacionadas aos grupos finitos de matrizes, que são as usadas neste trabalho: 
Definição 2.3 (Grupo). Um grupo é um conjunto $G$ de elementos $g_{1}, g_{2}, \ldots$ que possuem uma lei de composição (produto), onde cada par ordenado $g_{i}, g_{j} \in G$, pode ser associado a um outro elemento $g_{i} g_{j}$ de forma tal que se satisfaçam as seguintes propriedades:

i. Composição interna: $\operatorname{Se} g_{i}, g_{j} \in G$, então $g_{i} g_{j} \in G$

ii. Associatividade: para todo $g_{i}, g_{j}, g_{k} \in G, g_{i}\left(g_{j} g_{k}\right)=\left(g_{i} g_{j}\right) g_{k}$

iii. Existência de um elemento unitário: Existe um único elemento denotado $e$, que satisfaz à seguinte propriedade: Para $\forall g_{i} \in G, e g_{i}=g_{i} e=g_{i}$

iv. Existência do inverso: Para cada $g_{i}, \exists$ um único elemento $\left(g_{i}\right)^{-} 1$, tal que, $g_{i}^{-} 1 g_{i}=g_{i} g_{i}^{-} 1=e$

Definição 2.4 (Ordem). O número de elementos de um grupo $G$ é denominado ordem de $G$, e denotado $O(G)$. Se a ordem é um número finito, se diz que $G$ é um grupo finito.

Definição 2.5 (Subgrupo). Um subconjunto não-vazio $S$ de um grupo $G$ é um subgrupo de $G$ se é um grupo com a mesma composição de $G$.

Definição 2.6 (Polinômio simétrico). O polinômio $f \in A=K\left[x_{1}, \ldots, x_{n}\right]$ é simétrico se e somente se $f\left(x_{i 1}, \ldots, x_{i n}\right)=f\left(x_{1}, \ldots, x_{n}\right)$ para todas as possíveis permutações $x_{i 1}, \ldots, x_{i n}$ das variáveis $x_{1}, \ldots, x_{n}$.

Definição 2.7. Seja $G \subset G L(n, k)$ um grupo finito de matrizes, então o polinômio $f(x) \in$ $k\left[x_{1}, \ldots, x_{n}\right]$ é invariante sob $G$ se $\forall A \in G . f(x)=f(A x)$. Ao conjunto de todos os polinômios invariantes se denota: $k\left[x_{1}, \ldots, x_{n}\right]^{G}$.

\subsubsection{Invariantes na ciência da computação}

Na ciência da computação um invariante é definido de forma geral, como uma propriedade que se mantém estável durante a execução de um programa. Consequentemente, o descobrimento dos invariantes em um programa é uma técnica fundamental na análise e verificação de programas procedurais. Devido à complexidade do cálculo de invariantes, surgiu a necessidade de automatizar este processo. Existem várias pesquisas nesta linha, e vários resultados foram obtidos (COUSOT; HALBWACHS, 1978), (TIWARI et al., 2001) (BJORNER; BROWNE, 1997). 
Similarmente ao que se faz com as redes de Petri P/T, em programas procedurais os loops podem representar um problema para a terminação dos programas - assim como os traps representam para as redes de Petri. Assim surgiu uma abordagem para a verificação de programas conhecida como Floyd-Hoare (FLOYD, 1967), (HOARE, 1969) que consiste exatamente em atribuir um invariante (uma propriedade em lógica de predicados) a cada comando de repetição. Esta propriedade deve ser válida no início - antes de rodar o loop pela primeira vez e no final de cada repetição. Se as repetições convergem para um ponto (fixo) onde a propriedade não é mais verdadeira, o loop termina (e o programa também). Este procedimento direto de verificação pode ficar bem mais sofisticado quando se usa chamadas recursivas, o que o torna também importante para garantir a qualidade dos programas.

\subsection{Análise dos Invariantes nas redes de Petri}

A análise de invariantes permite investigar propriedades da rede de Petri similarmente ao uso de invariantes na verificação de programas: o usuário constrói um conjunto de equações que deseja testar, e pode verificar se estas são satisfeitas em todos os estados atingíveis. Este processo pode ser repetido para todas as propriedades desejáveis do sistema.

No caso da rede de Petri clássica existem vários métodos para a análise de propriedades, onde os métodos baseados em álgebra linear e em programação linear são os mais usados (SILVA; TERUE, 1998; WAKUDA et al., 1999), devido ao baixo custo computacional.

Por outro lado, o surgimento da rede de Petri de alto nível foi motivado justamente pelo cálculo dos invariantes. O trabalho de K. Jensen para o cálculo das invariantes em redes de Petri coloridas (JENSEN, 2013) é uma referência nesta área, onde um conjunto de regras de transformação heurísticas são usadas para fazer uma simplificação interativa das equações do sistema, sem modificar o conjunto dos invariantes. Outros trabalhos apresentam um método para o cálculo dos invariantes em redes de Petri coloridas usando o método de eliminação de Gauss sobre a matriz de incidência da rede, (ALLA et al., 1985). O principal problema destes métodos é o processo de redução da matriz de incidência. Nesse caso, as regras de transformação são baseadas nas mesmas transformações usadas para resolver sistemas de equações usando o método de Gauss; só que o método de Gauss resolve sistemas de equações clássicos: $A \cdot x=0$, 
onde $x$ é a incógnita, enquanto no caso das redes de Petri de alto nível, o sistema a ser resolvido é da forma $x \cdot A=0$; isto significa que a manipulação será feita por coluna ao invés de linhas. Além disto tem-se que as entradas da matriz de incidência não são números inteiros e sim funções, o que gera um sistema de segunda ordem.

Portanto, um dos principais problemas para modelar sistemas usando rede de Petri de alto nível é a complexidade dos métodos existentes para a análise de propriedades, entre eles o cálculo de invariantes. Uma solução para este problema poderia ser transformar a RdP de alto nível em uma RdP clássica (unfolding) onde os métodos de análise são razoavelmente eficientes, baseados fundamentalmente em álgebra linear.

\subsubsection{Análise dos invariantes em redes clássicas}

Para a análise de invariantes em redes clássicas, vários métodos foram já desenvolvidos, a grande maioria baseados fundamentalmente em duas técnicas: técnicas de programação linear e técnicas de álgebra linear.

Os métodos baseados na programação linear usualmente trabalham com o algoritmo Simplex, que tem como principal vantagem o custo computacional polinomial. Porém, para sistemas muito grandes este algoritmo pode ter complexidade exponencial (SILVA; TERUE, 1998), (GE FUKUNAGA T., 2005). O uso de programação linear na obtenção dos invariantes tem uma desvantagem: nem sempre os invariantes obtidos são corretos, e, há sempre a possibilidade de explosão combinatória.

Colom e Silva(SILVA; TERUE, 1998) propuseram a análise de propriedades dos sistemas (limitação, exclusão mútua, deadlock, etc.) usando as equações de estado. Este método é mais preciso e eficiente do que o método clássico, que, por sua vez é mais fácil de entender. Por outro lado, o método baseado na equação de estado é mais adequado para analisar características de segurança, ou seja, a existência ou não de marcas e vetores de disparo admissíveis. Portanto, é possível analisar as propriedades apenas parcialmente, ou seja, encontrar apenas as condições necessárias ou suficientes. (R.; A.E., 2005) considerou aspectos estruturais das redes de Petri e tentou melhorar a ligação entre redes de Petri e as técnicas de álgebra linear.

Entre as técnicas para obtenção dos invariantes baseadas em álgebra linear destacam-se as 
propostas de (R.; A.E., 2005), (REISIG, 2011). Estes métodos usam o algoritmo de Gauss-Jordan para reduzir a matriz de incidência e obter os invariantes. Geralmente têm custo computacional baixo, sendo esta sua principal vantagem. Existe entretanto a desvantagem de que, em muitos casos, os invariantes obtidos não são suficientes para analisar todos os requisitos desejados, uma vez que na maioria dos casos só é possível obter um subconjunto destes. Mesmo assim, estes métodos são amplamente usados na verificação de requisitos de sistemas, onde restrições relacionadas com o domínio de aplicação são colocadas na forma de invariante e depois testadas usando métodos de álgebra linear.

\subsubsection{Análise dos invariantes em redes de alto nível}

Os métodos para calcular os invariantes nas redes de Petri de alto nível são em geral baseados na fatoração da matriz de incidência. O processo para obter um conjunto de invariantes que representem um gerador para os demais invariantes tem sido considerado por vários autores especialmente por Jensen(KURT, 1981).

Nas redes de Petri Coloridas (CP-nets), assim como na rede de Petri clássica, o uso de invariantes é similar ao método de Floyd para verificação de programas. Invariantes descrevem propriedades que são satisfeitas em todos os estados alcançáveis, o que possibilita a verificação de várias propriedades dinâmicas como alcançabilidade, vivacidade, limitação, etc. A análise de invariantes também é usada nas redes Coloridas hierárquicas, quando é possível combinar invariante de módulos individuais, facilitando assim a análise de sistemas de grande porte. Nestas redes, os invariantes podem ser definidos durante o processo de design dos sistemas, ou na fase de análise de requisitos. A principal desvantagem da análise dos invariantes nas CP-nets é que esta requer habilidades ainda maiores no tratamento do formalismo, comparado a outros métodos de análise.

No caso dos invariantes de lugar, o principal objetivo é achar um conjunto de equações que caracterizem todas as marcações alcançáveis, e depois usar estas equações para provar as propriedades do sistema. Um invariante de lugar é a soma linear das marcações dos lugares individuais: cada lugar é marcado por uma função peso e mapeado em um multiset ${ }^{1}$. No entanto,

1 Um multiset é uma estrutura similar a um conjunto, só que pode conter várias ocorrências de um mesmo elemento. 
para calcular os invariantes em CP-nets é preciso calcular a matriz de incidência da rede. A matriz de incidência determina um sistema de equações homogêneo, onde os lugares invariantes são as soluções do sistema (cada solução é um vetor de funções peso). Este sistema de equações pode ser resolvido de várias formas: uma possibilidade é transformar a matriz de funções em uma matriz de inteiros e resolver o sistema usando o método de eliminação de Gauss. Outra possibilidade seria trabalhar diretamente com a matriz de funções, no entanto esta é opção mais trabalhosa e difícil, uma vez que algumas funções não possuem inversa. Com este método não é possível obter todos os invariantes mas apenas conjuntos básicos, ou geradores, e a partir deles é possível gerar todos os demais invariantes. Entretanto isto leva a um outro problema: como, a partir de este conjunto básico pode se obter os invariantes que interessam - isto é, fisicamente realizáveis - de um sistema. Uma solução para isto é calcular os invariantes de forma interativa.

Em 1981 Kur Jensen propôs um método para a obtenção de invariantes em CP-nets(JENSEN, 1981), mas atualmente este método não é usado, uma vez que não existe nenhum algoritmo computável para obter de forma automática os invariantes, exceto transformando a rede de alto nível em uma rede Place/Transition, usando os algoritmos de unfolding(SMITH, 1998). Existem trabalhos que propõem algoritmos similares ao de Kurt Jensen para a obtenção dos invariantes(JENSEN, 2013), onde um conjunto de regras de transformação heurísticas é usado para fazer uma simplificação interativa das equações do sistema, sem modificar o conjunto dos invariantes. O principal problema em todos estes métodos é o processo de redução da matriz de incidência.

\subsubsection{Métodos para calcular os invariantes em CP-nets}

Na rede CP-nets o cálculo dos invariantes pode ser expresso em termos da resolução do sistema de equações matriciais:

$$
x \cdot W=0
$$

onde $x: P \rightarrow[C(p) \rightarrow[U \rightarrow Z]]$ e $U$ é um conjunto não vazio de cores. Existem na literatura vários métodos para a obtenção dos invariantes em CP-nets (SILVA J. MARTINEZ, 1985) (JENSEN, 1981) (JENSEN, 2013), todos eles baseados em um conjunto de regras para a redução da matriz de incidência sem mudar o conjunto dos invariantes. Em geral as regras de transformação estão baseadas no método de eliminação de Gauss, com 
a diferença que ao invés de realizar produto de inteiros, realiza-se composições de funções. Cada vez que se consegue fazer aparecer uma linha (ou uma coluna) de zeros na matriz $W$ obtém-se uma componente. Por outro lado, o conjunto das componentes não forma necessariamente um espaço vetorial. Embora não exista um algoritmo geral para resolver a matriz, muitas vezes a matriz reduzida obtida após a aplicação das regras permite que os invariantes sejam encontrados por inspeção.

Em (SILVA J. MARTINEZ, 1985) é apresentado um método para calcular invariantes simbólicos nas CP-nets baseado nas regras de transformação propostas por (KURT, 1981) para reduzir a matriz de incidência. Este método tem sido aplicado com sucesso para a avaliação de sistemas complexos modelados em CP-nets. Com a aplicação do método de fatoração da matriz de incidência é possível obter os invariantes de lugar, mas é possível aplicar o mesmo método à transposta da matriz de incidência, e assim obter os invariantes de transição. O problema deste método é que em geral, o processo para obter os invariantes é controlado por regras heurísticas que nem sempre garantem a obtenção dos invariante.

Existem outros trabalhos que tratam do cálculo de invariante em CP-nets (VAUTHERIN, 1985; ALLA et al., 1985; HADDAD; COUVREUR, 1988), a maioria deles baseados nas regras propostas por Jensen (KURT, 1981) para reduzir a matriz de incidência.

Para o cálculo automático dos invariantes nas redes de Petri coloridas, primeiramente o sistema modelado tem que ser representado em termos da matriz de incidência. Em uma CP-net a matriz de incidência contém uma linha para cada lugar, $p \in P$ e uma coluna para cada transição $t \in T$

Depois de obter a matriz de incidência do sistema, o passo seguinte é resolver o sistema de equações (2.4) para encontrar os invariantes.

Para as matrizes onde os elementos são números inteiros ou reais, a solução do sistema de equações poderia ser obtida com o método de eliminação de Gauss. Mas no caso das matrizes que representam os modelos das $\mathrm{CP}$-nets temos algumas dificuldades, algumas já mencionadas:

- Primeiramente os elementos da matriz de incidência das CP-net são funções e não números, portanto, nem sempre esta matriz tem uma inversa. Este problema poderia ser solucionado, mas os algoritmos para isto seriam extremamente complexos; 
- O segundo problema é a dificuldade para interpretar as soluções do sistema de equações representado pela matriz de incidência;

- Um terceiro problema é que o sistema de equações geralmente tem infinitas soluções. Muitas vezes é possível representar estas soluções como um conjunto finito de fluxos a partir do qual outros fluxos podem ser gerados. No entanto, obter os invariantes a partir destes conjuntos geradores é uma tarefa muito difícil.

A complexidade dos métodos existentes para o cálculo dos invariantes está justamente no processo de redução da matriz de incidência.

Em (KURT, 1981) é apresentado um método para obter os invariantes através de transformações que visam mapear a matriz de incidência em uma matriz cada vez mais simples, mas conservando o mesmo conjunto de invariantes. Estas transformações estão baseadas em quatro regras, inspiradas no método de eliminação de Gauss.

Por causa das características da matriz de incidência das CP-nets, e da complexidade para achar as soluções deste sistema de equações, não existe nenhum algoritmo que resolva o sistema de equações homogêneos formado pela matriz de incidência. Portanto, as regras propostas por,(KURT, 1981) para reduzir a matriz de incidência não são completas, significando que nem sempre é possível achar os invariante por meio destas regras. No entanto, embora não seja completo, este conjunto de regras geralmente permite transformar a matriz de incidência de tal maneira que um determinado conjunto de invariantes pode ser obtido mediante uma simples inspeção da matriz reduzida.

No caso do cálculo interativo dos invariantes é preciso primeiramente ter um amplo conhecimento do sistema que está sendo modelado e de suas propriedades. Tanto os invariantes de lugar como os invariantes de transições têm que ser especificados durante a análise da CP-net. No entanto, o mais útil - e mais fácil - seria especificar estes invariantes enquanto a rede CP-net está sendo criada (SALMON et al., 2014), (SALMON; SILVA, 2012), (SALMON et al., 2016), isto é, na fase de modelagem de soluções ou na fase de requisitos.

Para obter os invariantes de forma interativa devem ser seguidos os seguintes passos:

- Primeiramente devem ser especificadas as propriedades do sistemas que deveriam ser 
satisfeitas em todos os estados alcançáveis;

- Estas propriedades devem ser expressas como um conjunto de invariantes;

- Finalmente, por meio de simulações iterativas, se verifica se estes invariantes são satisfeitos pelo modelo.

O método de cálculo iterativo dos invariante é mais apropriado quando se quer verificar alguns requisitos dos sistemas. Este método é também aplicado por Jensen para determinar invariante nas redes de Petri Coloridas Hierárquicas, onde os invariantes do sistema geral são uma combinação dos invariantes dos módulos individuais, o que facilita a análise de sistemas de maior porte.

A ferramenta CPN-tools, (JENSEN; KRISTENSEN; WELLS, 2007) está sendo modificada para possibilitar o cálculo iterativo de invariantes em CP-nets hierárquicas, (JENSEN, 2013).

\subsubsection{Exemplo}

Nesta seção é mostrado um exemplo de um sistema que possui três máquinas M1, M2, M3, as quais podem fabricar três tipos de peças P1, P2, P3. Se a máquina para a qual a peça foi destinada está livre, a operação se inicia imediatamente. Após o término da operação a máquina é liberada e a peça está pronta (CARDOSO; VALETTE, 1997). A figura 2 representa o modelo em rede de Petri Colorida do sistema descrito (usando o CPN Tools).

Figura 2 - Rede de Petri Colorida do sistema

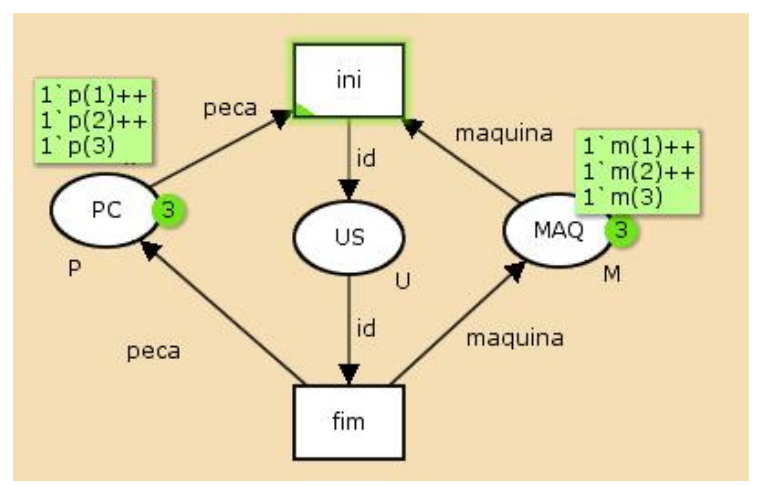

Fonte: Elaborada pela autora.

O conjunto de cores admissíveis no lugar PC é o conjunto $P=p(1), p(2), p(3)$ dos nomes das peças, e o conjunto de cores admissíveis no lugar MAQ é o conjunto dos nomes das máquinas 
$M=m(1), m(2), m(3)$. As cores do lugar US formam o conjunto $U=\{p(1): m(1), p(2): m(1)$, $p(3): m(1), p(1): m(2), p(2): m(2), p(2): m(3), p(3): m(1), p(3): m(2), p(3): m(3)\}$, que corresponde às diferentes atribuições de operação US e serão denotadas de forma simplificada por $\{\mathrm{u} 11, \mathrm{u} 12, \mathrm{u} 13 ; \mathrm{u} 21, \mathrm{u} 22, \mathrm{u} 23$; u31, u32, u33\}. As cores admissíveis nas transições ini e fim são as mesmas de US.

O modelo completo da rede de Petri colorida da figura 2 é dado por:

- $\Sigma=\{p(1) ; p(2) ; p(3) ; m(1) ; m(2) ; m(3) ; u 11 ; u 12 ; u 13 ; \ldots ; u 32 ; u 33\}$

- $C(P C)=\{p(1) ; p(2) ; p(3)\}$

- $C(M A Q)=\{(m(1) ; m a(2) ; m(3))\}$

- $C(U S)=C s c(i n i)=C s c(f i m)=\{u 11 ; u 12 ; \ldots ; u 32 ; u 33\}$;

$$
\mathbf{W}=\left[\begin{array}{c|cc} 
& \text { ini } & \text { fim } \\
\hline P C & - \text { peca } & \text { peca } \\
U S & i d & -i d \\
M A Q & - \text { maquina } & \text { maquina }
\end{array}\right]
$$

cujas funções são dadas por:

$$
\begin{gathered}
\left\{\begin{array}{l}
i d\left(u_{i j}\right)=u_{i j} \\
\operatorname{maquina}\left(u_{i j}\right)=m(j) \\
\operatorname{peca}\left(u_{i j}\right)=p(i)
\end{array}\right. \\
\mathbf{M}_{\mathbf{0}}=\left[\begin{array}{ccccccccc}
p(1) & p(2) & p(3) & m(1) & m(2) & m(3) & u 11 & \ldots & u 33 \\
\hline 1 & 1 & 1 & 0 & 0 & 0 & 0 & \ldots & 0 \\
0 & 0 & 0 & 0 & 0 & 0 & 0 & \ldots & 0 \\
0 & 0 & 0 & 1 & 1 & 1 & 0 & \ldots & 0
\end{array}\right]
\end{gathered}
$$


Na figfura 2 é possivel ver que as etiquetas dos arcos não são números inteiros como no caso da rede clássicas, e sim funções que representam matrizes de inteiros. Para cada cor de uma transição é necessário descrever quais cores de marcas serão retiradas dos lugares de entrada (pre condição) e quais cores de marcas serão colocadas nos lugares de saída (pós condição). A função associada ao arco tem como domínio o produto cartesiano entre o conjunto de cores da transição e o conjunto de cores do lugar (de entrada ou saída da transição, segundo a orientação do arco). O conjunto imagem da função Pre é o conjunto $N$ dos inteiros positivos que descreve quantas marcas de cada cor devem ser retiradas dos lugares de entrada quando a transição for disparada:

$$
\operatorname{Pre}(p, t): C(t) X C(p) \rightarrow N
$$

o conjunto imagem da função Post é o conjunto $N$ que descreve quantas marcas de cada cor devem ser colocadas no lugar de saída quando a transição for disparada:

$$
\operatorname{Post}(p, t): C(t) X C(p) \rightarrow N
$$

A partir das matrizes Pre e Post, define-se a matriz:

$$
W(p, t)=\operatorname{Post}(p, t)-\operatorname{Pre}(p, t)
$$

As matrizes Pre, Post e $W$ são matrizes de matrizes, pois seus elementos (as etiquetas dos arcos), descritos por funções, são de fato matrizes cujas linhas são as maneiras de disparar as transições, e as colunas, as cores possíveis nos lugares.

A rede de Petri colorida representada na figura 2 possui três funções: peca, máquina e id. Esta última não modifica as cores das marcas. A matriz Pre é dada por:

$$
\text { Pre }=\left[\begin{array}{cc}
\text { ini } & \text { fim } \\
\hline \operatorname{Pre}(P C, \text { ini }) & \operatorname{Pre}(P C, \text { fim }) \\
\operatorname{Pre}(U S, \text { ini }) & \operatorname{Pre}(U S, f i m) \\
\operatorname{Pre}(M A Q, i n i) & \operatorname{Pre}(M A Q, f i m)
\end{array}\right]
$$

A função Pre $(P C$, ini $)$, que etiqueta o arco ligando o lugar de entrada PC a transição ini é dada pela matriz $\operatorname{Pre}(P C$, ini $): U S X P C \rightarrow N$ onde $U S=C($ ini $)$ e $P C=C(P C)$. A função Post $(M A Q$, ini $)$ que etiqueta o arco que liga a transição ini ao lugar de saída MAQ é dada pela matriz Post $(M A Q$, ini $): U S X M A Q \rightarrow N$ onde $M A Q=C(M A Q)$. As funções Pre $(P C$, ini $)$ e Post $(M A Q$, ini $)$ são, respectivamente, descritas pelas matrizes: 


$\left[\begin{array}{c|ccccccc} & u 11 & u 12 & u 13 & u 21 & u 22 & \ldots & u 33 \\ \hline p(1) & 1 & 1 & 1 & 0 & 0 & \ldots & 0 \\ p(2) & 0 & 0 & 0 & 1 & 1 & \ldots & 0 \\ p(3) & 0 & 0 & 0 & 0 & 0 & \ldots & 1\end{array}\right]$

$\left[\begin{array}{c|ccccccc} & u 11 & u 12 & u 13 & u 21 & u 22 & \ldots & u 33 \\ \hline m(1) & 1 & 0 & 0 & 1 & 0 & \ldots & 0 \\ m(2) & 0 & 1 & 0 & 0 & 1 & \ldots & 0 \\ m(3) & 0 & 0 & 1 & 0 & 0 & \ldots & 1\end{array}\right]$

No exemplo da figura 2, a função $\operatorname{Pre}(P C$, ini $)$ é dada pela peca $: U S \rightarrow P C$, que etiqueta o $\operatorname{arco}(P C$, ini $)$. Esta função, aplicada às cores uij do conjunto de cores US da transição ini, indica que uma marca de cor $p(i)$ deve ser retirada do lugar $P C$, peca $(U i j)=p(i)$. Esta mesma função, etiquetando o arco $(f i m, P C)$, aplicada ao conjunto de cores $U S$ da transição fim, indica que uma marca de cor $\mathrm{p}(\mathrm{i})$ deve ser colocada no lugar $P C$.

\section{Análise dos invariantes}

Para fazer a análise dos invariantes nas redes de Petri coloridas existem duas maneiras:

1. Utilizar diretamente a matriz de funções lineares entre os conjuntos de cores.

2. Trabalhar com a rede de Petri clássica obtida através do desdobramento (unfolding) da rede original.

\section{Analisando os invariantes usando o método iterativo de Jensen}

No sistema da figura 2 um comportamento desejável seria a conservação das peças e das máquinas em todas as marcações alcançáveis, ou seja, o número de peças e máquinas deve ser sempre o mesmo. Em termos dos invariantes isto pode ser expresso como:

$$
M(P C)+\operatorname{peca}(M(U S))=P
$$




$$
\operatorname{maquina}(M(U S))+M(M A Q)=M
$$

onde:

$$
\left\{\begin{array}{l}
P=\{p(1), p(2), p(3)\} \\
M=\{m(1), m(2), m(3)\} \\
U=\{(p, m) \in P X M\}
\end{array}\right.
$$

A equação (2.5) representa a conservação das peças e a equação (2.6) a conservação das máquinas. Mediante a simulação interativa do modelado, usando a ferramenta CPN-tool, é possível verificar os invariantes definidos nas equações (2.5) e (2.6). As figuras 3 e 4 mostram alguns dos passos desta simulação, onde se verifica a veracidade dos invariantes que estão sendo testados.

Figura 3 - Simulção do sistema em CPN-Tools(a)

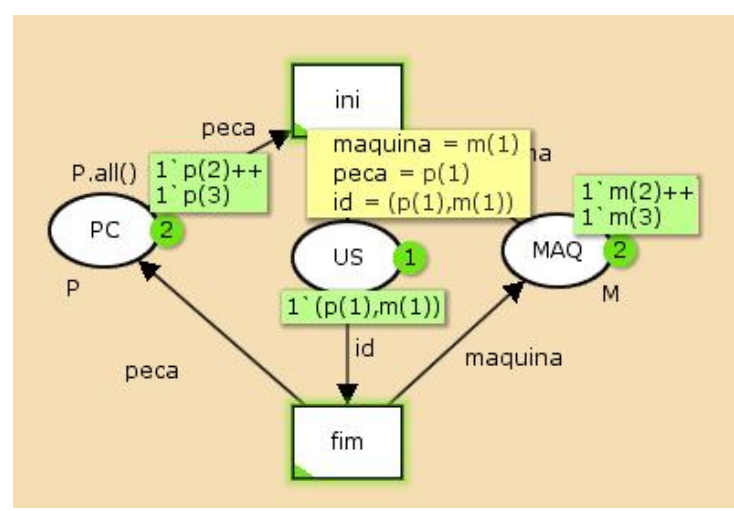

Fonte:Elaborada pela autora

Figura 4 - Simulção sistema em CPN-Tools (b)

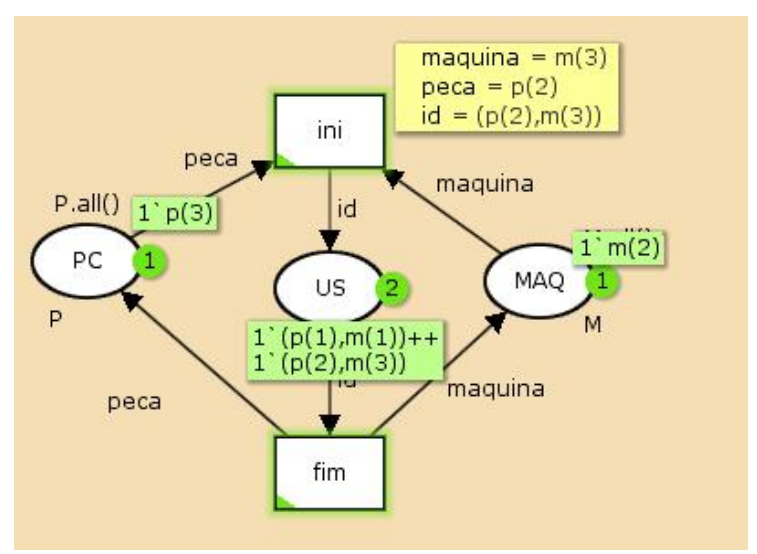

Fonte:Elaborada pela autora 


\section{Trabalhando com a rede de Petri clássica obtida por desdobramentos}

Seguindo o algoritmo de desdobramento de redes proposto por (SMITH, 1998), é possível transformar uma rede de Petri Colorida em uma rede clássica lugar-transição. Aplicando isso à rede colorida da figura 2 pode-se obter a rede lugar-transição mostrada na figura 5.

Figura 5 - Rede de Petri clássica obtida a partir da figura 2

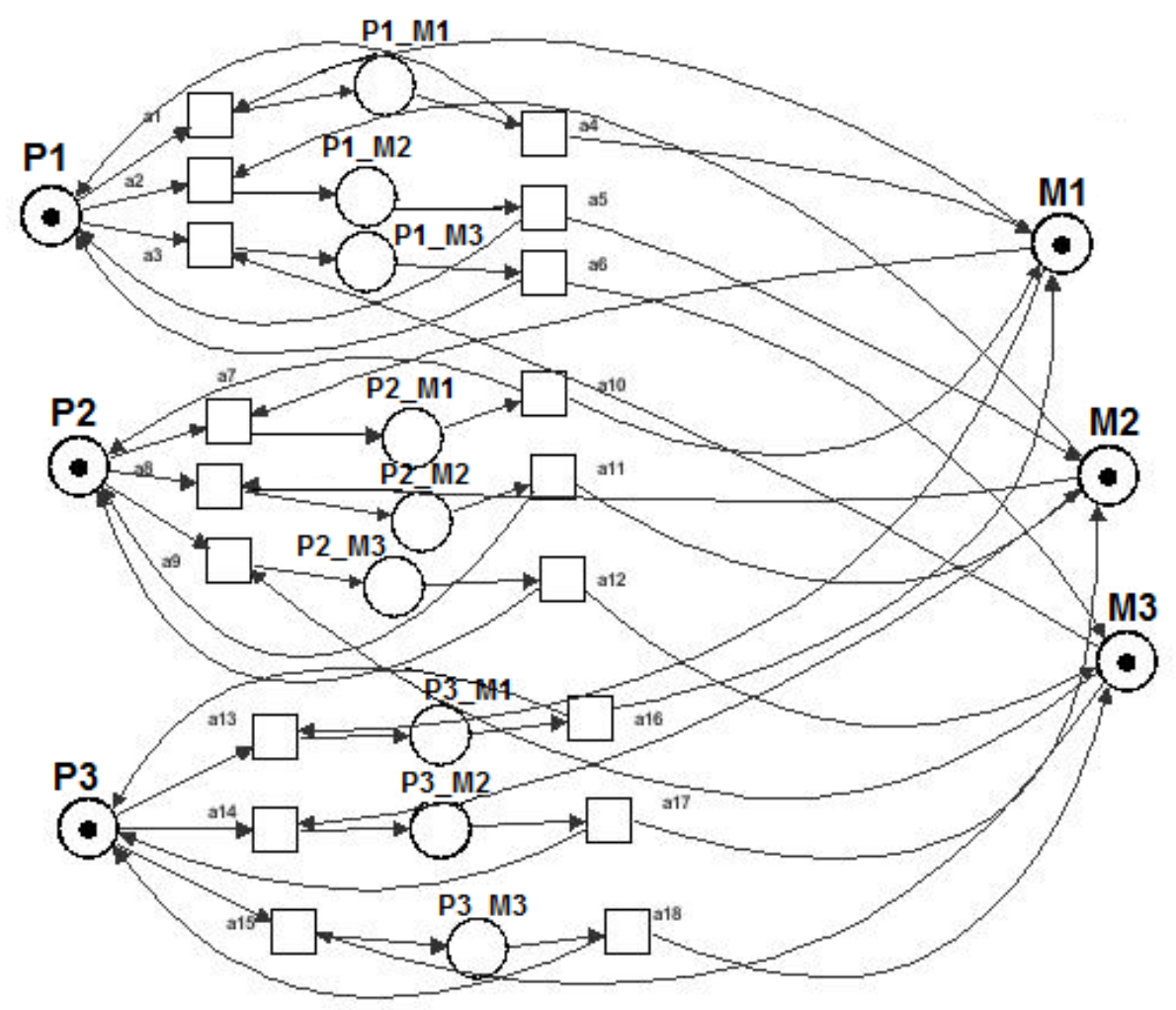

Fonte: Elaborada pela autora.

Na figura 6 é apresentada a matriz de incidência correspondente à rede da figura 5, calculada usando a ferramenta GHENeSys (General Hierarchical Enhanced Net System)(SALMON et al., 2011). Os invariantes correspondentes à rede lugar-transição da figura 5 foram também computados usando o GHENeSys e são mostrados na figura 7. 
Figura 6 - Matriz de incidência da rede da figura 5

\begin{tabular}{|c|c|c|c|c|c|c|c|c|c|c|c|c|c|c|c|c|c|c|}
\hline \multicolumn{19}{|c|}{ 多 Incidence Matrix } \\
\hline & a1 & a2 & a3 & a4 & a5 & $a 6$ & a? & a8 & a9 & $\mathrm{a} 10$ & a11 & $a 12$ & a13 & a14 & $a 15$ & a16 & a17 & a18 \\
\hline $\mathrm{P} 1$ & -1 & -1 & -1 & 1 & 1 & 1 & 0 & 0 & 0 & 0 & 0 & 0 & 0 & 0 & 0 & 0 & 0 & 0 \\
\hline$M 1$ & -1 & 0 & 0 & 1 & 0 & 0 & -1 & 0 & 0 & 1 & 0 & 0 & -1 & 0 & 0 & 1 & 0 & 0 \\
\hline$M 2$ & 0 & -1 & 0 & 0 & 1 & 0 & 0 & -1 & 0 & 0 & 1 & 0 & 0 & -1 & 0 & 0 & 1 & 0 \\
\hline M3 & 0 & 0 & -1 & 0 & 0 & 1 & 0 & 0 & -1 & 0 & 0 & 1 & 0 & 0 & -1 & 0 & 0 & 1 \\
\hline P1_M1 & 1 & 0 & 0 & -1 & 0 & 0 & 0 & 0 & 0 & 0 & 0 & 0 & 0 & 0 & 0 & 0 & 0 & 0 \\
\hline $\mathrm{P} 1 \_\mathrm{M} 2$ & 0 & 1 & 0 & 0 & -1 & 0 & 0 & 0 & 0 & 0 & 0 & 0 & 0 & 0 & 0 & 0 & 0 & 0 \\
\hline P1_M3 & 0 & 0 & 1 & 0 & 0 & -1 & 0 & 0 & 0 & 0 & 0 & 0 & 0 & 0 & 0 & 0 & 0 & 0 \\
\hline $\mathrm{P} 2$ & 0 & 0 & 0 & 0 & 0 & 0 & -1 & -1 & -1 & 1 & 1 & 1 & 0 & 0 & 0 & 0 & 0 & 0 \\
\hline $\mathrm{P} 2$ M1 & 0 & 0 & 0 & 0 & 0 & 0 & 1 & 0 & 0 & -1 & 0 & 0 & 0 & 0 & 0 & 0 & 0 & 0 \\
\hline $\mathrm{P} 2$ M2 & 0 & 0 & 0 & 0 & 0 & 0 & 0 & 1 & 0 & 0 & -1 & 0 & 0 & 0 & 0 & 0 & 0 & 0 \\
\hline $\mathrm{P} 2$-M3 & 0 & 0 & 0 & 0 & 0 & 0 & 0 & 0 & 1 & 0 & 0 & -1 & 0 & 0 & 0 & 0 & 0 & 0 \\
\hline P3 & 0 & 0 & 0 & 0 & 0 & 0 & 0 & 0 & 0 & 0 & 0 & 0 & -1 & -1 & -1 & 1 & 1 & 1 \\
\hline P3_M1 & 0 & 0 & 0 & 0 & 0 & 0 & 0 & 0 & 0 & 0 & 0 & 0 & 1 & 0 & 0 & -1 & 0 & 0 \\
\hline $\mathrm{P} 3 \_\mathrm{M} 2$ & 0 & 0 & 0 & 0 & 0 & 0 & 0 & 0 & 0 & 0 & 0 & 0 & 0 & 1 & 0 & 0 & -1 & 0 \\
\hline P3_M3 & 0 & 0 & 0 & 0 & 0 & 0 & 0 & 0 & 0 & 0 & 0 & 0 & 0 & 0 & 1 & 0 & 0 & -1 \\
\hline & & & & & & & & & & & & & & & & & Clos & \\
\hline
\end{tabular}

Fonte: Elaborada pela autora.

Figura 7 - Invariantes de lugar da rede da figura 5

\begin{tabular}{|c|c|c|c|c|c|}
\hline \multicolumn{4}{|c|}{ Invariants } & \multirow{2}{*}{\multicolumn{2}{|c|}{-10}} \\
\hline Place & Tran & sition & & & \\
\hline \multicolumn{6}{|l|}{ Results } \\
\hline P1 & 1.0 & 0.0 & 0.0 & 0. & \\
\hline M1 & 0.0 & 0.0 & 1.0 & 0. & \\
\hline M2 & 0.0 & 0.0 & 0.0 & 1. & \\
\hline M3 & 0.0 & 0.0 & 0.0 & 0. & \\
\hline P1_M1 & 1.0 & 0.0 & 1.0 & 0 . & \\
\hline P1_M2 & 1.0 & 0.0 & 0.0 & 1. & \\
\hline P1_M3 & 1.0 & 0.0 & 0.0 & 0 . & \\
\hline P2 & 0.0 & 1.0 & 0.0 & 0. & \\
\hline P2_M1 & 0.0 & 1.0 & 1.0 & 0 . & \\
\hline P2_M2 & 0.0 & 1.0 & 0.0 & 1. & \\
\hline P2_M3 & 0.0 & 1.0 & 0.0 & 0. & \\
\hline P3 & 0.0 & 0.0 & 0.0 & 0. & \\
\hline P3_M1 & 0.0 & 0.0 & 1.0 & 0 . & \\
\hline P3_M2 & 0.0 & 0.0 & 0.0 & 1. & 0 \\
\hline \multirow[t]{2}{*}{ P3_M3 } & 0.0 & 0.0 & 0.0 & 0. & \\
\hline & ave & & & lose & \\
\hline
\end{tabular}

Fonte: Elaborada pela autora.

\subsubsection{Considerações finais}

Na rede de Petri clássica os principais métodos são baseados em programação linear e álgebra linear, sendo que a maioria destes métodos possui uma complexidade computacional razoável, o que não é o caso das redes de Petri de alto nível.

A análise de invariantes na rede de Petri de alto nível pode ser feita de forma similar à da rede clássica: onde os invariantes podem ser obtidos reduzindo a matriz de incidência, usando 
para isso um conjunto de regras baseadas no método de eliminação de Gauss, também usado para reduzir a matriz de incidência no cálculo dos invariantes nas redes clássicas, com a diferença de que nas redes de alto nível a matriz de incidência é formada por funções e não por inteiros.

A rede de Petri de alto nível mais usada na literatura é a rede de Petri Colorida, proposta por Kurt Jensen. Para este tipo de rede existem vários trabalhos que propõem métodos para obter os invariantes (JENSEN, 2013). A maioria destes métodos estão direcionados à resolução do sistema de equações homogêneos representado pela matriz de incidência, e para obter um conjunto de invariantes a partir do qual seja possível gerar outros invariantes. Em geral, os métodos existentes para resolver o sistema de equações estão baseados na redução da matriz de incidência, através de uma sequência de regras propostas por Jensen, e baseadas no método de eliminação de Gauss que preserva conjunto dos invariantes. Porém, este conjunto de regras é incompleto, no sentido que nem sempre garantem a obtenção dos invariantes; portanto não se tem algum algoritmo que implemente estas regras. Entretanto, mesmo que as regras sejam incompletas, e que não exista um algoritmo que resolva o sistema de equações, muitas vezes com a aplicação destas regras é possível reduzir a matriz de incidência, e obter um conjunto de invariantes por simples inspeção.

O problema da análise de invariantes nas redes de alto nível se resume a achar um algoritmo geral para reduzir a matriz de incidência. Existe também o problema da interpretação dos invariantes obtidos, dado que não existe um método que permita automatizar esta interpretação. Portanto a alternativa é confiar na habilidade do projetista, o que dificulta a disseminação do método. Tentando minimizar estas dificuldades, Kurt Jensen propôs uma análise iterativa dos invariantes (JENSEN; KRISTENSEN, 2009), ou seja, definir alguns invariantes durante a fase de projeto e verificar se o modelo os satisfaz ou não. Esta seria uma solução razoável para fazer a análise dos sistemas usando invariantes, mas, por enquanto, não existem algoritmos nem ferramentas computacionais que permitam fazer isto de forma automática ou semi-automática.

Embora a rede de Petri de alto nível possua o mesmo nível de expressividade que a rede de Petri clássica, são mais adequadas para modelar sistemas complexos. O principal problema destas redes reside na análise dos modelos através de invariantes, uma vez que ainda não existem métodos razoavelmente eficientes que permitam automatizar o cálculo destes invariantes. Neste sentido, as redes clássicas estão em vantagem. 
Assim, este trabalho está focado na análise de invariantes em rede de Petri clássica, baseados na analise estrutural da rede. Muitos usam algoritmos de programação linear, que geralmente tem uma complexidade computacional polinomial, mas para problemas de maior porte a complexidade computacional pode ser exponencial. Outros autores se baseiam no cálculo dos invariantes para conseguir analisar propriedades diretamente dependentes destes. Nestes trabalhos o foco principal é a obtenção dos vetores invariantes, através de algoritmos que usam fundamentalmente álgebra linear. Porém, os algoritmos propostos não oferecem todos os invariantes possíveis para a rede. Este trabalho propõe um algoritmo para o cálculo de invariantes baseado em métodos de álgebra linear que oferece um conjunto de vetores representando um gerador mínimo de todos os invariantes possíveis, dado que qualquer combinação linear deles é também um invariante. Com isto, se garante a obtenção de todos os invariantes possíveis.

\subsection{Engenharia de requisitos: Visão Geral}

O processo de desenvolvimento de projetos compreende um conjunto de atividades que engloba métodos, ferramentas e procedimentos, com o objetivo de produzir sistemas que atendam aos requisitos especificados pelos usuários.

A Engenharia de requisitos (ER) é a primeira etapa do processo de desenvolvimento de um sistema, e está relacionada à identificação de objetivos a serem atingidos pelo sistema a ser desenvolvido (LAMSWEERDE, 2000). Um dos principais objetivos da ER é, melhorar a modelagem de sistemas e a capacidade de analisá-los, possibilitando maior entendimento de suas características antes da implementação.

Engenharia de requisitos envolve a elicitação de requisitos, análise, especificação, validação e gerenciamento de requisitos (LAMSWEERDE, 2004), (LAPOUCHNIAN, 2005),(SOMMERVILLE, 2004).

No processo de identificação de requisitos estabelecido na ER, o que debe ser feito no sistemas é elicitado, modelado e analisado. Esse processo deve lidar com diferentes stakeholders.

Na fase de elicitação de requisitos o processo de captura dos requisitos é feito à partir de usuários preferenciais (stakeholders), de usuários finais, e dos próprios engenheiros de desenvolvimento. Posteriormente, a fase de análise tem como objetivo sistematizar o processo 
de definição dos requisitos, obtendo uma especificação correta e completa do mesmo. Nesta fase ocorre a análise e integração dos diversos pontos de vista e introdução de requisitos nãofuncionais, organizacionais e de performance. Por fim, estes requisitos devem ser documentados para posterior utilização.

Os problemas mais comuns que podem surgir na engenharia de requisitos, estão associados à complexidade, à volatilidade, à ambigüidade e ao desentendimento entre stakeholders.

\subsubsection{Definição de requisitos}

Existem inúmeras definições disponíveis na literatura para o termo requisitos.

Segundo (KOTONYA; SOMMERVILLE, 1998) e (SOMMERVILLE; SAWYER, 1997) os requisitos são definidos como descrições de: como o sistema deveria se comportar, do domínio da aplicação, das restrições na operação do sistema, e das especificações de uma propriedade de sistema ou atributo. Uma definição simples para requisitos é dada em(MACAULAY, 2012), onde se define requisito como algo que o cliente necessita. Em (JACKSON, 1995), requisitos são definidos como propriedades do domínio da aplicação que devem ser executados.

Os requisititos podem ser expressos em linguagem natural, diagrama informal ou outra notação apropriada ao entendimento do cliente e da equipe de desenvolvimento. Por tanto, o uso de modelos e visões na engenharia de requisitos é extremamente importante. Usando modelos gráficos consegue-se representar e visualizar os requisitos, focando as características de interesse a cada momento do processo. Assim, a engenharia de requisitos tem abordado o princípio de separação de características por meio de métodos de modelagem em conjunto com o uso de visões, com o intuito de prover facilidades para o reuso, rastreabilidade e evolução.

A obtenção de requisitos é considerada uma das tarefas mais complexas no desenvolvimento de um sistema. Isto se deve fundamentalmente à dificuldade dos analistas em extrair informação dos usuários, as quais podem estar incompletas, sendo necessário transformar las em completas e consistentes. Outro fator que torna complexo o processo de obtenção dos requisitos, é o fato de que os requisitos possuem volatilidade; devido a que os desejos do usuário nem sempre estão relacionados na especificação do projeto já que raramente o cliente e a equipe possuem um acordo comum. Dificilmente as especificações permanecem inalteradas durante o 
processo; Geralmente, os stakeholders, oferecem informações ambiguas sobre sistemas. Esta volatilidade pode ocasionar um custo e tempo maior. Por tanto, os analistas têm a responsabilidade em extrair requisitos dos usuários, sintetizando a informação adquirida e modelar ou desenvolver uma representação dos requisitos do sistema.

\subsubsection{Classificação dos requisitos}

Existem dois tipos fundamentais de classificação de requisitos, são eles: Requisitos Funcionais (RF) e Requisitos Não-Funcionais (RNF) (SOMMERVILLE, 2007).

Os requisitos funcionais especificam as funções que o sistema ou seus componentes deverão ser capazes de realizar, podem ser definidos como atividades que o software ou sistema faz ou fará com o objetivo de capacitar os usuários a realizar suas funções. Esses requisitos devem ser bem definidos e descritos claramente para que não exista ambigüidade na sua funcionalidade (DORFMAN; THAYER, 1990). Requisitos funcionais preocupam-se com a funcionalidade e os serviços do sistema, ou seja, as funções que o sistema deve fornecer para o cliente e como o sistema se comportará em determinadas situações.

Entretanto, os requisitos Não-Funcionais descrevem as restrições e condições dos requisitos funcionais, como por exemplo: adaptabilidade, confiabilidade, eficiência, performance, portabilidade, segurança, flexibilidade, usabilidade, entre outros (CHUNG et al., 2012). Os requisitos não funcionais são geralmente mensuráveis, e podem estar associados a uma medida ou referência.

\subsubsection{Atividades envolvidas na Engenharia de Requisitos}

A engenharia de requisitos é um processo que envolve um conjunto de atividades interligadas, que tem como objetivo criar um documento de requisitos do sistema. Em (SULTAN; BANO; HUNDEWALE, 2011) e (LAMSWEERDE, 2000) se descrevem as seguintes atividades:

Análise de domínio: Deve ser estudado primeiramente o ambiente onde o sistemas será implementado, e os stakeholders devem ser identifidados e entrevistados. Nesta fase, devem ser definidos os objetivos do sistema, além de ser identificados e analisados os problemas do sistema atual, e as posíveis melhorias. 
Elicitação : São identificados os requisitos necessários para o desenvolvimento do sistema. Durante o processo de elicitação os clientes e o desenvolvedores de um sistema descobrem, e compreendem a necessidade do usuário. São analisados modelos alternativos para o sistema que será desenvolvido. A elicitação pode ser feita, entre outras, através de entrevistas, cenários, observação e análise social, etnografia e leitura de documentos.

Análise e negociação de requisitos: Requisitos alternativos e suposições são avaliados. O objetivo é estabelecer um acordo do conjunto de requisitos que são completos e consistentes. Estes requisitos não devem ser ambíguos.

Especificação de requisitos: Requisitos e suposições são formulados com precisão. Diferentes linguagens têm sido propostas para expressar e descrever requisitos, desde a linguagem natural até a lógica.

Verificação de Requisitos: As especificações são verificadas para checar problemas como incompletude, inconsistência entre outras. O principal objetivo nesta atividade é garantir que os requisitos estejam definidos corretamente e satisfaçam as necessidades dos stakeholders.

Documentação de Requisitos: Descrição detalhada do sistema e dos requisitos na forma de um documento. Várias decisões tomadas durante o processo de engenharia de requisitos são documentadas.

Evolução: São gerenciadas as mudanças de requisitos que ocorrem no sistema. Os requisitos são modificados para adaptar correções, mudanças ambientais ou novos objetivos. 


\subsubsection{Engenharia de Requisitos Orientada a Objetivos}

A Engenharia de Requisitos Orientada a Objetivos (EROO) é definida como o estudo ou aplicação de modelos de metas na Engenharia de Requisitos (HORKOFF et al., 2016). Requisitos são geralmente difíceis de serem entendidos pelos stakeholders, mas podem ser justificados e explicados por uma discussão através de objetivos. Um dos principais motivos para a elicitação dos objetivos é descobrir e estruturar os requisitos, evitar requisitos ambíguos e incompletos e permitir a comunicação entre os stakeholders de uma maneira fácil e eficiente. Portanto, a Engenharia de Requisitos Orientada a Objetivos tende a facilitar a fase de modelagem dos requisitos, pois funciona como um mecanismo de validação dos requisitos que resulta em um melhor entendimento, e ajuda na elicitação e elaboração dos requisitos.

Abordagens orientadas a objetivos definem os objetivos como metas que clientes e usuários possuem em relação ao sistema. Uma meta se define como um objetivo que o sistema deve alcançar (LAMSWEERDE, 2000). Segundo (KAIYA; HORAI; SAEKI, 2002), uma meta é um objetivo não operacional a ser alcançado pelo sistema.

Um modelo de objetivo é um modelo expresso em uma linguagem orientada a objetivos (HORKOFF et al., 2015). Essas linguagens são muitas vezes gráficas e oferecem uma sintaxe visual, por exemplo, i * (YU, 1997), KAOS (Knowledge Acquisition in automated Specification) (DARDENNE; LAMSWEERDE; FICKAS, 1993); mas também pode ser textual, por exemplo, GBRAM (Goal Based Requirements Analysis Method) (ANTÓN; POTTS, 1998). A principal desvantagem em estas técnicas orientadas a objetivos, é que nenhuma delas possui um método adequado para capturar os requisitos.

Nos últimos anos, a popularidade da abordagem de Engenharia de Requisitos Orientada a Objetivos aumentou drasticamente (PARVEEN; IMAM, 2017). A principal razão para isso é a inadequação das abordagens tradicionais de análise de sistemas ao lidar com sistemas de software cada vez mais complexos. No nível de requisitos, essas abordagens tratam os requisitos como consistindo apenas em processos e dados e não capturam a lógica dos sistemas de software, dificultando assim a compreensão dos requisitos em relação a algumas preocupações de alto nível no domínio do problema. 


\section{$2.8 \mathrm{UML}$}

A UML é uma linguagem sólida para modelar sistemas, e tem sido usada com sucesso em diferentes projetos, muitos deles ligados ao desenvolvimento de software, mas também em outros projetos de natureza mais geral envolvendo sistemas automatizados onde predominam o controle baseado em software (RUMBAUGH; JACOBSON; BOOCH, 2004). A UML oferece um conjunto de notações e diagramas para representar requisitos eliciados observando diferentes aspectos (onde predomina o funcional) sem que haja uma forte interferências entre eles. Em tese, isto deveria acelerar o processo de detecção de contradições e omissões, desde que a disciplina seja seguida à risca. Por outro lado, o que mais se apresenta no mercado (e por vezes também na academia) é o excesso de zelo funcional, dando um poder maior ao chamado Use-case, cuja inclusão no conjunto de diagramas base é bastante questionado atualmente (DOBING; PARSONS, 2006), (IRWIN; TURK, 2005), (SIAU; LEE, 2004).

Portanto, com ou sem a presença dos diagramas Use-case, a notação de requisitos em UML sofre uma dicotomia: por um lado não pode ser estritamente formal ou perderia a flexibilidade, e aderência a diferentes situações do processo de elicitação, por outro, exatamente por não poder ser formal, perde por não poder incluir uma fase de análise de requisitos subsequente, já incorporada à fase de elicitação (como proposto na moderna Engenharia de Requisitos). Por consequência, não é possível realizar validações completas do sistema. Por exemplo, não é possível garantir a coerência do comportamento de um mesmo objeto no diagrama de transição de estados e no diagrama de sequência. Além disso, não existe, na UML (até a versão 2.3), um diagrama que represente o modelo de estados global do sistema. Mesmo que se tentasse descrever todo o sistema através de um único diagrama de transição de estados, esta tarefa poderia se tornar impraticável em razão da explosão na combinação de estados. UML é atualmente aceita como padrão para modelagem de projeto de software, e apresenta diversos diagramas focando em aspectos distintos do software mas, ao mesmo tempo, provê descrições redundantes dos mesmos aspectos do sistema.

A UML não é uma metodologia de desenvolvimento, significa que não oferece um método para projetar sistemas, porém serve de ajuda para modelar, visualizar e documentar sistemas. Junto com uma notação gráfica, a UML também especifica significados, isto é, semântica. 
Sendo assim são necessárias técnicas de verificação e validação de assegurar a consistência das descrições. Porém, verificação e validação de sistemas complexos desenvolvidos de acordo com UML não é um processo simples, devido à complexidade dos sistemas além de que existem vários diagramas em UML que podem ser usados para modelar o comportamento e a estrutura do sistema.

A especificação da UML 2.5 define dois grupos de diagramas UML: diagramas estruturais e diagramas comportamentais. Na figura 8 pode-se observar a hierarquia dos diagramas UML na versão 2.5 .

Figura 8 - Hierarquia dos diagramas da UML 2.5

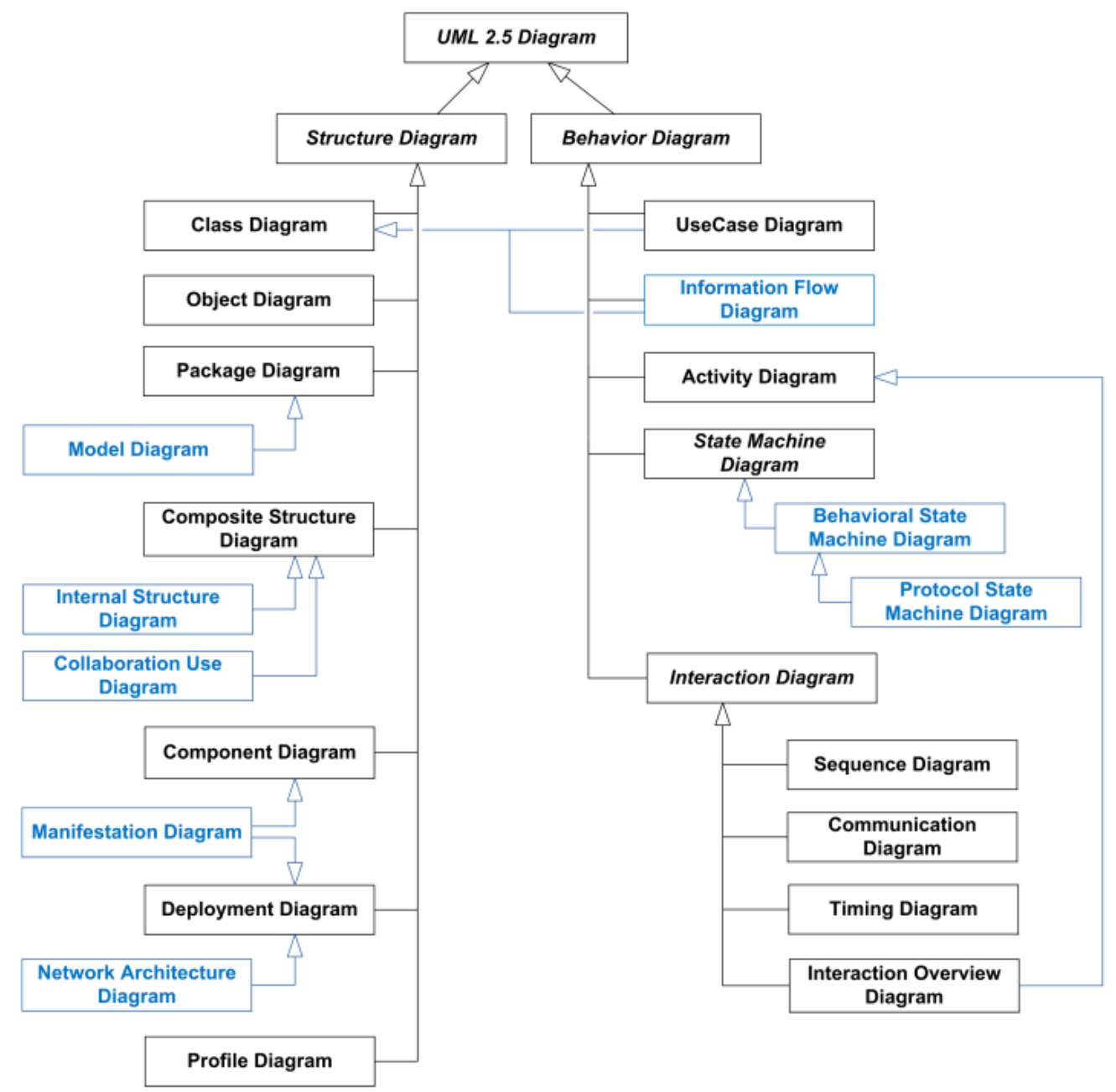

Fonte: (OMG, 2015)

Os diagramas estruturais mostram a estrutura estática do sistema e suas partes em níveis de abstrações diferentes e as relações entre eles. Os elementos em um diagrama de estrutura representam os conceitos significativos de um sistema e podem incluir abstrações, aspectos do mundo real, e conceitos de implementação. 
Os diagramas comportamentais mostram o comportamento dinâmico do sistema, que podem ser descritos como uma série de alterações no sistema durante um intervalo de tempo.

\subsubsection{OCL}

Embora a UML possua um alto poder de expressão gráfica, existem propriedades e restrições de sistemas que são muito complexas ou impossíveis de serem expressas adequadamente em um diagrama visual (visual diagram). Mesmo os mecanismos de extensão da UML: estereótipos, valores etiquetados e restrições pré-definidas, podem ser insuficientes para compor uma especificação de requisitos completa ${ }^{2}$. As linguagens formais foram desenvolvidas para resolver os equívocos nas restrições, mas são de difícil uso, requerendo uma forte base matemática. Para enfrentar esse problema foi criada a OCL (Object Constraint Language), uma linguagem formal, fácil de ler e escrever.

A OCL é uma linguagem composta de expressões para especificar restrições sobre modelos orientados a objetos ou outros artefatos da linguagem UML (CABOT; GOGOLLA, 2012). É uma linguagem precisa, textual e formal. Uma das suas principais características é que seu uso não exige um forte conhecimento matemático.

A OCL foi idealizada por Grady Booch, Ivar Jacobson e James Rumbaugh no final dos anos 90 e mantida desde então pela OMG (Object Management Group). A última versão, v. 2.4, foi lançada em fevereiro de 2014, e está associada à versão 2.4.1 e ao Modeling Objects Framework, MOF, 2.4.1. Entretanto, a base para o desenvolvimento da OCL foi o método de modelagem de negócios Syntropy, e o objetivo desde o início foi o de ter uma linguagem de uso fácil, acessível ao mercado e não só aos membros da academia ou àqueles com um forte background matemático.

Os principais tipos da OCL são: tipos primitivos e tipos coleção. Os tipos primitivos são: Boolean, Integer, Real e String. Os tipos coleção são: Collection (aglomerado qualquer de elementos do mesmo tipo, duplicados ou não, ordenados ou não; coleção); Set (conjunto de elementos do mesmo tipo, não-ordenados, sem duplicatas, aderente à definição matemática de conjunto); Bag (parecido com o conceito de Set, só que permite duplicatas, multi-conjunto);

2 Neste trabalho, especificação de requisitos completa, é àquela que permite compor o arquétipo de um artefato e não apenas aspectos dele. Alguns autores chamariam esta especificação de holística 
OrderedSet (como Set, mas seus elementos possuem um índice interno de ordenação, conjunto ordenado); Sequence (similar ao Bag, mas seus elementos possuem índice interno de ordenação).

Expressões em OCL não possuem efeitos colaterais: apenas retornam um valor, não alterando nenhuma informação do modelo. Sua avaliação é instantânea (os estados dos objetos não podem ser alterados durante essa avaliação). Além disso, utilizando expressões OCL, é possível a navegação entre as classes de um modelo UML, a partir de uma classe-base, que fornece o contexto da expressão.

\subsubsection{UML e redes de Petri na modelagem de sistemas}

Uma maneira efetiva de garantir a qualidade da especificação dos requisitos é a utilização de métodos formais para sua representação. Alguns pesquisadores propõem converter requisitos semi-formais diretamente em uma representação formal, por exemplo, passando de UML para Redes de Petri (BARESI; PEZZÈ, 2001).

Portanto, para viabilizar a fase de análise de requisitos e evitar a transferência de problemas pertinentes à fase inicial de design para as fases posteriores é preciso fazer uma transferência semântica dos requisitos para uma linguagem - e para uma fase - formal (FOYO; SALMON; SILVA, 2011).

Existe na literatura uma ampla discussão sobre a escolha da linguagem de especificação (de requisitos) mais adequada (FRAPPIER; HABRIAS, 2012). No escopo deste trabalho são analisados sistemas de automação que, portanto, possuem uma certa dinâmica, que é sua característica principal. Sendo assim, admite -se, respaldado por algumas referências (FRAPPIER; HABRIAS, 2012) que as redes de Petri, e em especial as redes de Petri orientadas a objeto podem ser a melhor opção.

Existem varias propostas para transferir a semântica de requisitos da UML para redes de Petri e suas extensões (BARESI; PEZZÈ, 2001),(ZHAO et al., 2004),(SALDHANA; SHATZ, 2000),(KERKOUCHE et al., 2010). Muitos destes trabalhos oferecem métodos para construir redes de Petri que representem o comportamento dos sistemas partindo dos diagramas de sequência, diagramas de atividades, diagramas de estados, diagramas de caso de uso, ou diagramas de atividades. Em (ZHAO et al., 2004) são discutidas algumas técnicas de transformação de grafos, 
que podem ser usadas para converter diagramas UML em redes de Petri.

Para transformar modelos de UML, em uma rede de Petri, deve-se levar em consideração tanto a estrutura estática e dinâmica dos diagramas, como as relações entre eles. Em (ZHAO et al., 2004) estas relações foram classificadas em três níveis:

- relações entre os mesmos diagramas de UML de diferentes contextos;

- relações entre vários diagramas de uma mesma vista;

- relações entre vários diagramas de várias vistas do sistema.

Este terceiro nível descreve as relações entre os diagramas estáticos e os diagramas que representam a dinâmica. Neste trabalho se propõe a verificação de modelos que integram diagramas com vistas estática e dinâmica, contribuindo assim ao terceiro nível de relacionamento. 
Neste capítulo primeiramente são apresentados os métodos e os algoritmos computacionais para a análise dos invariantes, assim como de outras propriedades estruturais das rede de Petri que podem ser deduzidas a partir do cálculo matemático dos invariantes. A estrutura hierárquica da rede GHENeSys é utilizada para tratar a evolução do processo de design e dos invariantes por extensões conservativas. Neste caso é de vital importância a identificação de condições para que o cálculo de invariantes seja escalável e extensível de forma conservativa, isto é, preservando as propriedades que já foram identificadas. Este resultado é muito importante para que o cálculo e a análise de invariantes em redes de Petri possa ser usado em várias áreas do conhecimento, e em diversos tipos de processos de design, além de poder ser usado em várias fases de um mesmo processo de design.

Os invariantes podem também desempenhar um papel destacado na modelagem e análise de requisitos. Resultados nesta linha são também muito importantes uma vez que a maioria das ferramentas de apoio ao desenvolvimento de software (incluindo o desenvolvimento de software de controle e automação), cerca de $92 \%$, é direcionada para as fases finais, isto é, a modelagem detalhada e implementação. Apenas 5\% se destinam à fase de elicitação e análise de requisitos e, mesmo assim, grande parte não faz uma análise sistemática destes requisitos (dados extraídos de estudos não publicados feitos por grupos de design da Universidade de Otawa, Canadá).

Uma das vantagens de representar requisitos usando invariantes é a redução do custo 
computacional no processo de verificação, uma vez que não é necessário analisar todos os estados alcançáveis. Os invariantes estão de fato relacionados com propriedades gerais do sistema e ligados à estrutura da rede e/ou ao estado inicial.

A utilização de métodos formais garante a qualidade da especificação de requisitos e a acurácia dos métodos de análise. Uma vez formalizados, livres de contradições, possíveis omissões, e formando um conjunto consistente - e incluindo os requisitos não-funcionais (ROBINSON WILLIAM N; PAWLOWSKI, 2003) - se pode chegar a uma fase onde não se vê mais nenhuma possibilidade de avanço no processo de design via processo de elicíação: pode se então chamar a este conjunto de requisitos especificações, e que, especialmente quando se trata de sistemas automatizados e problemas de planning, permanecer usando as redes de Petri como a representação formal. Embora existam experiências e empresas que usam métodos formais para especificações de requisitos, é preciso reconhecer que a interpretação destes requisitos não é trivial, e por isso a sua utilização é por vezes questionada em alguns setores industriais e até de Eng. de Software (DENARO; PEZZE, 2004), (ZEICHICK, 2004).

No decorrer deste capítulo é apresentada uma proposta de disciplina de projeto para analisar, modelar e verificar requisitos, partindo da sua representação semi-formal em UML, e utilizando métodos formais baseados em Rede de Petri para proceder à modelagem, análise e verificação. Para sistemas modelados usando UML, os invariantes podem ser formulados a partir de restrições representadas na linguagem ontológica OCL (Object Constraint Language). Uma vez obtidos os invariantes, estes podem ser usados na síntese do modelo em rede de Petri.

\subsection{Análise de propriedades estruturais usando os invari- antes}

Os invariantes são propriedades que permeiam toda a fase de desenvolvimento de projeto - seja qual for o tipo de projeto, desde que admitam um tratamento dinâmico discreto. Especialmente para os sistemas automatizados, onde a prevalência de propriedades específicas é de fundamental importância para garantir a aplicabilidade do sistema (ou mesmo produto), é fundamental que estas propriedades sejam analisadas desde a fase inicial de Engenharia de requisitos até a modelagem que antecede a implementação. Em especial, é fundamental poder 
provar que estas propriedades evoluem de forma conservativa, sem no entanto exceder os limites da especificação, especialmente para os sistemas ditos complexos. No caso destes sistemas, uma análise informal ou mesmo formal, baseada em autômatos ou redes de Petri não poderia ser feita tendo a representação gráfica como o seu elemento principal. Seja pelo tamanho ou pela complexidade das relações, estas propriedades teriam que ser avaliadas formalmente, como é feito neste trabalho.

\subsubsection{Cálculo dos invariantes}

O cálculo dos invariantes pode ser reduzido à resolução dos sistemas de equações homogêneos (2.1) e (2.3). Neste trabalho se propõe o método de Gauss-Jordan Elimination (PETERS; WILKINSON, 1975) (YALAMOV, 1991), para transformar a matriz de coeficientes numa matriz diagonal. Para as matrizes de tamanho $m x n$ a complexidade do método é $O\left(m n^{2}\right)$. Depois de transformar a matriz numa matriz diagonal é obtido um conjunto de vetores que representam a solução básica do sistema de equações. Qualquer combinação linear destes vetores é também uma solução do sistema de equações.

A seguir se descrevem os passos para obter os invariantes de transição e de lugar .

\section{- Passos para o cálculo dos invariantes de transição}

Passo 1: Calcular a matriz de incidência do sistema modelado $(A)$.

Passo 2: Aplicar o método de Gauss- Jordan para transformar a matriz de incidência em uma matriz diagonal. Se o posto da matriz de incidência $R(A)$ for menor que o numero de incógnitas (número de lugares da rede), então ir ao passo 3. Se e o posto da matriz de incidência for igual ao número de incógnitas, então terminar, o sistema não tem invariantes de transição.

Passo 3: Obter a solução básica do sistema representado pela matriz de incidência.

\section{- Passos para o cálculo dos invariantes de lugar}

Passo 1: Para obter os invariantes de lugar é preciso em primeiro lugar calcular a transposta da matriz de incidência $\left(A^{T}\right)$. 
Passo 2: Em seguida deve-se aplicar o método de Gauss- Jordan para transformar a matriz de incidência em uma matriz diagonal. Se o posto da matriz de incidência $R\left(A^{T}\right)$ for menor que o número de incógnitas (número de lugares da rede), então ir ao passo 3. Se o posto da matriz de incidência for igual ao numero de incógnitas, então terminar, o sistema não tem invariantes de lugar.

Passo 3: Obter a solução básica do sistema representado pela matriz de incidência.

\subsubsection{Método para obter a solução básica do sistema de equações lineares homogêneos}

Seja o sistema de equações lineares: $A \cdot x=0$, onde $A$ é uma matriz $m \times n$ ( $m$ equações e $n$ incógnitas), e seja $k$ o posto da matriz $A$. Seja $S$ o espaço solução do sistema, então, segundo o teorema dos sistemas de equações lineares homogêneos, $\operatorname{dim} S=n-k$.

Para encontrar uma base de $S$, é preciso achar $n-k$ vetores que gerem o espaço das soluções $S$. Para isto, o primeiro passo é aplicar o método de Gauss- Jordan para transformar a matriz numa matriz diagonal (isto já foi feito no passo 1), e depois isolar as variáveis linearmente independentes. Supondo que as variáveis linearmente independentes sejam: $x_{k+1}, x_{k+2}, \ldots, x_{n}$, então existem $n-k$ variáveis independentes.

Para cada conjunto de valores atribuídos às variáveis, obtém - se um conjunto de valores das variáveis dependentes. Para obter os $n-k$ vetores desejados, atribui-se a cada variável independente o seguinte conjunto de valores:

- $x_{k+1}=1, x_{k+2}=0, x_{k+3}=0, \ldots, x_{n}=0$;

- $x_{k+1}=0, x_{k+2}=1, x_{k+3}=0, \ldots, x_{n}=0$;

- $x_{k+1}=0, x_{k+2}=0, x_{k+3}=1, \ldots, x_{n}=0$;

- $x_{k+1}=0, x_{k+2}=0, x_{k+3}=1, \ldots, x_{n}=1$;

Assim é possível obter os $n-k$ vetores de $\mathrm{S}$ que formam uma base.

A seguir se apresenta os algoritmos para obter os invariantes: 

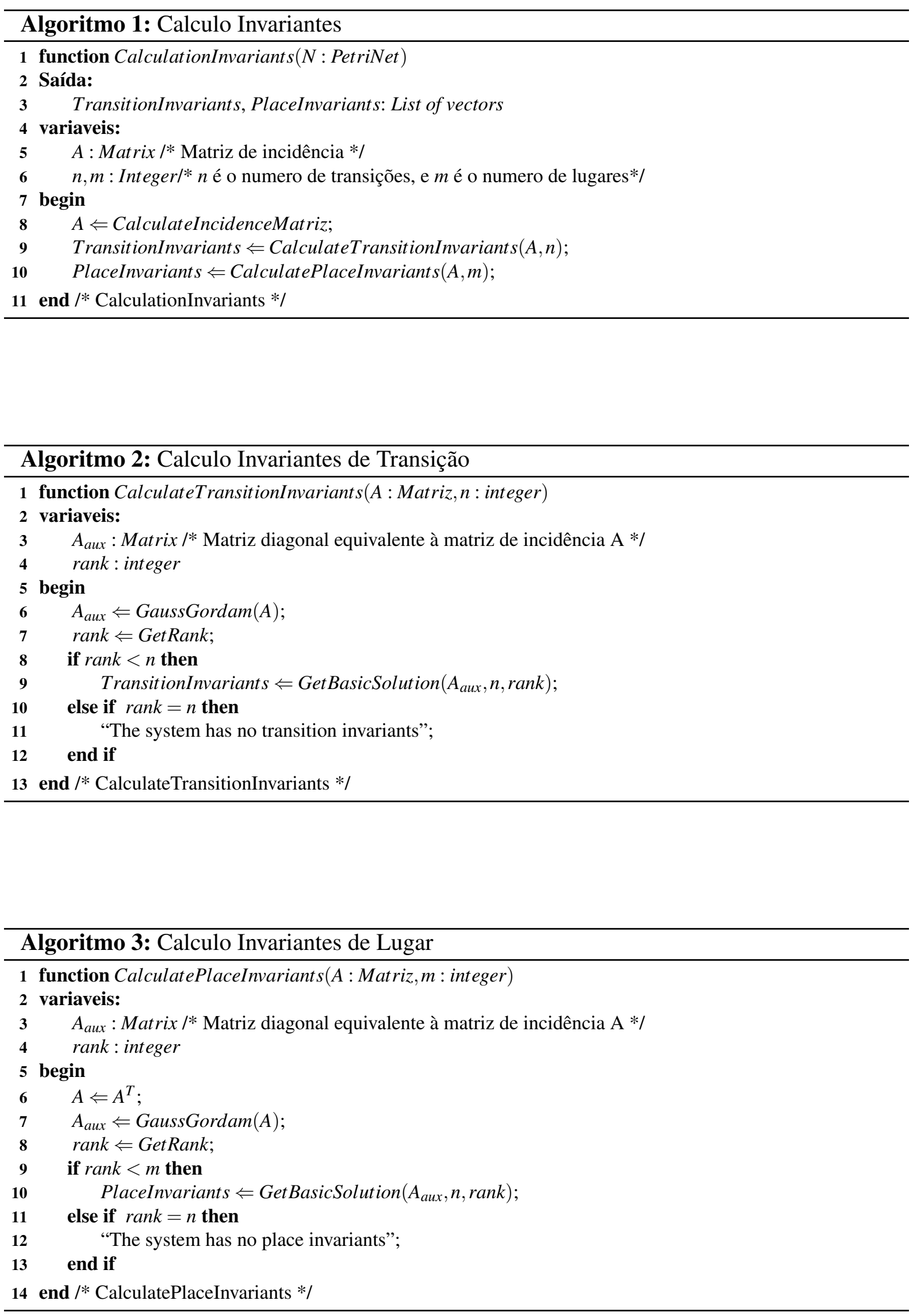


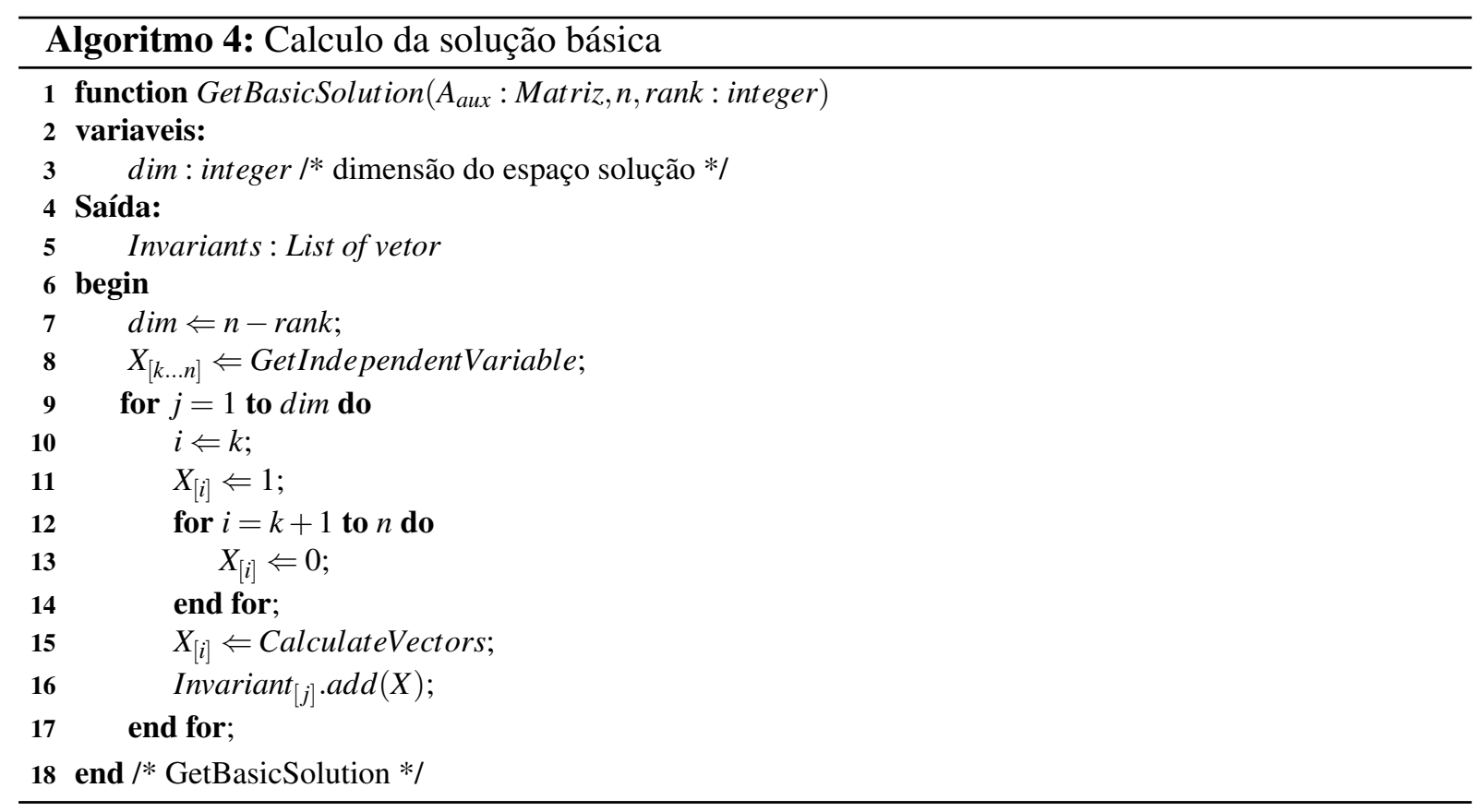

\subsubsection{Método para analisar outras propriedades partindo dos invari- antes}

Os invariantes oferecem informações matemáticas importantes para o estudo de outras propriedades estruturais das redes de Petri. Na tabela 1, mostram - se algumas das propriedades estruturais que podem ser analisadas usando invariantes.

Tabela 1 - Condições algebraicas das propriedades estruturais

\begin{tabular}{|l|l|}
\hline Propriedades estruturais & Condições necessárias e suficientes \\
\hline Limitação Estrutural & $\exists x>0, A^{T} \cdot x \geq 0$ \\
\hline Conservatividade & $\exists x>0, A^{T} \cdot x=0$ \\
\hline Repetitividade & $\exists y>0, A \cdot y \geq 0$ \\
\hline Consistência & $\exists y>0, A \cdot y=0$ \\
\hline
\end{tabular}

Analisando a Tabela 1 pode - se concluir o seguinte:

Para a análise da limitação estrutural e da conservatividade é preciso analisar os invariantes de lugar. Fazendo combinações lineares dos vetores invariantes de lugar, novos vetores serão obtidos. Se todos os elementos destes vetores são diferentes de zero, então a rede analisada é limitada estruturalmente e é conservativa. 
Para verificar as propriedades de repetitividade e consistência, deve-se analisar os invariantes de transição. Cada vetor invariante maior que zero obtido mostra como o sistema pode voltar a seu estado inicial, isto demonstra a presença de ciclos na rede (LAMCH, 2002). Partindo do estudo dos invariantes de transição também é possível analisar a vivacidade da rede. Para isso devem ser calculados os invariantes de transição e em seguida fazer combinações lineares destes vetores. Se todos os vetores são maiores que zero então o sistema está livre de estados mortos ou deadlocks, ou seja, isto garante que existe pelo menos um caminho na rede que é livre de deadlock, garantindo assim que a rede seja L1-viva (MURATA, 1989).

Alguns autores como (CAMPOS; SILVA, 1990) apresentam condições necessárias para que uma rede seja estruturalmente viva e estruturalmente limitada. Estas condições podem ser aplicadas a redes Place/Transition e se baseiam no rank da matriz de incidência da rede.

- Se a rede de Petri é estruturalmente livre então a rede é repetitiva.

- Uma rede de Petri é estruturalmente repetitiva e estruturalmente limitada se e somente se a rede é consistente e conservativa.

- Se uma rede de Petri é estruturalmente viva e estruturalmente limitada então o rank da matriz de incidência é menor que o mínimo entre o número de lugares e o número de transições $(\operatorname{Rank}(A)<\min (m-1, n-1))$.

\subsubsection{Exemplo}

Nesta seção é mostrado através de um exemplo simples tomado de (MURATA, 1989) a análise de algumas propriedades estruturais, partindo do cálculo dos invariantes.

A figura 9 mostra a rede de Petri desenhada no sistema GHENeSys (SALMON et al., 2011).

\subsubsection{Calculando os invariantes}

Seguindo o algoritmo proposto na seção 3.1.1 o primeiro passo para calcular os invariantes de transição é calcular a matriz de incidência. A seguir mostramos a matriz de incidência 
Figura 9 - Rede de Petri do sistemas readers-writers modelada em GHENeSys

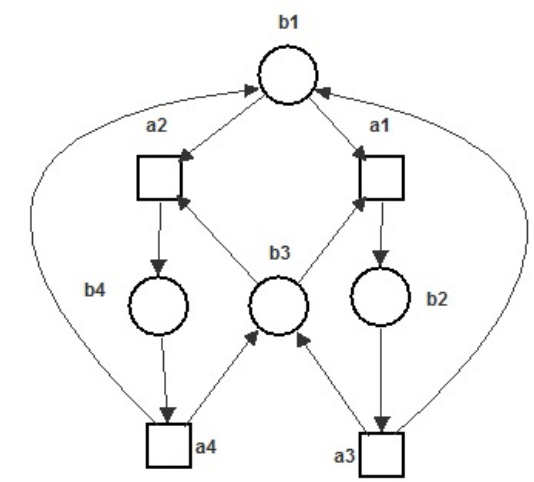

Fonte: Elaborada pela autora.

correspondente à rede de Petri mostrada na figura 9:

$$
\mathbf{A}=\left[\begin{array}{cccc}
-1 & -1 & 1 & 1 \\
1 & 0 & -1 & 0 \\
-1 & -1 & 1 & 1 \\
0 & 1 & 0 & -1
\end{array}\right]
$$

A figura 10 mostra a matriz de incidência calculada por GHENeSys.

Figura 10 - Matriz de incidência do sistemas readers-writers calculada por GHENeSys

\begin{tabular}{|c|c|c|c|c|}
\hline$\underline{\underline{\underline{\theta}}}$ & \multicolumn{4}{|c|}{ Incidence Matrix } \\
\hline Show & () A & $\bigcirc \mathrm{A}-$ & $\bigcirc \mathrm{A}$ & \\
\hline & al & $\mathrm{a} 2$ & $\mathbf{a} 3$ & a4 \\
\hline bl & -1.0 & -1.0 & 1.0 & 1.0 \\
\hline b2 & 1.0 & 0.0 & -1.0 & 0.0 \\
\hline b3 & -1.0 & -1.0 & 1.0 & 1.0 \\
\hline b4 & 0.0 & 1.0 & 0.0 & -1.0 \\
\hline
\end{tabular}

Fonte: Elaborada pela autora. 
Aplicando o método de Gauss- Jordan obtêm-se a matriz 3.2.

$$
\mathbf{A}=\left[\begin{array}{cccc}
-1 & -1 & 1 & 1 \\
0 & -1 & 0 & 1 \\
0 & 0 & 0 & 0 \\
0 & 0 & 0 & 0
\end{array}\right]
$$

$\mathrm{O} R(A)=2<$ numero de transições da rede, portanto o sistema de equações é compatível indeterminado (tem varias soluções).

Seguindo o algoritmo apresentado em 3.1.1 o próximo passo é calcular as soluções básicas do sistema, que representam o conjunto de invariantes de transição.

As soluções básicas do sistema representado pela matriz 3.1 (invariantes de transição) são:

$$
\mathbf{Y}=\left(\begin{array}{c}
y_{1} \\
y_{2} \\
y_{3} \\
y_{4}
\end{array}\right)=\left(\begin{array}{c}
c_{1} \\
c_{2} \\
c_{1} \\
c_{2}
\end{array}\right), \forall c_{1}, c_{2} \in \mathbf{R}
$$

Assim, os invariantes de transição são todos os vetores $Y$ tal que $c_{1}, c_{2} \in \mathbf{R}$, e $c_{1} \geq 0$, $c_{2} \geq 0$.

A seguir se mostram os vetores que representam o conjunto gerador de todos os invariantes de transição do sistema modelado na figura 9:

$$
\mathbf{Y}_{1}=\left(\begin{array}{l}
0 \\
1 \\
0 \\
1
\end{array}\right), \mathbf{Y}_{2}=\left(\begin{array}{l}
1 \\
0 \\
1 \\
0
\end{array}\right)
$$


Para calcular os invariantes de lugar é preciso primeiramente calcular a transposta da matriz 3.1, e depois seguir os mesmos passos que para o cálculo dos invariantes de transição.

A matriz 3.3 mostra a transposta da matriz 3.1

$$
\mathbf{A}^{\mathbf{T}}=\left[\begin{array}{cccc}
-1 & 1 & -1 & 0 \\
-1 & 0 & -1 & 1 \\
1 & -1 & 1 & 0 \\
1 & 0 & 1 & -1
\end{array}\right]
$$

Aplicando o método de Gauss- Jordan obtêm-se a matriz 3.4.

$$
\mathbf{A}=\left[\begin{array}{cccc}
-1 & 1 & -1 & 0 \\
0 & -1 & 0 & 1 \\
0 & 0 & 0 & 0 \\
0 & 0 & 0 & 0
\end{array}\right]
$$

As soluções básicas do sistema representado pela matriz 3.3 (invariantes de lugar) são:

$$
\mathbf{X}=\left(\begin{array}{c}
x_{1} \\
x_{2} \\
x_{3} \\
x_{4}
\end{array}\right)=\left(\begin{array}{c}
c_{1} \\
c_{1}+c_{2} \\
c_{2} \\
c_{1}+c_{2}
\end{array}\right), \forall c_{1}, c_{2} \in \mathbf{R}
$$

Assim, os invariantes de lugar são todos os vetores $X$ tal que $c_{1}, c_{2} \in \mathbf{R}$, e $c_{1} \geq 0, c_{2} \geq 0$, $c_{1}+c_{2} \geq 0$.

Os vetores que se mostram a seguir, representam o conjunto gerador de todos os invariantes de lugar do sistema modelado na figura 9:

$$
\mathbf{X}_{\mathbf{1}}=\left(\begin{array}{c}
0 \\
1 \\
1 \\
1
\end{array}\right), \mathbf{X}_{\mathbf{2}}=\left(\begin{array}{l}
1 \\
1 \\
1 \\
0
\end{array}\right)
$$


A Figura 11 mostra os invariantes de lugar e transição calculados pelos sistema GHENeSys.

Figura 11 - Invariantes de lugar e transição do sistemas readers-writers obtidos por GHENeSys

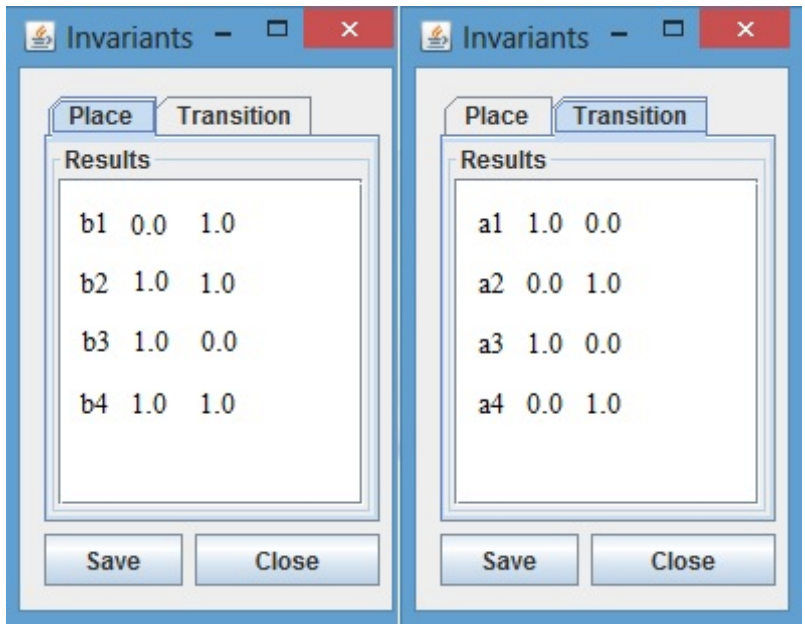

Fonte: Elaborada pela autora.

\subsubsection{Analisando outras propriedades estruturais}

Analisando os invariantes de uma rede de Petri é possível verificar algumas propriedades estruturais como foi mostrada na Tabela 1.

Para o exemplo mostrado nesta seção, e analisando os resultados obtidos no cálculo dos invariantes, podemos obter o seguinte:

$\exists x>0, A^{T} x=0$ então a rede é: Limitada e Conservativa.

$\exists y>0, A y=0$ então a rede é: Repetitiva e Consistente.

\subsection{Método de modelagem: UML- GHENeSys}

Existem três vertentes na pesquisa sobre o tratamento de requisitos e sua transferência para uma representação formal:

- a primeira vertente tenta garantir o devido acoplamento entre requisitos funcionais e nãofuncionais (NoF) durante a fase de elicitação de requisitos, usando linguagens alternativas 
para os requisitos não-funcionais, assim como para as restrições (requisitos negativos e/ou pertinentes à interação entre o sistema e o seu contexto). Tendo este conjunto em mente, fazer a transferência semântica para uma representação formal executável - o que é importante especialmente para sistemas dinâmicos e distribuídos. A opção de linguagem mais usada para este tipo de sistema, notadamente os sistemas dinâmicos discretos, é a rede de Petri.

- a segunda vertente consiste em investigar qual conjunto de diagramas - eventualmente excluindo o diagrama de casos de uso - seria a base mínima para representar completamente, sem o perigo de excessos de zelo funcional, um sistema, e daí então ecolher uma linguagem alvo formal para fazer a transferência. Neste caso a rede de Petri é ainda uma boa candidata, ao lado de B, Z, e outras.

- a terceira seria abandonar por completo a abordagem baseada em UML e seguir um caminho alternativo, por exemplo, usando os métodos orientados a objetivos. Neste caso, usando métodos como o KAOS (DARDENNE; LAMSWEERDE, 1993), onde a formalização seria feita em LTL ${ }^{1}$.

No presente trabalho se segue a primeira alternativa. Outras propostas de tese do D-Lab investigam as demais alternativas.

\subsubsection{Proposta de um conjunto mínimo de diagramas para modelar sistemas a eventos discretos}

Para o que segue foi escolhida uma versão mais recente da UML, sobre a qual estão baseados os resultados deste trabalho: a UML 2.5.

Neste trabalho propõe-se o uso de um conjunto mínimo de diagramas para modelar os requisitos dos sistemas automatizados.

\subsubsection{Diagrama de classes}

Para representar a parte estática do sistemas propomos primeiramente o uso do diagrama de classes. Este é um diagrama estático da UML onde é exibido um conjunto de classes, interfaces, 
e seus relacionamentos. Neste diagrama é possível representar alguns dos classificadores do sistema, subsistemas ou componentes, os diferentes relacionamentos entre estes, seus atributos, operações e restrições (em OCL).

A estrutura de uma classe se divide em três partes:

- nome da classe;

- propriedades (atributos);

- operações.

\subsubsection{Diagrama de Pacote (Package Diagram)}

Para sistemas com muitos componentes, pode-se dividir o diagrama de classes em módulos para facilitar a modelagem do sistema. Para isto pode- se usar o diagrama de Pacotes. Pacotes são estruturas que permitem agrupar qualquer construção da UML em estruturas. Os diagramas de pacotes mostram os pacotes e seus relacionamentos.

\subsubsection{Diagrama de Objeto}

O diagrama de objetos é outro dos diagramas propostos, e deve ser usado para representar, caso existam, diferentes instâncias de classes. O diagrama de objetos representa uma fotografia do sistema em um dado momento. Mostra os vínculos entre os objetos conforme estes interagem, e os valores de seus atributos.

\subsubsection{Diagramas comportamentais}

Para representar a dinâmica do sistema, propõe-se o uso de três diagramas comportamentais: diagrama de tempo, diagrama de máquina de estados, e o diagrama de interação geral.

\subsubsection{Diagrama de tempo}

Para sistemas com restrições de tempo, propõe-se o uso de diagramas de tempo. Os diagramas de tempo capturam o comportamento de objetos ao longo do tempo e a duração na qual eles permanecem em um determinado estado; permitindo representar as mudanças de 
estados do sistema. Este diagrama é considerado uma mistura entre o diagrama de sequência e o diagrama de máquina de estados.

\subsubsection{Diagrama de máquina de estados}

O diagrama de máquina de estados é usado para modelar o comportamento discreto por transições de estados. Este diagrama mostra os vários estados possíveis por quais um objeto pode passar. Ao longo do tempo um objeto muda de estado quando acontece algum evento interno ou externo ao sistema. Através da análise das transições entre os estados, pode-se prever todas as possíveis operações realizadas, em função dos eventos que podem ocorrer.

Os elementos do diagrama de estados são:

- Estados: Situações na vida de um objeto na qual ele satisfaz uma ou mais condições ou realiza alguma atividade.

- Transições: Estados são associados através de transições, e estas transições têm eventos asociados.

- Ações: Ao passar de um estado para o outro o objeto pode realizar ações.

- Atividades: Executadas durante a permanência em um estado.

A proposta do presente trabalho é construir uma rede de Petri a partir dos diagramas de máquina de estados. A figura 12 mostra a representação gráfica dos elementos do diagrama de máquina de estados que devem ser usados nos modelos.

\subsubsection{Diagrama de interação geral}

Por último propõe- se o uso do diagrama de interação geral, quando as sequências das interações se mostraram muito complexas. Estes diagramas fornecem uma visão geral do controle de fluxo entre objetos. É uma mistura entre diagramas de sequência e diagramas de atividade. A figura 13 mostra um exemplo deste diagrama. 
Figura 12 - Elementos do diagrama de Máquina de Estados

\begin{tabular}{|c|c|}
\hline Tipo & Representação Gráfica \\
\hline Entry point & \\
\hline Final state & \\
\hline Simple state & s \\
\hline \multirow{3}{*}{ Composite state } & s \\
\hline & Sb2 \\
\hline & $\mathrm{Sb} 1 \rightarrow$ \\
\hline \multirow[t]{2}{*}{ Choice pseudostate } & {$[\mathrm{I} \diamond>10]$} \\
\hline & V \\
\hline
\end{tabular}

Fonte: (OMG, 2015)

Figura 13 - Diagrama de Integração Geral

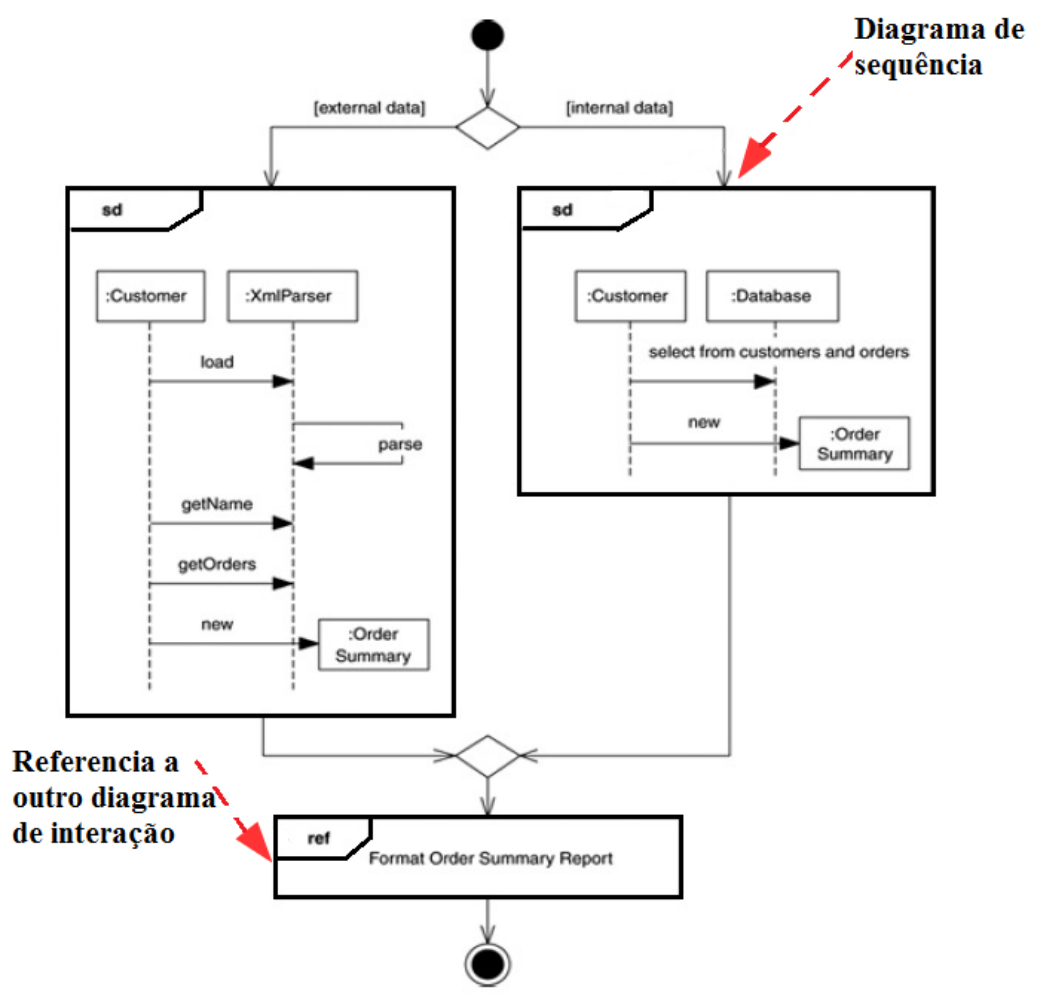

Fonte: (OMG, 2015) 


\subsection{Disciplina de Projeto UML- GHENeSys}

Nesta seção apresenta- se uma proposta de disciplina de projeto para sistemas automatizados. A disciplina propõe, à partir da modelagem em UML- a passagem para uma representação formal em redes de Petri, onde será possível realizar a análise e verificação (formal) dos requisitos usando invariantes definidos sobre estas redes. O processo de análise deve resultar em requisitos sem contradições, sem omissões, satisfazendo diferentes viewpoints (LEITE, 1996),(SILVA JOSÉ REINALDO; SANTOS, 2005)² e deverão ser a base da especificação formal. Os invariantes também podem ser usados para mapear os requisitos e os features do sistema, gerando o que se chama em Engenharia de Requisitos tracebility, mas este aspecto está fora do escopo deste trabalho.

O processo de tradução da representação semi-formal UML para uma representação formal executável tem obtido muita atenção dos diversos pesquisadores que propõem diferentes métodos de conversão baseados em grafos e esquemas. Entretanto, neste trabalho o objetivo é mais direto e específico, consiste em, depois de modelar os requisitos usando os digramas da UML, usar a linguagem OCL para representar restrições e requisitos não-funcionais, que não poderiam ser claramente representados nos diagramas da UML, usando em seguida esta base para formalizar o processo como um todo, transferindo este conjunto de diagramas e restrições para um grafo (uma rede de Petri).

Usando OCL serão também definidas as regras para expressar os requisitos do sistema que sejam invariantes. Uma vez especificados estes requisitos como regras formais, o próximo passo será converter estas regras em um conjunto de equações que representem as restrições do sistema. A partir daí é possível passar à construção da rede de Petri usando alguns dos métodos de transformação propostos na literatura - eventualmente com as extensões propostas neste trabalho - mas levando em consideração as restrições (representadas por equações). As restrições expressas nestas equações devem ser satisfeitas em todos os estados do sistemas, e é isto que significa ser invariante.

É bom destacar que nem todos os invariantes se apresentam na forma de restrição (e nem toda restrição é um invariante). Ainda assim, no caso geral de sistemas automatizados,

2 Os viewpoints são uma forma de estruturar os requisitos para representar as perspectivas de diferentes stakeholders. Os stakeholders podem ser classificadas sob diferentes pontos de vista. 
as restrições funcionais e não-funcionais determinam regras de adequação do sistema ao seu domínio de aplicação, e são de grande importância, mesmo quando não constituem um invariante. Também é verdade que inúmeras vezes estas restrições são bastante genéricas e se apresentam como um invariante.

Um modo de verificar este tipo de requisitos usando invariantes poderia ser simplesmente construir a rede de Petri e obter os invariantes da rede. Mas, uma vez obtidos os invariantes da rede, um dos grandes problemas é a sua interpretação. Assim, como na maioria dos métodos usados para a obtenção de invariante, geralmente só é possível obter um subconjunto deles. Em geral, são obtidos conjuntos geradores a partir dos quais é possível obter os demais invariantes. Isto leva ao seguinte problema: como obter os invariantes que interessam em cada sistema partindo deste conjunto básico. Isto requer um conhecimento grande sobre o sistema e seu contexto para determinar quais invariantes precisam ser testados. Assim, o mais eficiente seria definir os invariantes antes de construir a rede de Petri, o que facilita a sua posterior análise.

A disciplina de projeto proposta é descrita a seguir:

1. Representar os requisitos do sistemas usando os diagramas da UML (a representação do sistema em UML deve conter necessariamente o diagrama de classes e de estado da UML).

2. Definir restrições para expressar os requisitos do sistema que sejam invariantes, usando a linguagem OCL.

3. Transformar as restrições em OCL em um conjunto de inequações que representem os invariantes de lugar de uma rede de Petri.

4. Transformar a representação em UML em uma rede GHENeSys, através de um método desenvolvido sobre a proposta de (BARESI; PEZZÈ, 2001).

5. Verificar requisitos detectando inconsistências e/ou usando os invariantes da rede de Petri. 
A figura 14 mostra um esquema que descreve a disciplina de projeto proposta

Figura 14 - Esquema da proposta

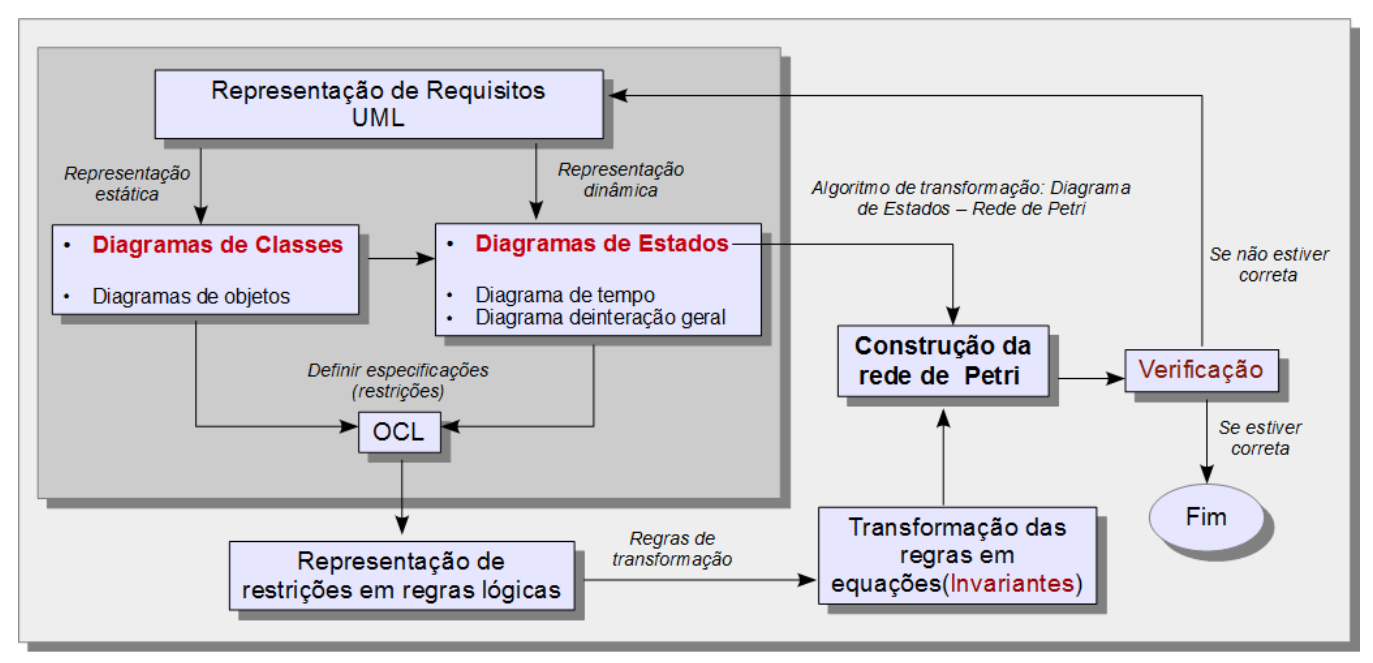

Fonte: Elaborada pela autora.

\subsubsection{Método para transformar os diagramas de estado de UML em redes de Petri}

Nesta seção se apresenta a proposta de um método para transformar diagramas UML em redes de Petri. Este método foi baseado no método proposto em (BARESI; PEZZÈ, 2001), mas acrescentando os novos elementos do diagrama de estados da UML 2.5. Com isto, podem ser geradas redes de Petri hierárquicas (o método proposto em (BARESI; PEZZÈ, 2001) gera uma rede de Petri clássica). Além disso, o método que se propõe no presente trabalho, leva em consideração as instâncias de um objeto, significa que, se as instâncias de um objeto são iguais, são representadas por tokens nos lugares, caso contrario, são modeladas todas as instâncias. No método de transformação proposto, o diagrama de estados é construído levando em consideração os diagramas de classes e objetos, além das pre e post condições descritas em OCL. A seguir se descreve o método proposto: 
1. Os estados de um diagrama de estados são modelados como lugares de uma rede de Petri e as transições do diagrama de estados são modeladas como transições das redes de Petri.

2. Se os estados do diagrama de estados da UML possuem restrições formuladas em OCL que representam pre-condições, estas serão modeladas como lugares da seguinte forma: seja $p_{i}$ o conjunto de lugares que representam as restrições $r_{i}$, e seja $e$ o lugar que representa o estado que possue as restrições $r_{i}$, então temos que, ${ }^{\bullet} e_{i}=\left\{t_{i}\right\}$ e $p_{i} \in t^{\bullet}$.

3. As relações entre os estados e as transições no diagrama de estados são modelados com arcos entre os lugares e as transições correspondentes à rede de Petri.

4. As instâncias são modeladas com os tokens.

5. Se as instâncias de uma classe são diferentes, isso significa que objetos com caraterísticas diferentes podem formar parte de uma mesma classe, então estes objetos devem ser representados no diagrama de objetos. Neste caso as instâncias de uma classe devem ser definidas por diferentes tokens; porém, isto só seria possível numa rede de alto nível. No método que está sendo proposto, cada classe que represente um elemento dinâmico do sistema deve ter um diagrama de estados associados; portanto na modelagem deste diagrama de estados, cada estado deve ser multiplicado pelo número de instâncias diferentes da classe associada; o que significa que para cada estado da classe, deverão ser desenhados estados distintos para os diferentes objetos pertencentes a esta classe. Em termos lógicos isto pode ser expressado como segue:

Seja $M$ um diagrama de estados associado a uma classe $C$. Sejam $e_{i}$ os diferentes estados do diagrama $M$, e $o_{k}$ os diferentes objetos da classe $C$, onde $i=1 \ldots m, k=1 \ldots n$, então: $\forall e_{i} \in M, e_{i}$ deve ser substituido por um conjunto de estados $e_{j}$, onde $j=1 \ldots n$.

6. Os estados compostos serão modelados como macro elementos da rede de Petri GhENeSys. 
As figuras 15 e 16 mostram o mapeamento dos diagramas UML na rede GHENeSys.

Figura 15 - Mapeamento dos elementos do diagrma de estados de UML e os elementos da rede GHENeSys

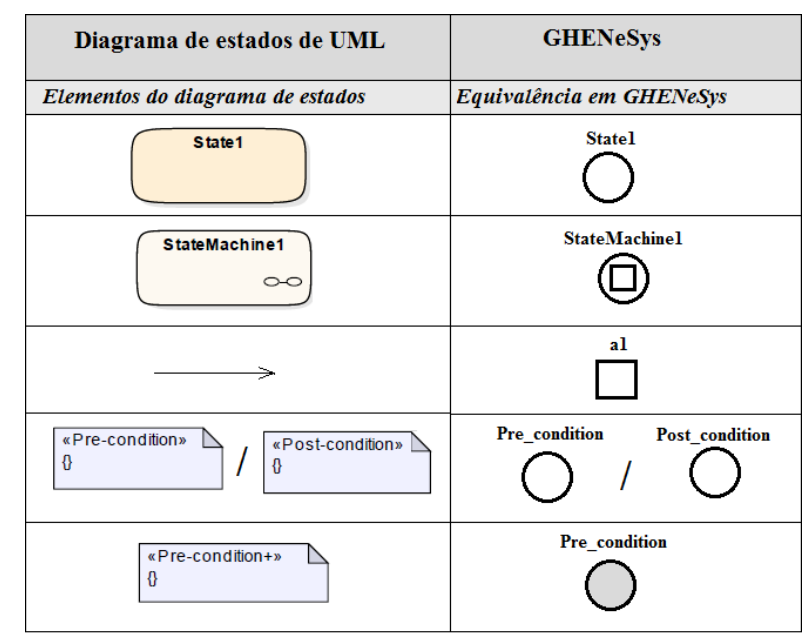

Fonte: Elaborada pela autora. 
Figura 16 - Mapeamento das relações entre elementos do diagrama de estados de UML e a rede GHENeSys

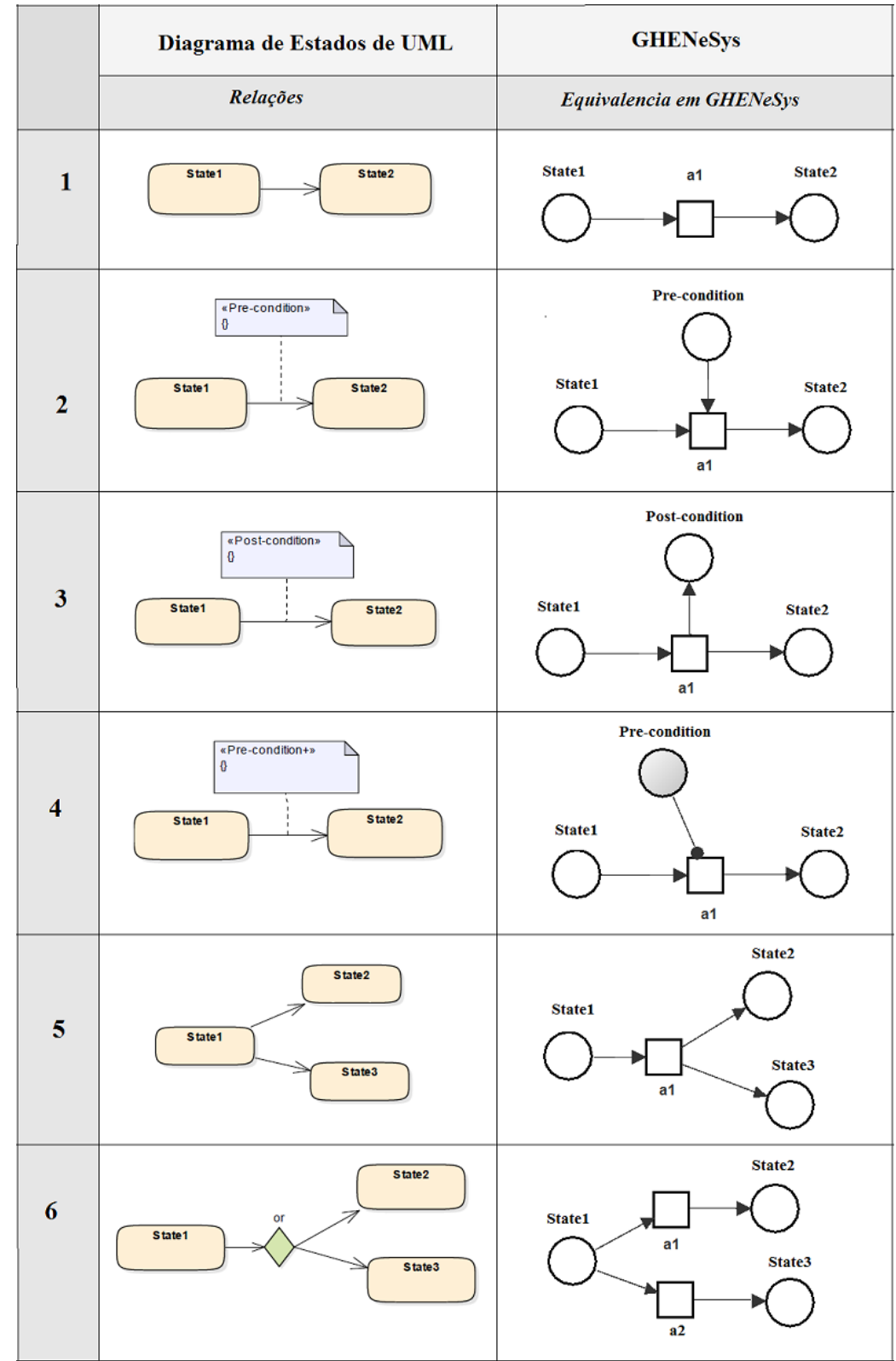

Fonte: Elaborada pela autora.

\subsubsection{Algoritmo de transformação UML- GHENeSys}

Nesta seção apresentam- se os algoritmos propostos neste trabalho que permitem transformar os diagramas de estados de UML em uma rede GHENeSys.

Os diagramas de classes descritos nas figuras 17 e 18 mostram a estrutura de classes que representam os diagramas de máquina de estado da UML, e a rede GHENeSys respectivamente. Esta estrutura de classe é usadas pelos algoritmos propostos. 
Figura 17 - Estrutura de clases que representam os diagramas de estados da UML

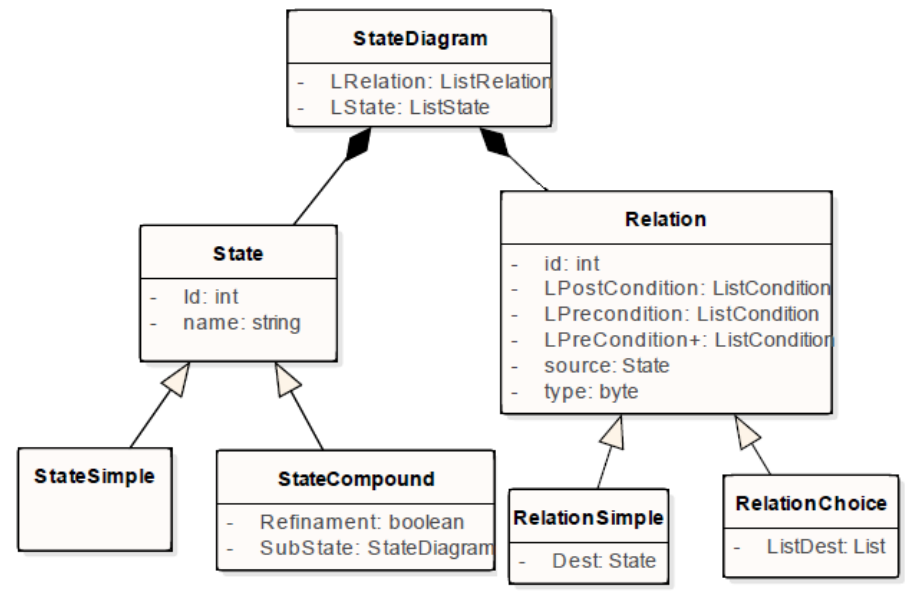

Fonte: Elaborada pela autora.

Figura 18 - Estrutura de clases que representam a rede GHENeSys

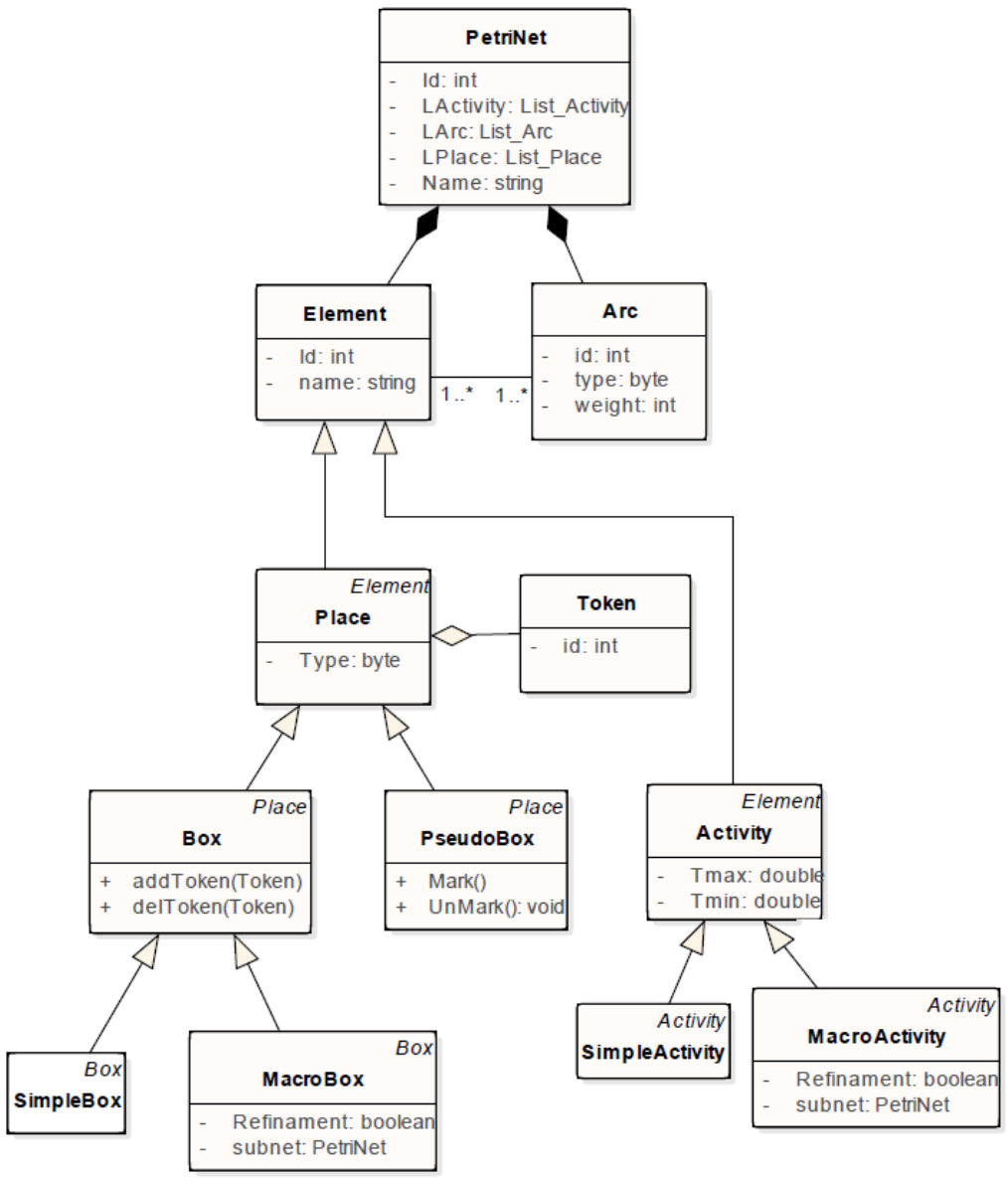

Fonte: Elaborada pela autora.

A seguir se mostram os algoritmos de tranformação do diagrama de estados da UML a uma rede GHENeSys: 


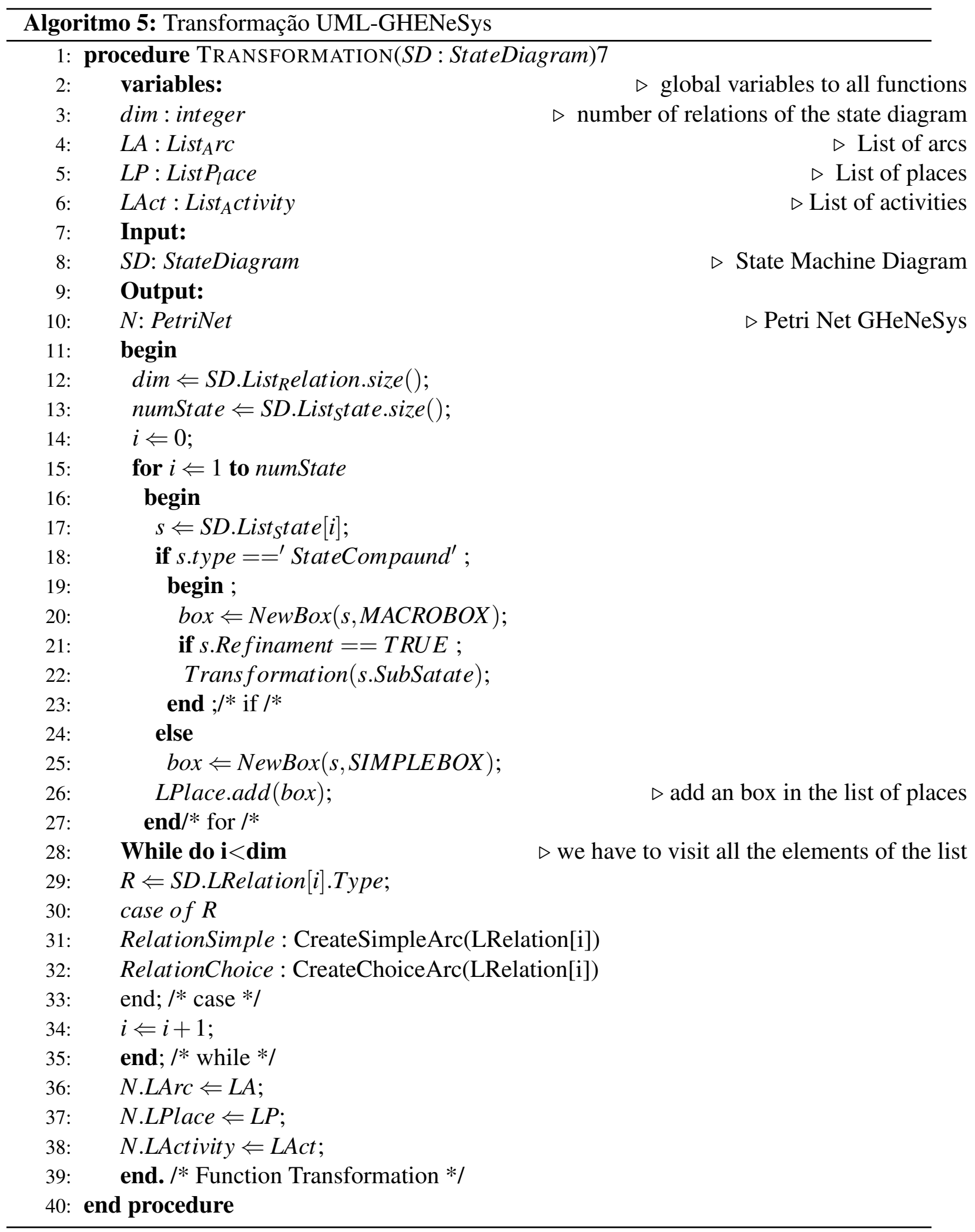




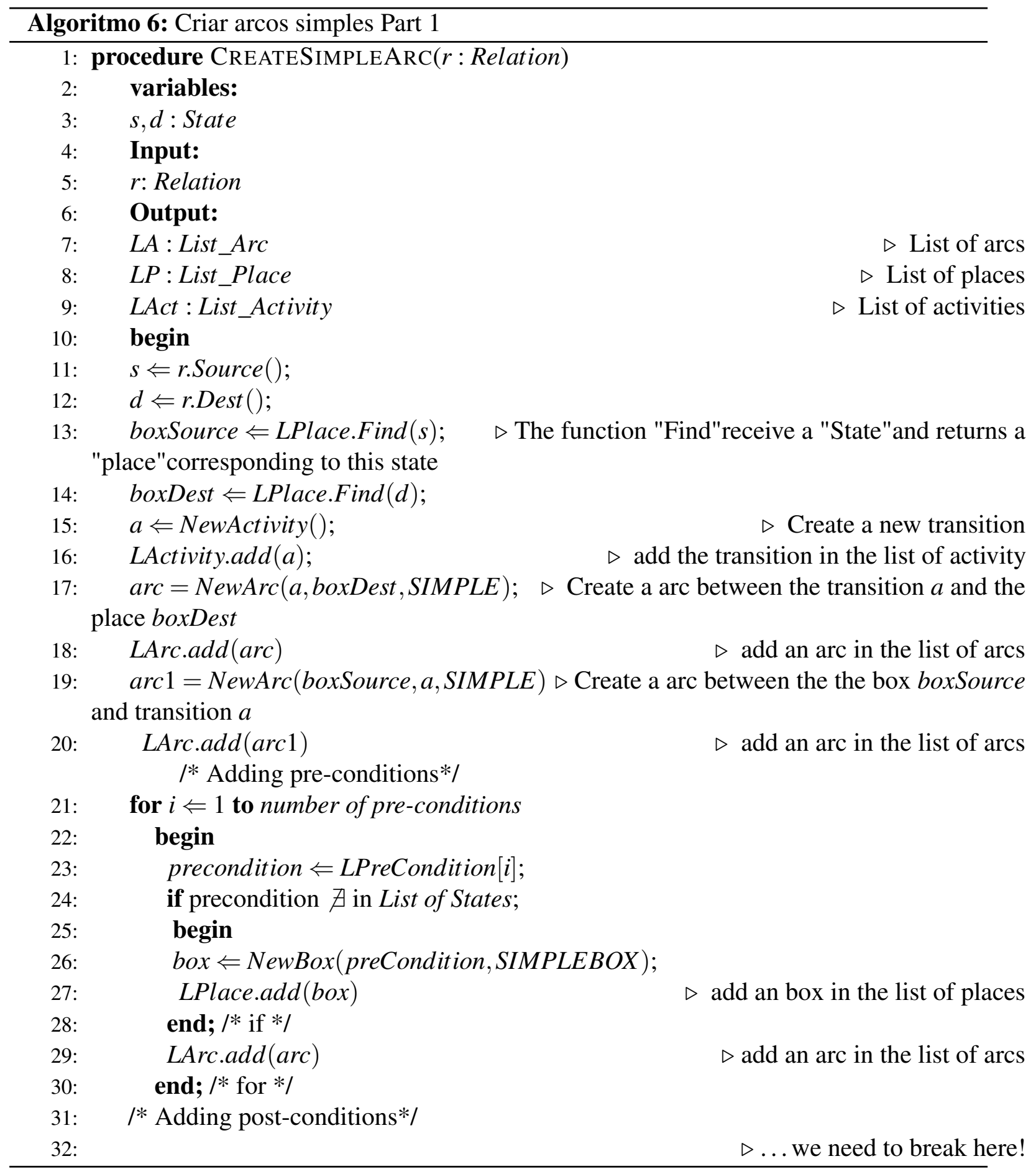




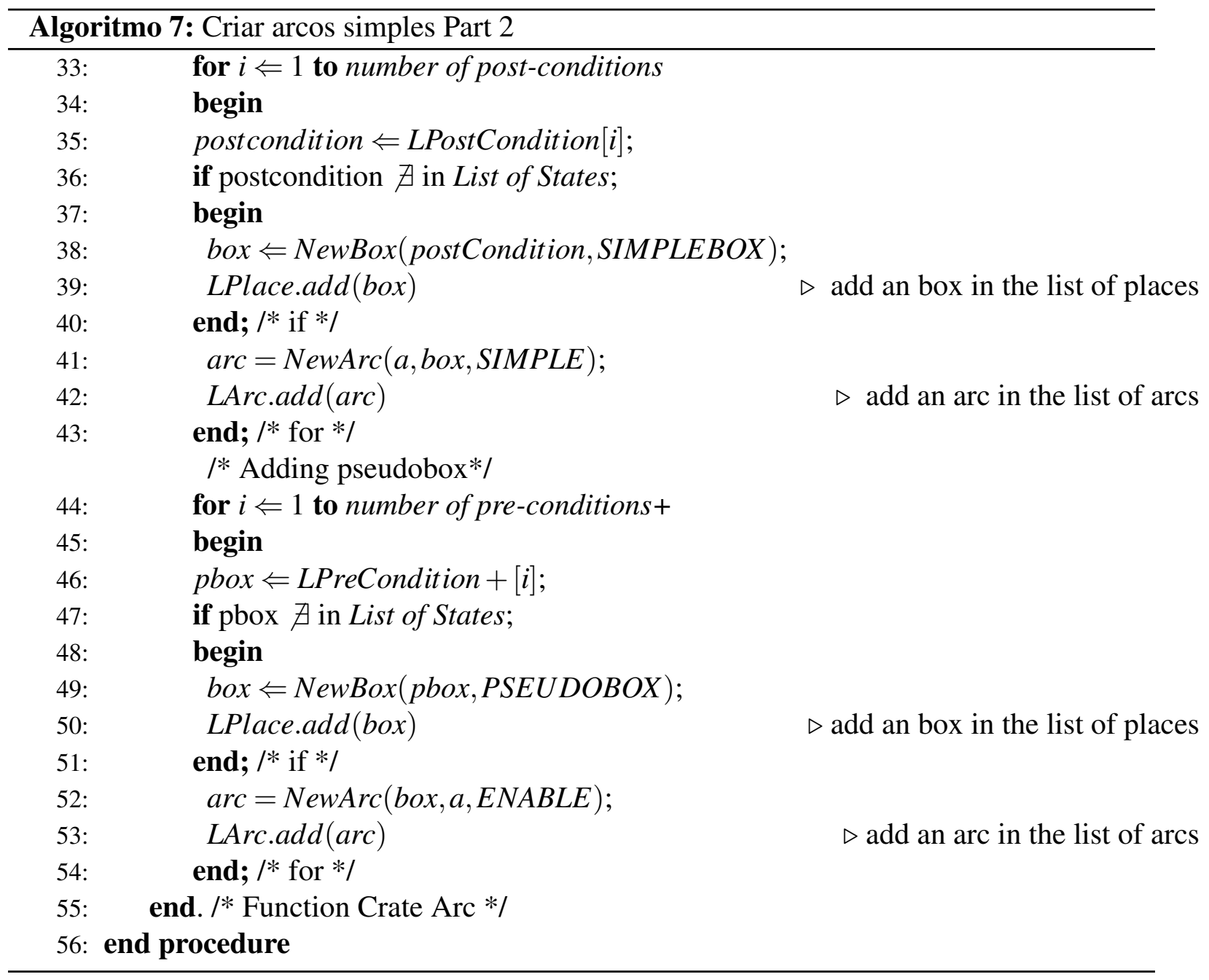




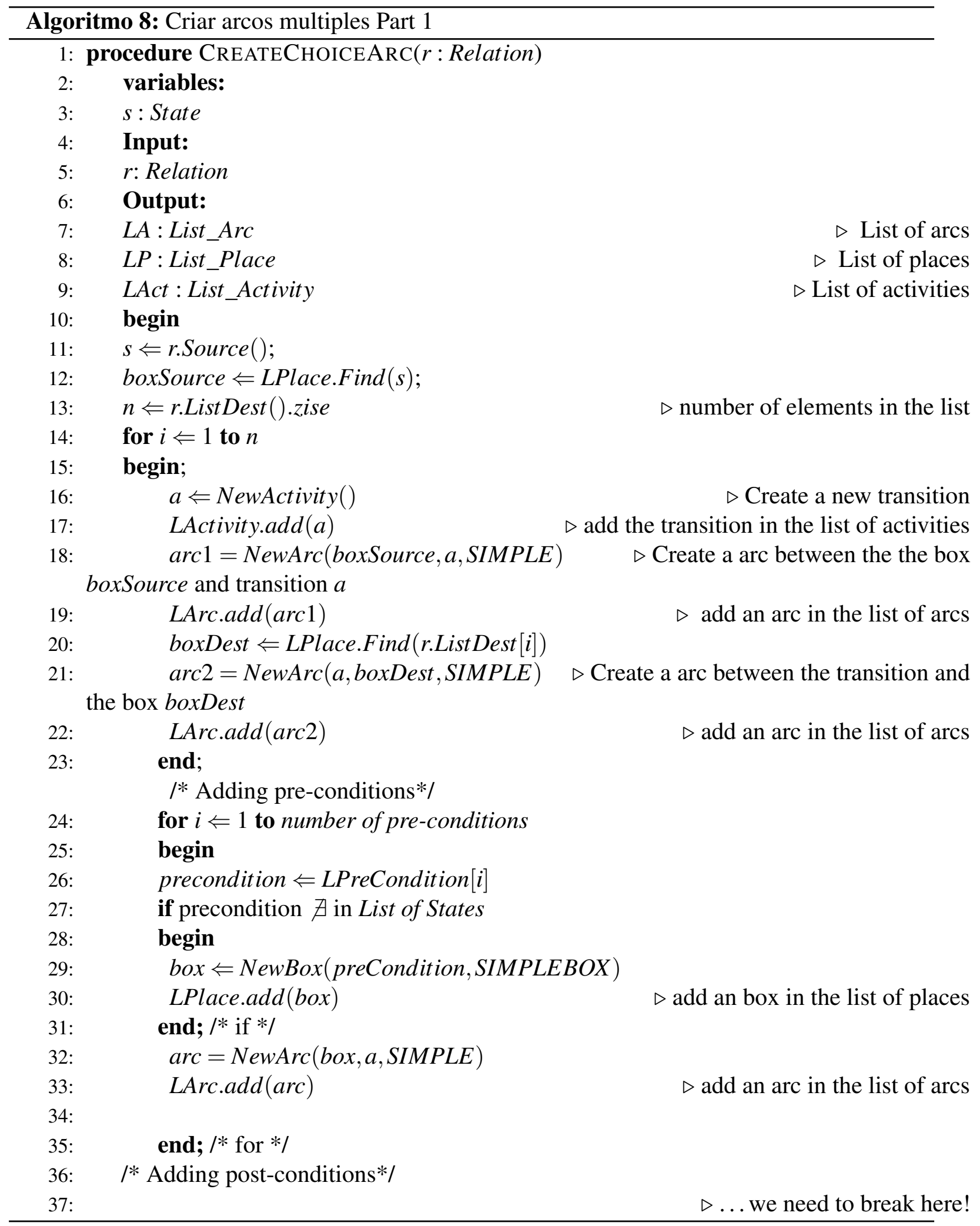




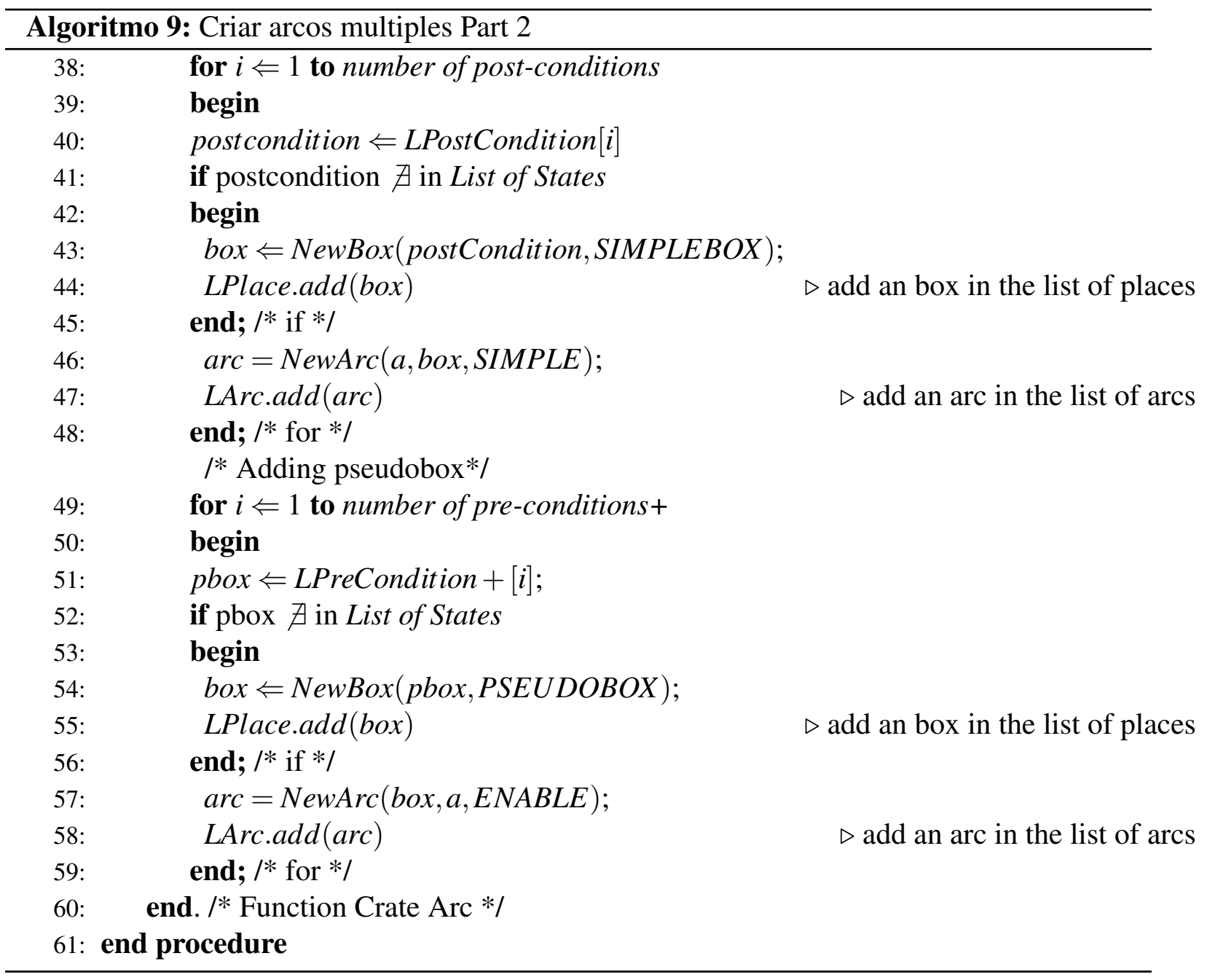

\subsubsection{Transformação de restrições em equações}

As restrições de um sistema podem estar diretamente ligadas ao conceito de invariantes. No entanto, nem todas as restrições podem ser escritas inicialmente desta forma, portanto os outros tipos de restrições devem ser transformadas para que possam ser representadas como equações. Nesta seção serão mostrados diferentes tipos de restrições e as transformações adequadas para descrever cada uma delas. Estas transformações estão baseadas no método proposto em (YAMALIDOU et al., 1996). Existem três categorias para as restrições: restrições lógicas escritas em fórmulas conjuntivas, restrições escritas em equações e na forma de inequações.

\subsubsection{Restrições lógicas}

Uma restrição pode ser escrita como uma equação lógica na forma normal conjuntiva:

$$
A \rightarrow \Phi_{1} \wedge \Phi_{2} \wedge \ldots \wedge \Phi_{g}
$$


onde $A$ é uma variável proposicional e cada $\Phi_{i}$ é uma disjunção da forma:

$$
\Phi_{i} \equiv \Psi_{i 1} \vee \Psi_{i 2} \vee \ldots \Psi_{i h}
$$

e onde cada $\Psi_{i}$ é também uma variável proposicional (E.; KANTOR, 1991). A fórmula (3.6) pode ser transformada em um conjunto de inequações lineares simultâneas e equivalentes:

$$
\left(1-\Psi_{i 1}\right)+\left(1-\Psi_{i 2}\right)+\ldots+1-\Psi_{i h}+A \leq h_{i}
$$

sendo $i=1,2, \ldots, g$.

O conjunto de inequações (3.7) irá representar as restrições que o sistema terá que satisfazer. As inequações obtidas da transformação da fórmula (3.5) podem ser descritas como se mostra a seguir.

\subsubsection{Restrições como inequações (menor que, ou igual a)}

\section{Restrições que envolvem o vetor de marcação}

As restrições que devem ser satisfeitas pelo sistema podem ser escritas como uma soma dos elementos do vetor de marcação:

$$
\sum_{i=1}^{r} p_{i} \leq k
$$

Isto significa que a soma dos tokens nos lugares $p_{1}, \ldots, p_{r}$ da rede de Petri nunca pode exceder o numero $k$.

Restrições envolvendo os elementos do vetor de disparo Estas restrições se referem a ocorrência simultânea de dois ou mais eventos. Elas podem ser descritas como:

$$
\sum_{j=1}^{r} q_{j} \leq r-1
$$

A equação (3.9) indica que nem todas as transições $q_{1}, q_{2}, \ldots, q_{r}$ podem ser disparadas simultaneamente.

\section{Restrições que envolvem lugares e transições}

$$
M\left(p_{i}\right)+t_{j} \leq 1
$$


onde $M\left(p_{i}\right)$ é a marcação do lugar $p_{i}$ e $t_{j}$ é uma transição.

A equação 3.10 significa que $t_{j}$ não pode disparar se $p_{i}$ está marcado. Substituindo $t_{j}$ por:

$$
t_{j}=\sum_{j=1}^{c} p_{j} \leq c
$$

Substituindo 3.11 em 3.10:

$$
M\left(p_{i}\right)+\sum_{j=1}^{c} p_{j} \leq c
$$

Caso Geral:

$$
\sum_{i=1}^{k} M\left(p_{i}\right)+\sum_{j=1}^{c} p_{j} \leq k+c-1
$$





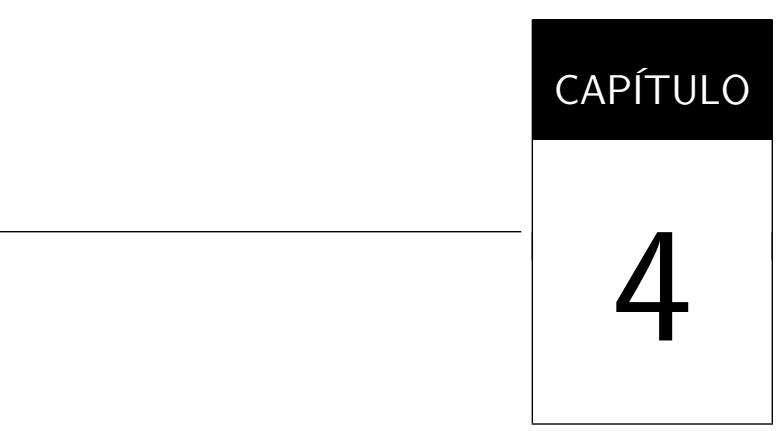

ESTUDOS DE CASOS

Para mostrar os resultados da disciplina de projeto proposta neste trabalho, foram selecionados tres estudos de casos: O problema proposto pelo ROADEF $2005^{1}$, um sistema de evaporação tomado de (MACHADO et al., 2007), e por último um sistema real de planejamento de transporte de carga por navios para um conjunto de plataformas no mar (ambiente do pre-sal).

\subsection{Problema proposto pelo ROADEF 2005}

O problema proposto pelo ROADEF 2005 (SOLNON et al., 2008) consiste no trabalho diário de uma fábrica que tem duas funções principais: atribuir um dia de produção a cada veículo encomendado, de acordo com a capacidade da linha de produção; e programar a ordem em que os carros devem ser colocados na linha de produção, enquanto satisfaz o maior número de requisitos dos processos de carroceria, pintura e montagem.

Não é objetivo neste trabalho, modelar o planejamento da fabricação dos carros, e sim mostrar a modelagem do processo de fabricação. Para simplificar a modelagem será considerada que a linha de produção tem capacidade para três carros. Na modelagem deste sistema um dos requisitos fundamentais é garantir que a linha de montagem não possa ter mais de um carro em cada processo. No problema não se especificam restrições para a montagem da carroceria, portanto neste trabalho não serão dados detalhes da modelagem deste processo.

1 Société française de Recherche Opérationnelle et Aide à la Décision 


\subsubsection{Modelagem usando a linguagem UML}

Seguindo o esquema mostrado na figura 14 primeiramente representaremos os requisitos do sistema usando os diagramas de classes e estados da linguagem UML. As figuras 19 e 21 mostram o diagrama de classes e os diagramas de estados respectivamente, correspondentes à modelagem do problema do ROADEF 2005.

Figura 19 - Diagrama de classes

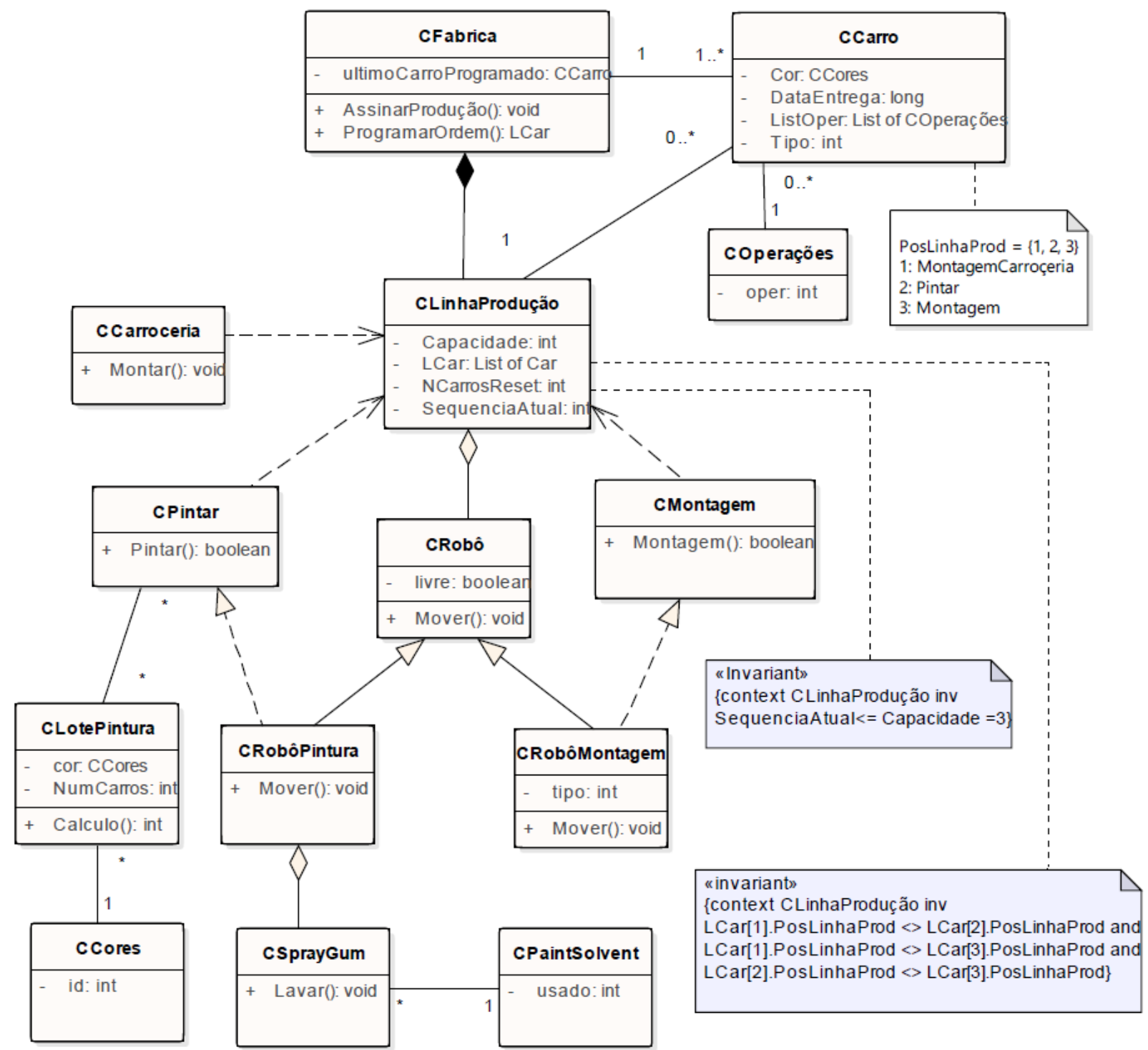

Fonte: Elaborada pela autora.

A figura 20 mostra o diagrama de objetos correspondente à classe CCarro 
Figura 20 - Diagrama de objetos correspondena à classe CCarro

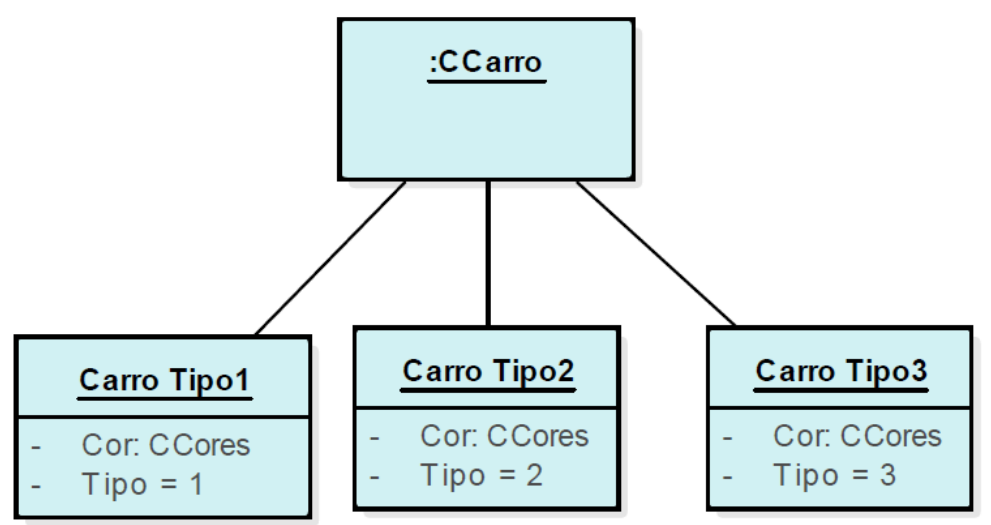

Fonte: Elaborada pela autora.

\subsubsection{Transformando os diagramas de estados em redes de Petri}

Para este trabalho, é considerado que a capacidade da linha de produção é três. Portanto, na modelagem será considerada que foram programados três carros para a produção. Estes carros são programados numa ordem específica, de acordo com as restrições da linha de produção.

Seguindo o algoritmo para transformar diagramas de estados em redes de Petri proposto no capítulo 3, para o digrama de estados mostrado na figura 21(b), um lugar é associado à montagem da carroceria, um à pintura e outro à montagem. Os tokens nestes lugares representariam a presença ou não de carros. Mas, como os carros têm características diferentes, não é adequado colocar vários tokens que representam diferentes carros em um mesmo lugar, porque não seria possível distinguir um carro de outro. Por isso, cada estado do diagrama de estados da figura 21(b) será representado por três estados como se mostra na figura 22.

Cada estado do diagrama de estados da figura 22, será representado por um lugar marcado por un token, o que indica a presença de cada carro nesses estados.

Na tabela 2 se mostra o mapeamento de cada estado do diagrama de estados correspondente à classe CLinhaprodução como o seu lugar correspondente na rede de Petri.

Tabela 2 - Transformando o diagrama de estados da linha de produção em rede de Petri

\begin{tabular}{|l|l|}
\hline \multicolumn{2}{|c|}{ Linha de Produção } \\
\hline Estado & Lugar \\
\hline Montagem Carroceria & $\mathrm{b} 1, \mathrm{~b} 2, \mathrm{~b} 3$ \\
\hline Pintura & $\mathrm{b} 4, \mathrm{~b} 5, \mathrm{~b} 6$ \\
\hline Montagem & $\mathrm{b} 7, \mathrm{~b} 8, \mathrm{~b} 9$ \\
\hline
\end{tabular}


Figura 21 - Diagramas de estados: (a) Diagrama de estados correspondente à classe CFabrica, (b) Diagrama de estados correspondente à classe CLinhaProdução, (c) Diagrama de estados correspondente à classe CPintura

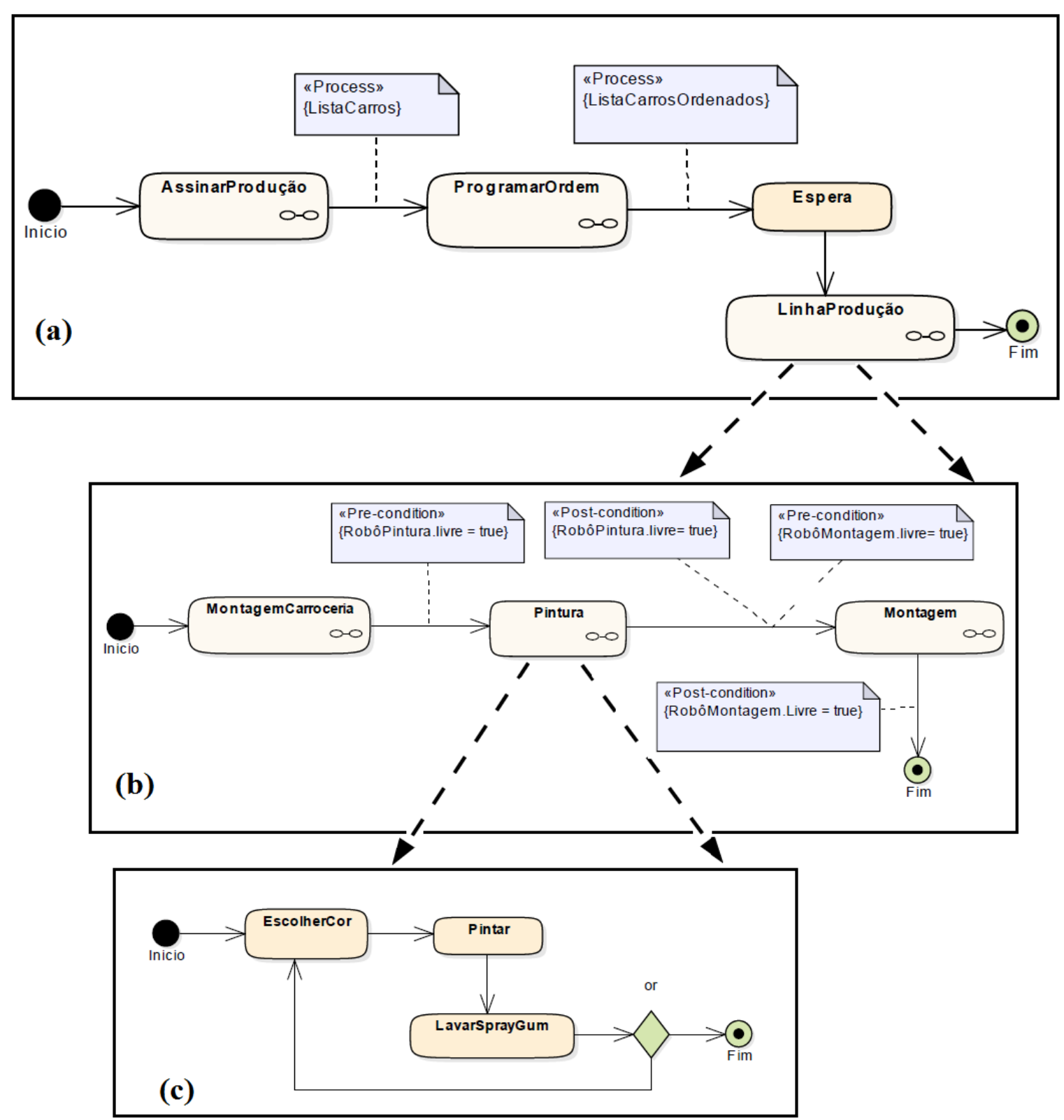

Fonte: Elaborada pela autora.

A figura 23 mostra a modelagem em GHENeSys (FOYO, 2001) da RdP correspondente ao diagrama de estados da figura 21(b) da linha de produção da fábrica.

\subsubsection{Representação das restrições em forma de regras}

Um dos requisitos do sistema é garantir que um carro esteja em apenas um processo da linha de produção. Isto significa que a soma dos tokens dos lugares que representam cada processo não pode ser maior que um. 
Figura 22 - Diagrama de estados correspondente à classe CLinhaProdução, considerando os diferentes objetos da classe

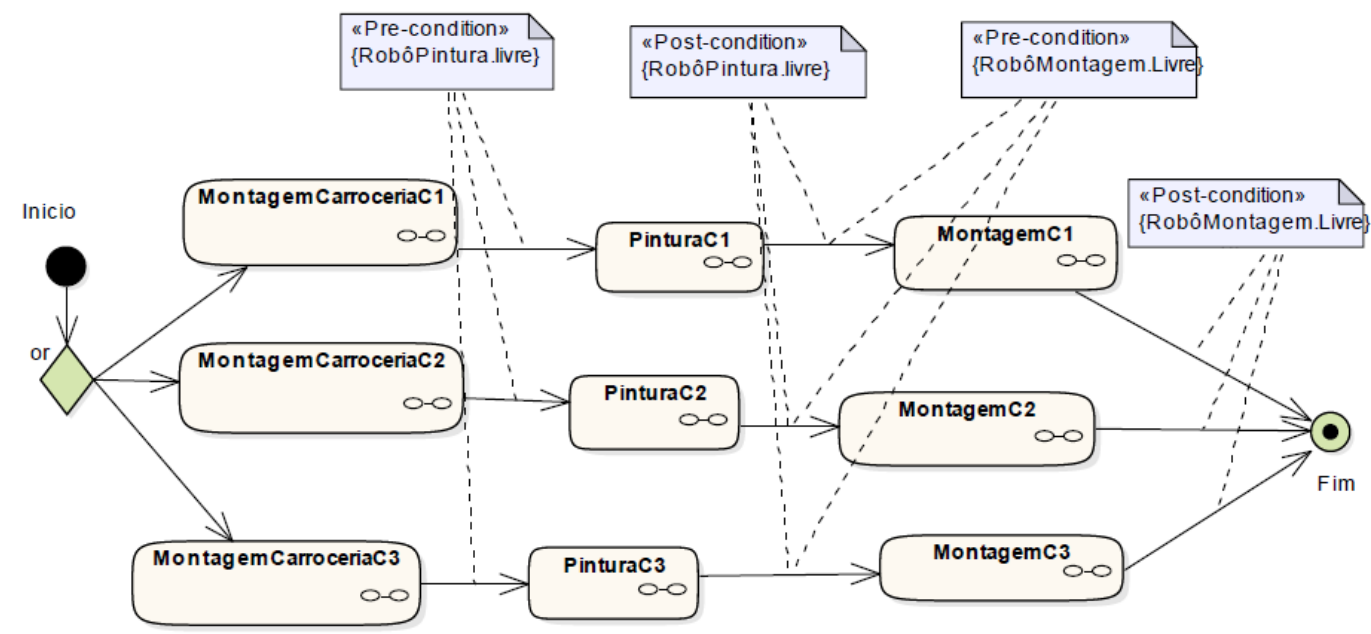

Fonte:

Figura 23 - Modelagem em GHENeSys da Linha de Produção

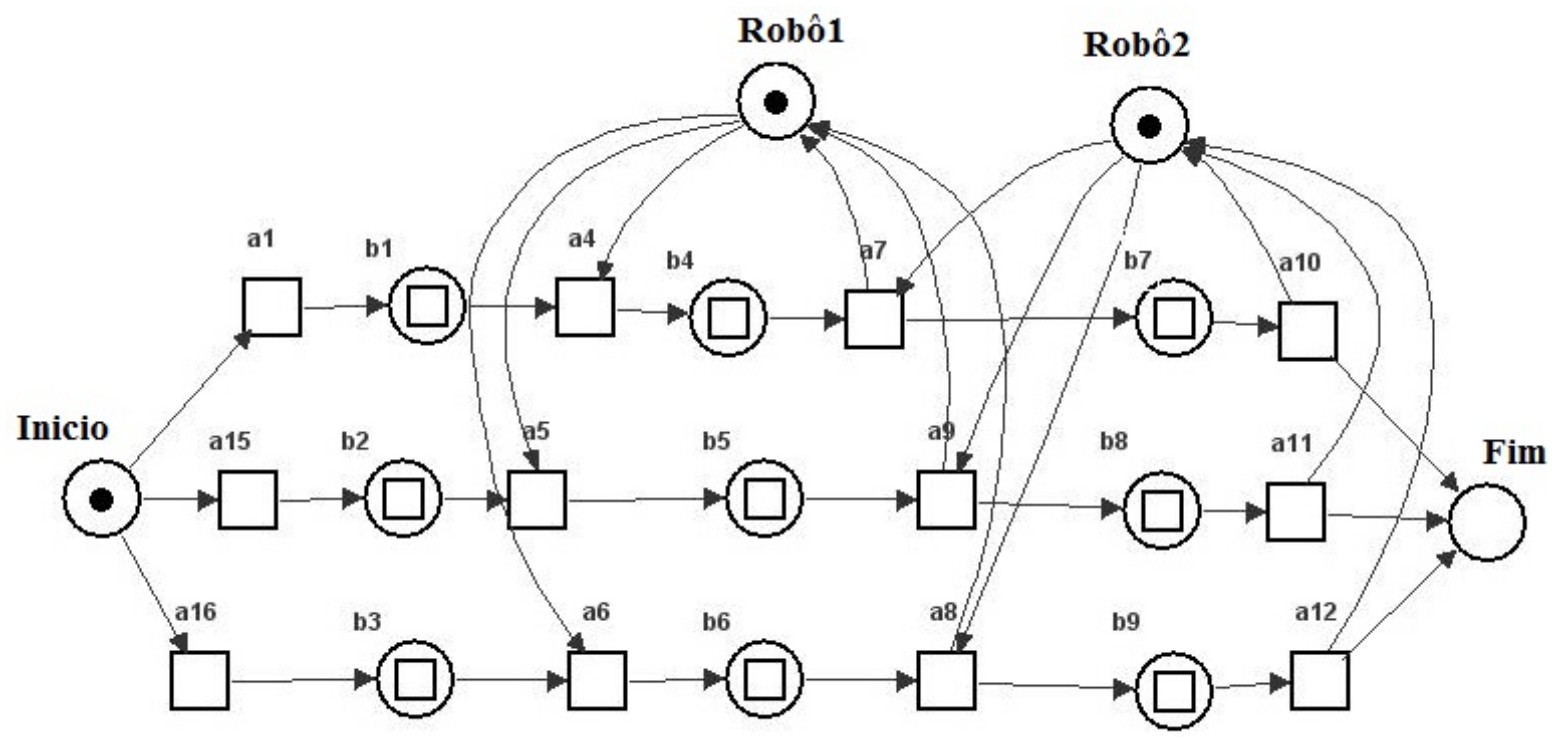

Fonte: Elaborada pela autora.

Partindo da informação representada nos diagramas e das notações em OCL, será gerada uma regra geral para representar estes requisitos de um modo mais formal. A seguir descreve-se a regra:

- Se LCar[i].PosLinhaProd $=j$, onde, $1 \leq i \leq 3$ e, $1 \leq j \leq 3$ então $L$ Car $[i+k]$.PosLinhaProd $=j+k$, onde $1 \leq k \leq 3-j$ 


\subsubsection{Definição das equações (invariantes)}

Como já foi mostrado na seção anterior, a soma dos tokens dos lugares que representam os processos da linha de produção, não pode ser maior que um. Estes requisitos podem ser convertidos em restrições, as quais representam os invariantes de lugar da rede. A seguir serão apresentadas estas inequações:

$$
\begin{aligned}
& b_{1}+b_{2}+b_{3} \leq 1 \\
& b_{4}+b_{5}+b_{6} \leq 1 \\
& b_{7}+b_{8}+b_{9} \leq 1
\end{aligned}
$$

Transformando estas inequações, são obtidas novas equações com novas variáveis:

$$
\begin{aligned}
& b_{1}+b_{2}+b_{3}+\text { slack } 1=1 \\
& b_{4}+b_{5}+b_{6}+\text { slack } 2=1 \\
& b_{7}+b_{8}+b_{9}+\text { slack } 3=1
\end{aligned}
$$

As variáveis slack1, slack2, slack3 representam os novos lugares que serão adicionados à rede de Petri da figura 23. Estes novos lugares são inseridos na rede seguindo a regra:

slackj $\bullet=\bigcup \bullet b_{i}$,

•slack $j=\bigcup b_{i} \bullet$, sendo que $1 \leq i \leq 3,1 \leq j \leq 3$, e $b_{i} \in$ Equação $j$

A figura 24 mostra a nova rede de Petri modelada em GHENeSys, com os novos lugares.

\subsubsection{Verificação dos requisitos usando os invariantes}

A figura 25 mostra os resultados do calculo dos invariantes de lugar obtidos pelo sistema GHENeSys. 
Figura 24 - Modelagem em GHENeSys da Linha de Produção com os novos lugares

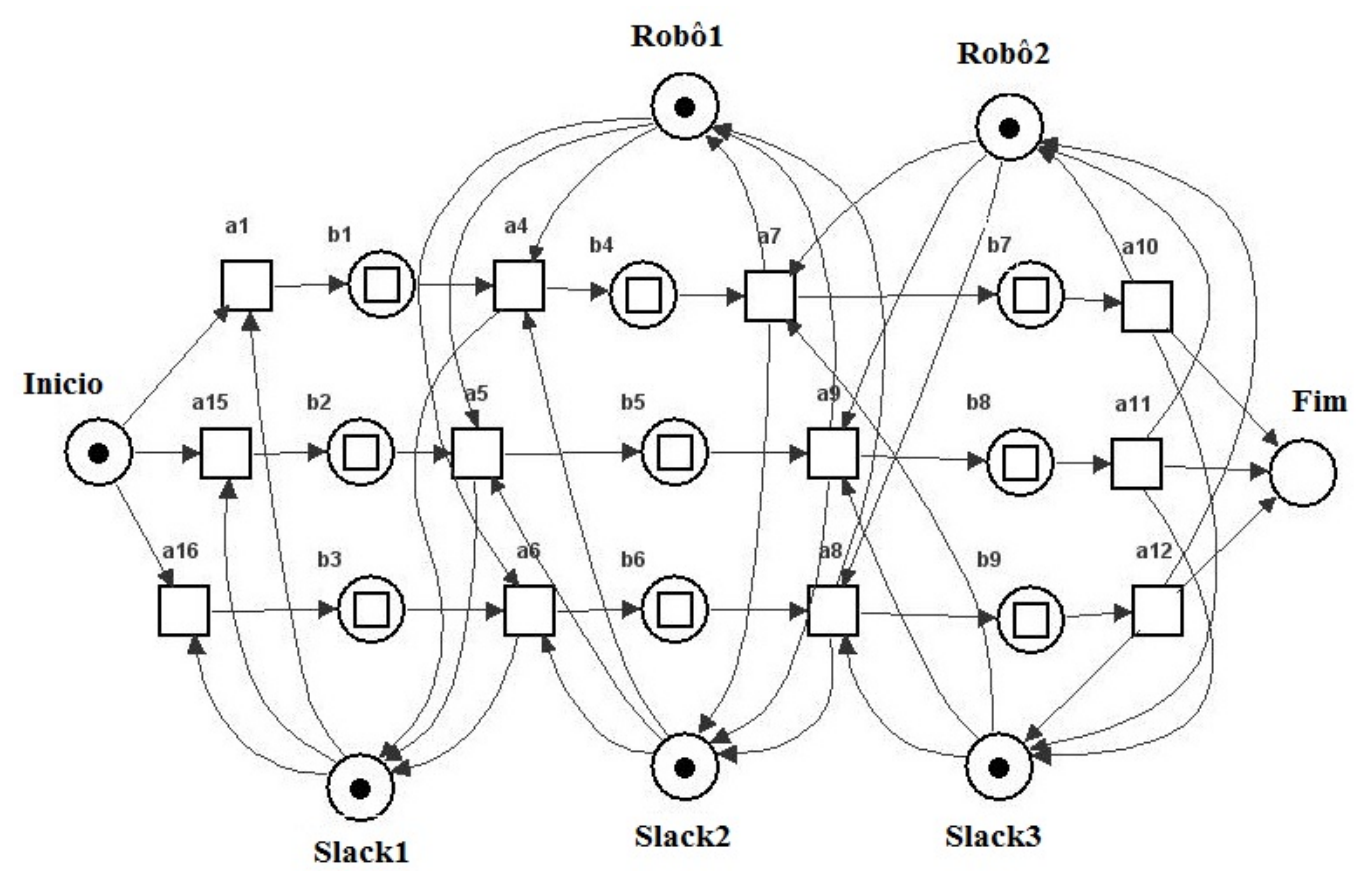

Fonte: Elaborada pela autora.

Figura 25 - Invariantes de lugar obtidos por GHENeSys

\begin{tabular}{|c|c|c|c|c|c|c|c|}
\hline \multicolumn{4}{|c|}{ Invariants } & \multicolumn{4}{|c|}{$=0 x$} \\
\hline Place & Tran: & sition & & & & & \\
\hline \multicolumn{8}{|l|}{ Results } \\
\hline Inicio & 1.0 & 0.0 & 0.0 & 0.0 & 0.0 & 0 & \\
\hline b1 & 1.0 & 1.0 & 0.0 & 0.0 & 0.0 & 0 & 0 \\
\hline b2 & 1.0 & 1.0 & 0.0 & 0.0 & 0.0 & 0 & 0 \\
\hline b3 & 1.0 & 1.0 & 0.0 & 0.0 & 0.0 & 0 & 0 \\
\hline b4 & 1.0 & 0.0 & 1.0 & 0.0 & 1.0 & 0 & 0 \\
\hline b6 & 1.0 & 0.0 & 1.0 & 0.0 & 1.0 & 0 & 0 \\
\hline b5 & 1.0 & 0.0 & 1.0 & 0.0 & 1.0 & & 0 \\
\hline b7 & 1.0 & 0.0 & 0.0 & 1.0 & 0.0 & 1 & 0 \\
\hline b8 & 1.0 & 0.0 & 0.0 & 1.0 & 0.0 & 1 & 0 \\
\hline b9 & 1.0 & 0.0 & 0.0 & 1.0 & 0.0 & & 0 \\
\hline Fim & 1.0 & 0.0 & 0.0 & 0.0 & 0.0 & & 0 \\
\hline slack1 & 0.0 & 1.0 & 0.0 & 0.0 & 0.0 & 0 & 0 \\
\hline slack2 & 0.0 & 0.0 & 1.0 & 0.0 & 0.0 & & 0 \\
\hline slack3 & 0.0 & 0.0 & 0.0 & 1.0 & 0.0 & & .0 \\
\hline Robot1 & 0.0 & 0.0 & 0.0 & 0.0 & 1.0 & & .0 \\
\hline \multirow[t]{2}{*}{ Robot2 } & 0.0 & 0.0 & 0.0 & 0.0 & 0.0 & & .0 \\
\hline & & & ve & & & & \\
\hline
\end{tabular}

Fonte: Elaborada pela autora. 
A partir dos invariantes de lugar obtidos podem ser definidas as equações (4.7) a (4.11).

$$
\begin{aligned}
& M(b 1)+M(b 2)+M(b 3)+M(\text { slack } 1)=\text { constante } \\
& M(b 4)+M(b 5)+M(b 6)+M(\text { slack } 2)=\text { constante }
\end{aligned}
$$

$$
M(b 7)+M(b 8)+M(b 9)+M(\text { slack3 })=\text { constante }
$$

$$
M(b 4)+M(b 5)+M(b 6)+M(\text { Robo } 1)=\text { constante }
$$

$$
M(b 7)+M(b 8)+M(b 9)+M(\text { Robo2 })=\text { constante }
$$

As equações (4.7) a (4.9) coincidem com as equações 4.4, 4.5 e 4.6. Já com as duas últimas, 4.10 e 4.11, verifica-se que em um mesmo momento só um carro pode estar sendo pintado e só um pode estar sendo montado.

Seguindo o método de modelagem do GHENeSys, foi construída uma rede hierárquica para representar todo o sistema. Na figura 26 é mostrada a rede completa. Para distinguir a ordem dos carros, foi considerado que o primeiro carro (representado por um token) na lista de montagem vai para o lugar $b 1$, o segundo para o lugar $b 2$ e o terceiro para o lugar $b 3$. Nesta rede foi feito o uso dos elementos macro da rede GHENeSys para estabelecer a hierarquia do modelo. 
Figura 26 - Modelagem em GHENeSys do sistema completo

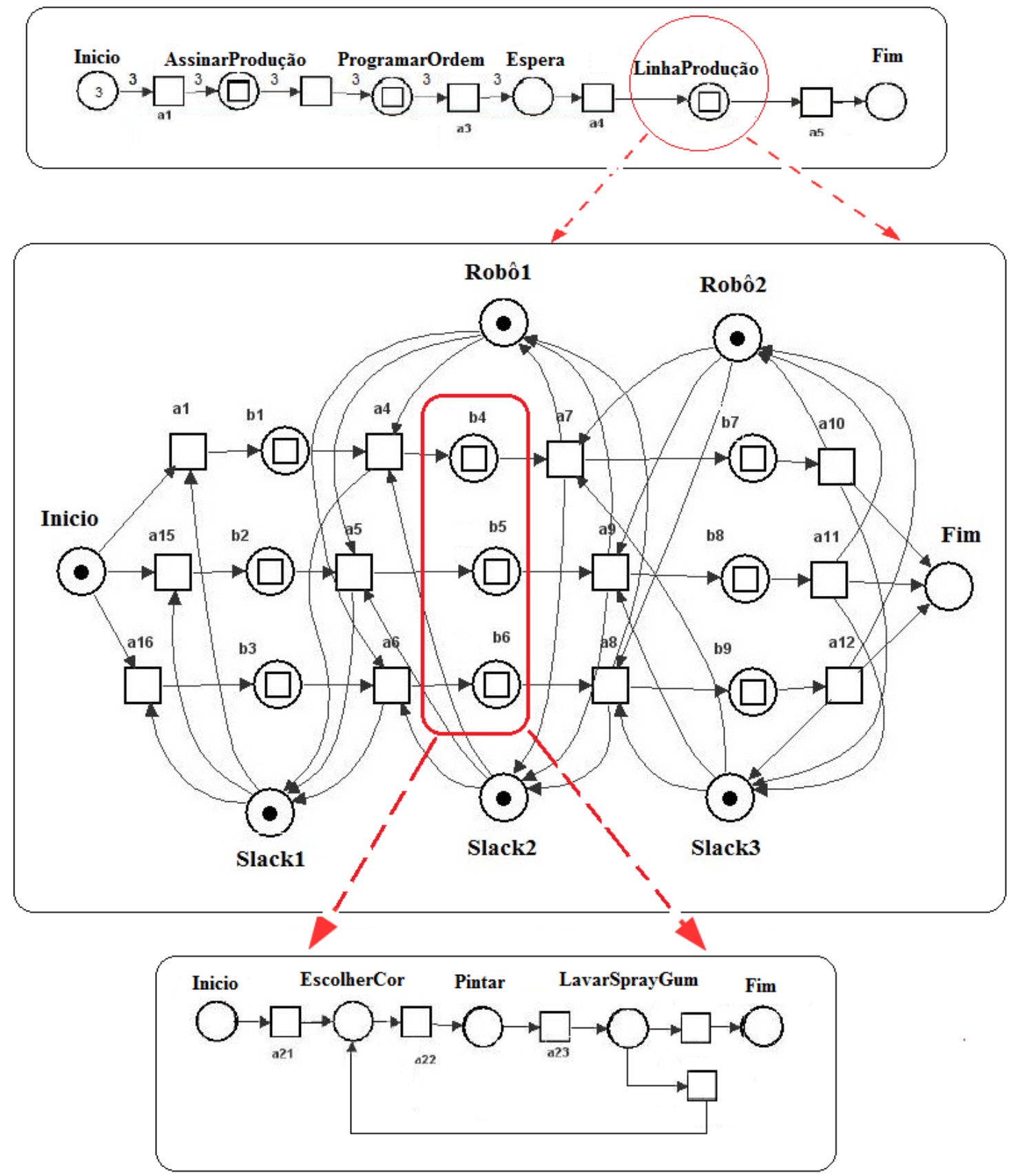

Fonte: Elaborada pela autora.

\subsection{Sistema de evaporação}

O sistema de evaporação (MACHADO et al., 2007) que se apresenta como estudo de caso é mostrado na figura 27. O sistemas está composto por: os tanques 1 e 2 , um condensador, censores de nível e válvulas on/off.

No modo de operação normal o sistema deve se comportar da seguinte forma: 
Figura 27 - Sistema de Evaporação

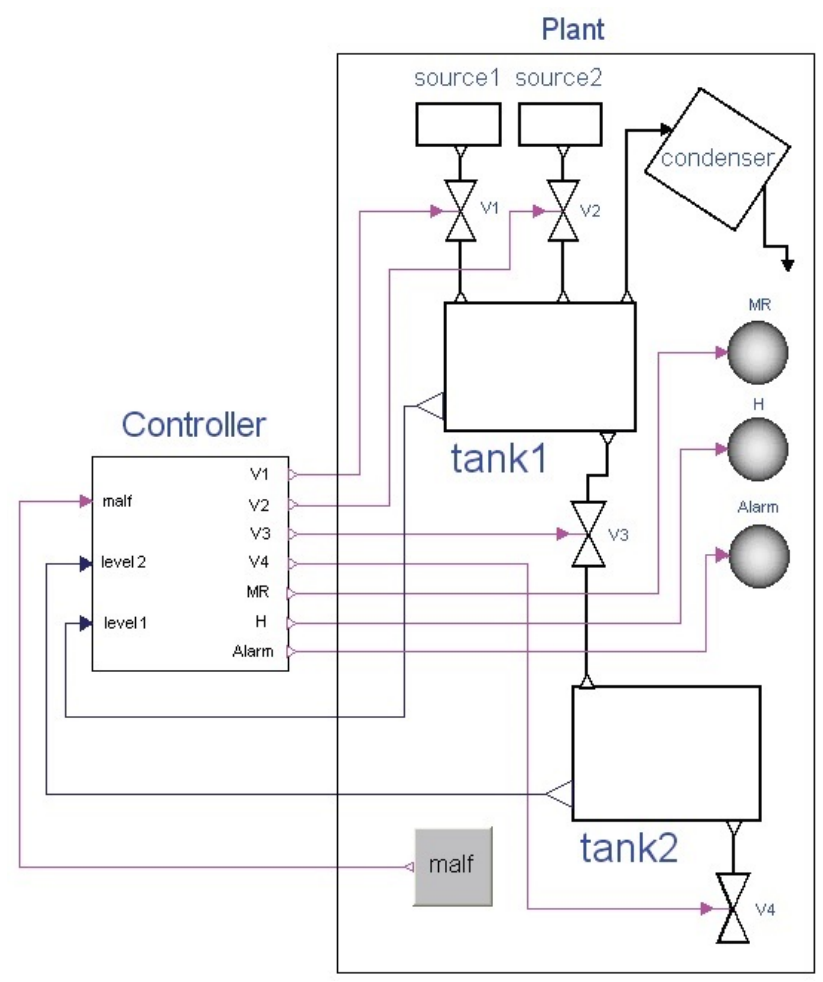

Fonte: (MACHADO et al., 2007)

- O tanque 1 começa a encher abrindo as válvulas V1 e V2.

- O misturador começa a funcionar para promover a mistura das duas soluções.

- Depois de 2 unidades de tempo, o aquecedor é ligado por um intervalo de 20 unidades de tempo para aumentar a temperatura da solução. Durante este período, parte do líquido é evaporado e resfriado no condensador. Neste ponto o aquecedor deve ser desligado.

- As válvulas V1 e V2 são fechadas uma vez que o tanque 1 está cheio.

- O líquido no tanque 1 é transferido para o tanque 2 através da abertura da válvula V3.

- O misturador é desligado uma vez que o tanque 1 é esvaziado e a válvula V3 é fechada.

- A solução deve permanecer no tanque 2 por 32 unidades de tempo quando deve ser descartada abrindo a válvula V4. 
Durante a operação normal do sistema, falhas podem acontecer. No processo de evaporação, o condensador pode falhar o que não permitiria que o vapor fosse resfriado causando aumento da pressão no condensador. Para evitar a explosão do condensador, o aquecedor deve ser desligado, restringindo a produção de vapor. Por causa disso, a temperatura do líquido no tanque 1 pode diminuir o que levaria a solidificação da solução impedindo a transferência para o tanque 2. Portanto, a solução no tanque 1 deve ser transferida antes de que solidifique. Isto é feito através da abertura das válvulas V3 e V4.

\subsubsection{Modelando o sistema em UML}

Seguindo a proposta de (DICESARE et al., 1994), a planta e o controle do sistema de evaporação, serão modelados de forma separada. As figuras 28, 29 e 30 mostram os diagramas de classes do sistema geral, da planta e do controle respectivamente.

Figura 28 - Diagrama de classes do Sistema

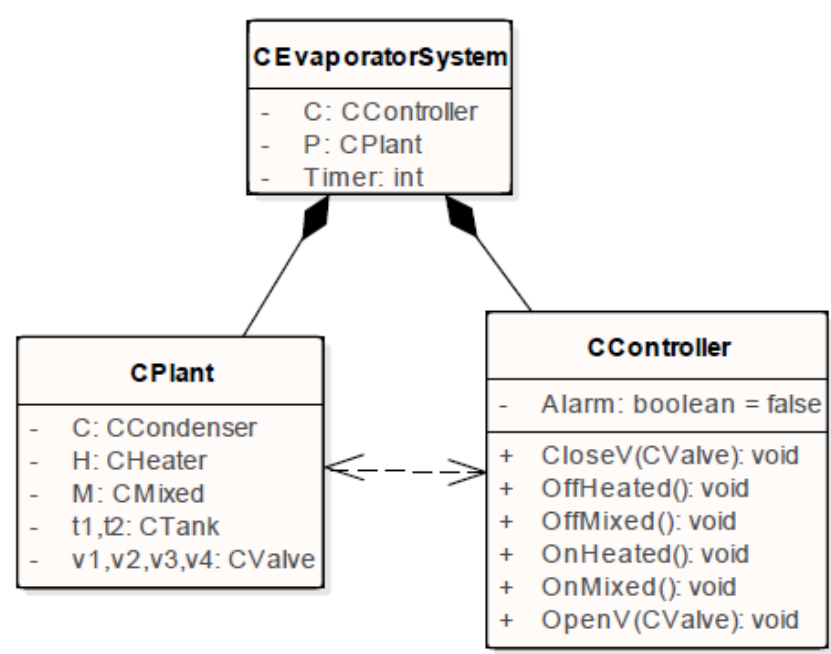

Fonte: Elaborada pela autora. 
Figura 29 - Diagrama de classes da planta

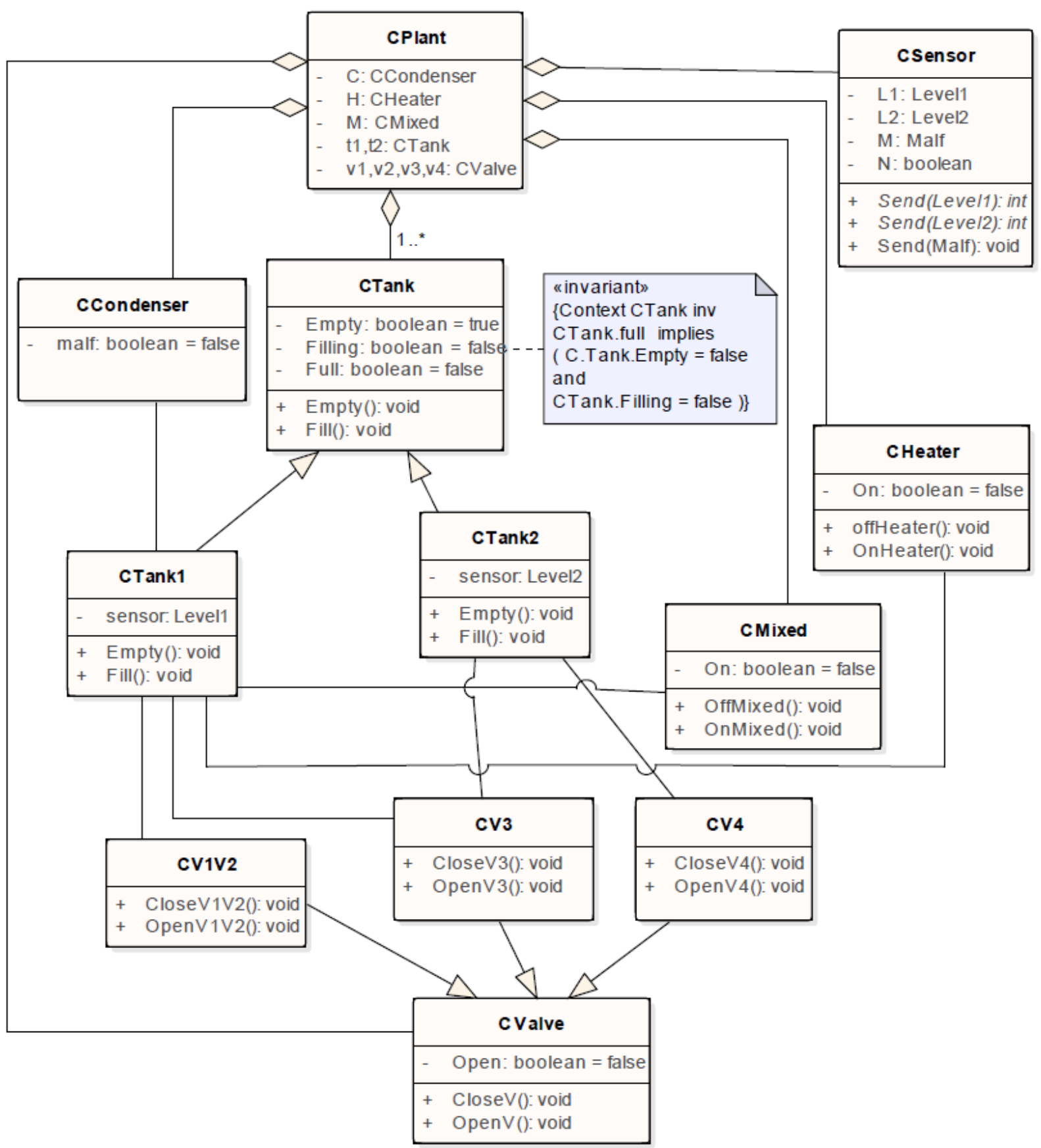

Fonte: Elaborada pela autora. 
Figura 30 - Diagrama de classes do controlador
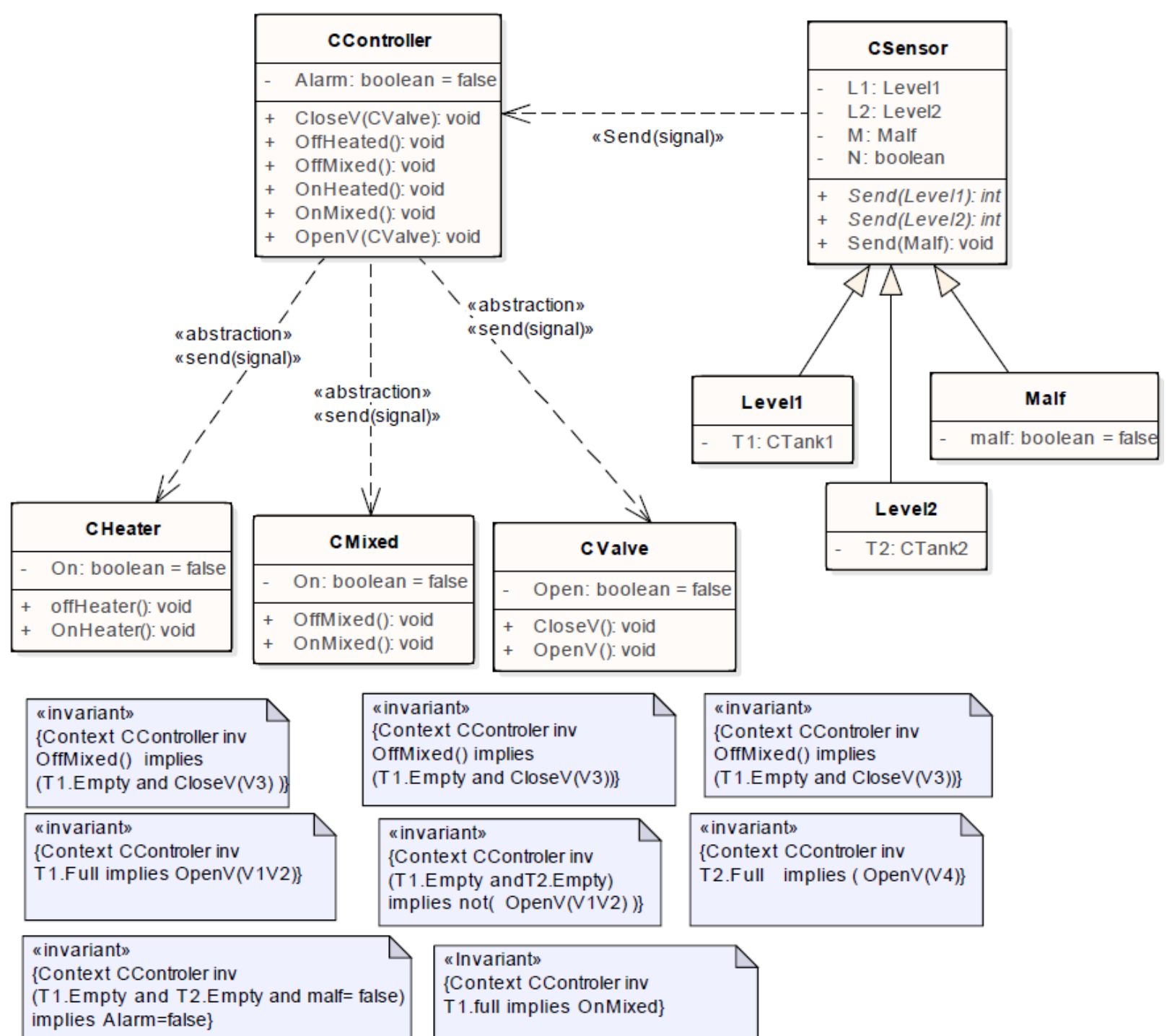

«Invariant»

\{Context CControler inv

T1.full implies OnMixed\}

Fonte: Elaborada pela autora. 
As figuras 31 e 32 mostram os diagramas de estados da planta e do controlador, correspondentes aos diagramas de classes da planta e do controlador do sistema, respectivamente.

Figura 31 - Diagrama de estados da Planta:(a)Tank1, (b)Tank2, (c)Condensador
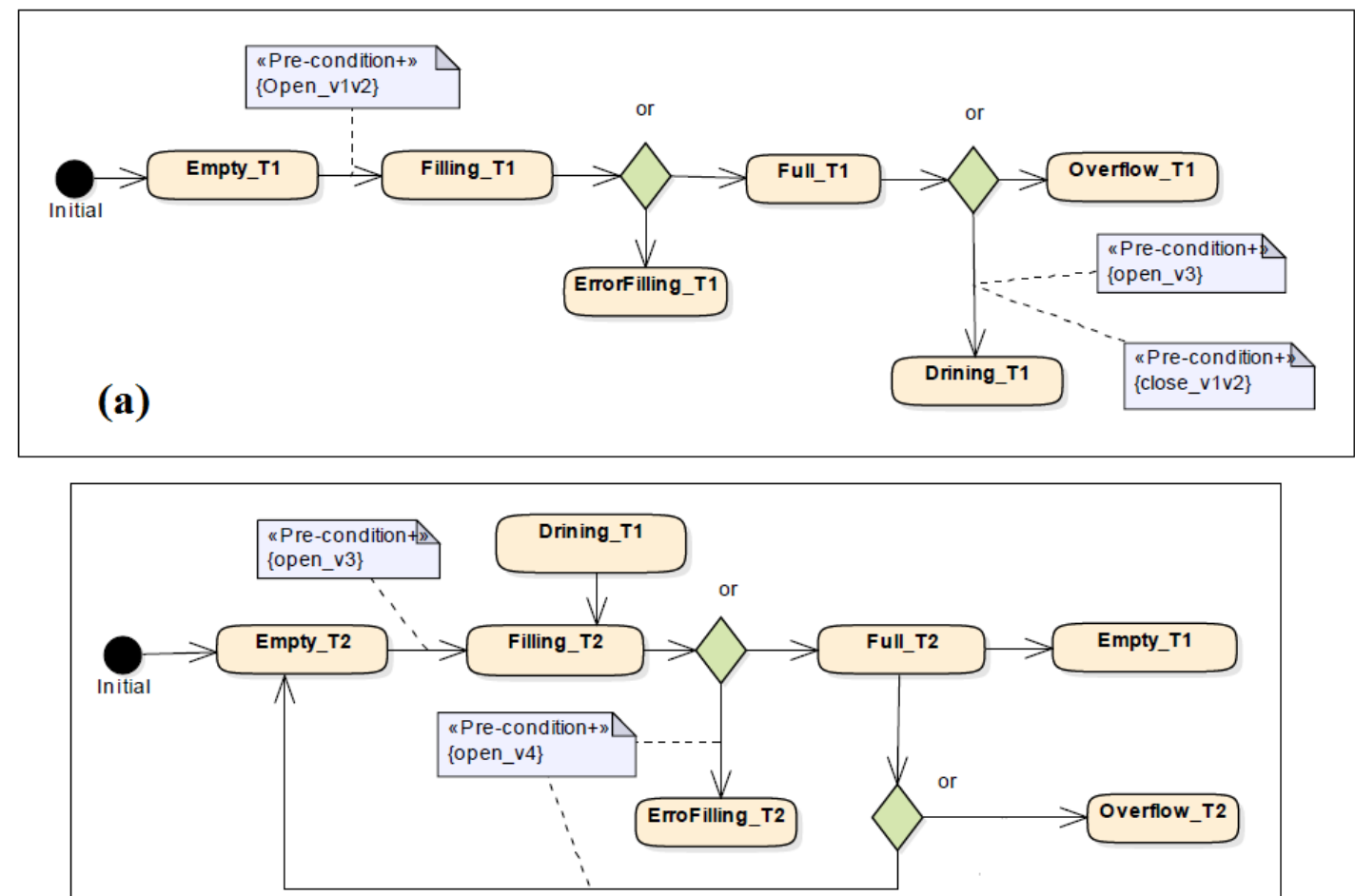

(b)

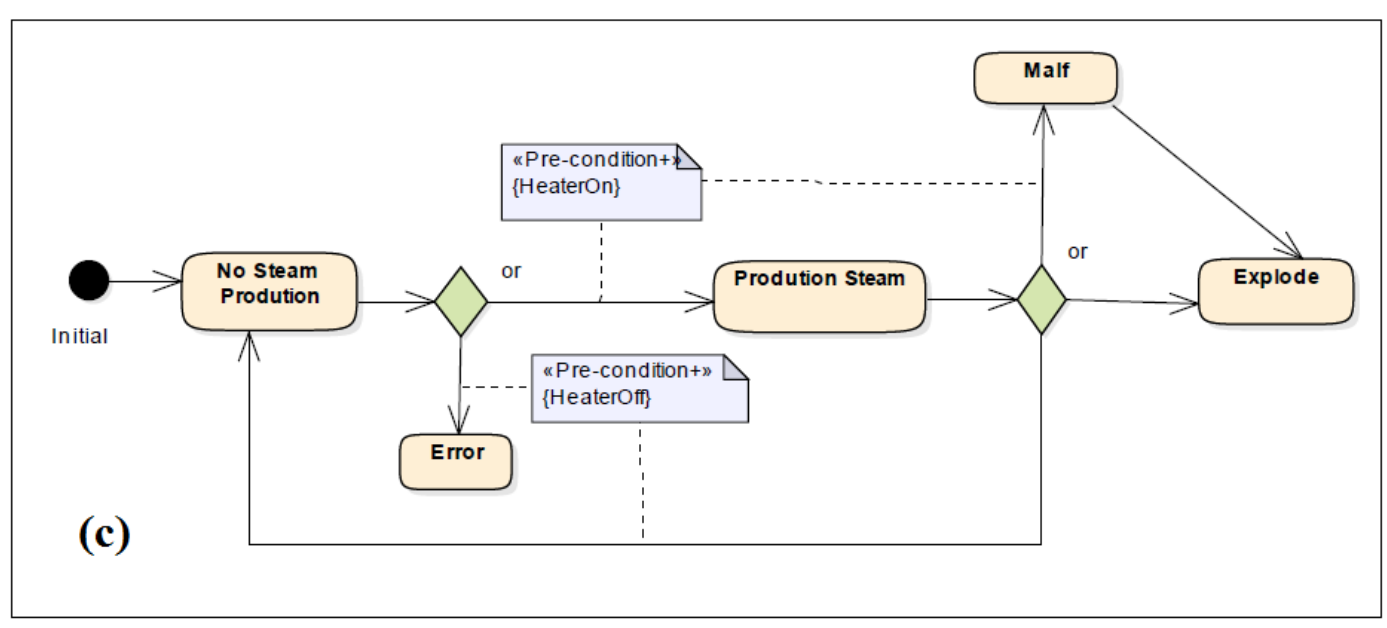

Fonte: Elaborada pela autora. 
Figura 32 - Diagrama de estados do Controlador

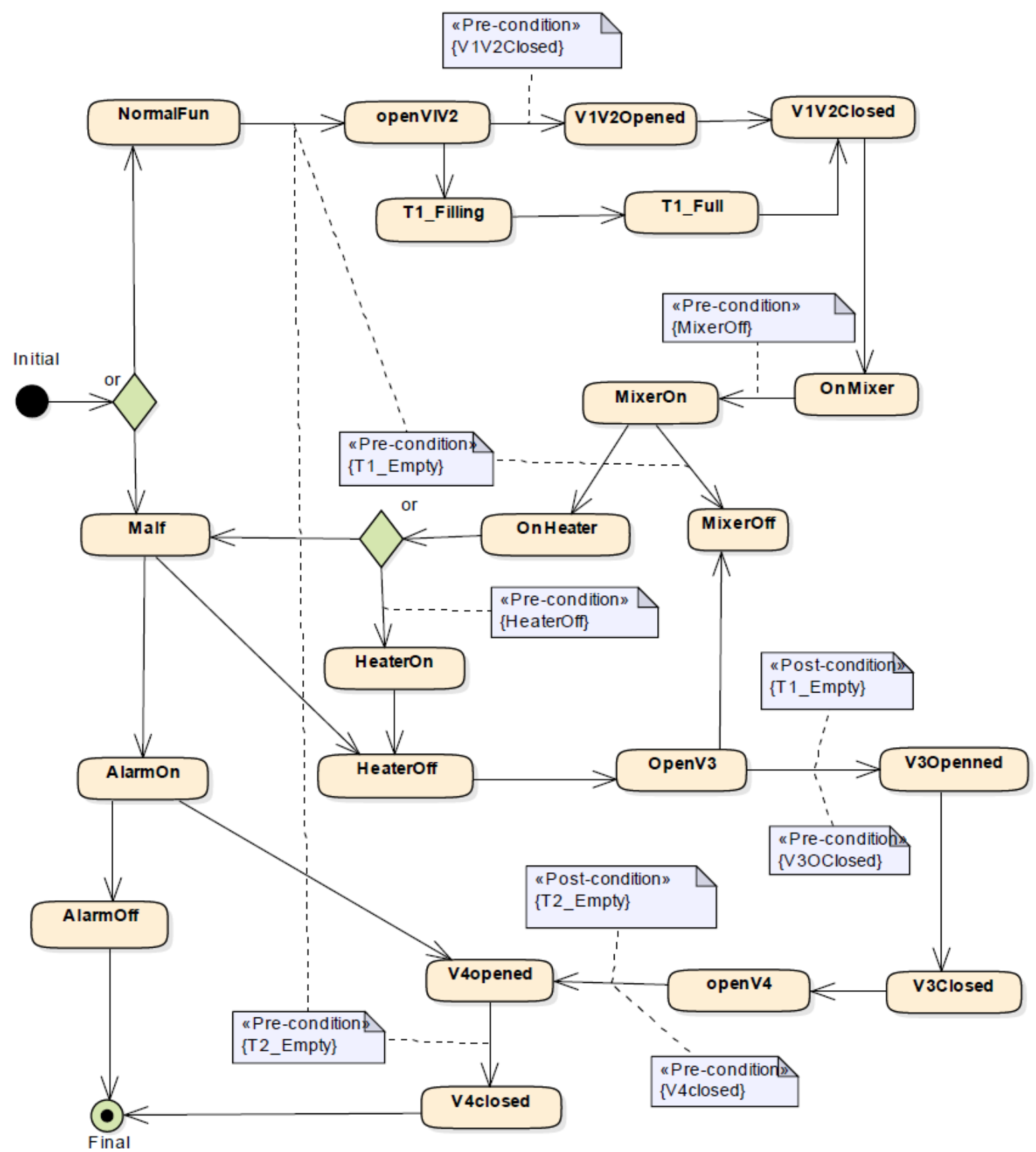

Fonte: Elaborada pela autora.

\subsubsection{Transformando os diagramas UML em rede de Petri}

Seguindo a abordagem apresentada no capítulo 3, foram transformados os diagramas de estados do sistema na rede GHENeSys apresentada em (FOYO, 2009). Neste trabalho foram desconsideradas as restrições de tempo especificadas na descrição do estudo de caso.

Os pseudo-boxes da rede GHENeSys, serão usados como elementos de conexão entre a 
planta e o controlador. A tabela 3 mostra a descrição dos pseudo-boxes.

Os pseudo-boxes openV1V2, openV3 e openV4 representam os estado das válvulas; e os pseudo-boxes Heateroff e Heateron representam o estado do heater no sistema de evaporação. Estes elementos constituem as saídas do controlador, e estão conectados, pela propriedade do psedo-boxe MasterElement, a lugares na rede que modela o comportamento do controlador.

A tabela 4 mostra o mapeamento de alguns dos estados dos diagramas de estados da planta e do controlador, com seus respectivos lugares na rede GHENeSys.

Tabela 3 - Sinais do controlador presentes no modelo da planta

\begin{tabular}{|ccl|}
\hline pseudo-box & MasterElement & Descrição \\
\hline openV1V2 & V1V2opened & válvula 1 e válvula 2 abertas \\
openV3 & V3opened & válvula 3 aberta \\
openV4 & V4opened & válvula4 aberta \\
Heateroff & Heateroff & heater desligado \\
Heateron & Heateron & heater ligado \\
\hline
\end{tabular}

Tabela 4 - Descrição dos lugares da rede de Petri, correspondentes aos estados dos diagramas de estados da UML.

\begin{tabular}{|c|c|}
\hline \multicolumn{2}{|c|}{ Sinais de entrada do controlador } \\
\hline Estados & Lugares \\
\hline Tank1 Full/Tank2 Full & T1F/T2F \\
\hline Tank1 Empty/Tank2 Empty & T1E/T2E \\
\hline \multicolumn{2}{|c|}{ Sinais de saída do controlador } \\
\hline OnHeater/OffHeater & HOn/ HOff \\
\hline OnMixer/OffMixer & MOn/MOff \\
\hline openV1V2 & V1V2opened \\
\hline closeV1V2 & V1V2closed \\
\hline openV3/V4 & V3/V4opened \\
\hline closeV3/V4 & V3/V4closed \\
\hline Malf & malf \\
\hline
\end{tabular}

As figuras 33 e 34 mostram a modelagem em redes de Petri da planta e do controlador do sistema respectivamente. 
Figura 33 - Modelagem em rede de Petri da planta

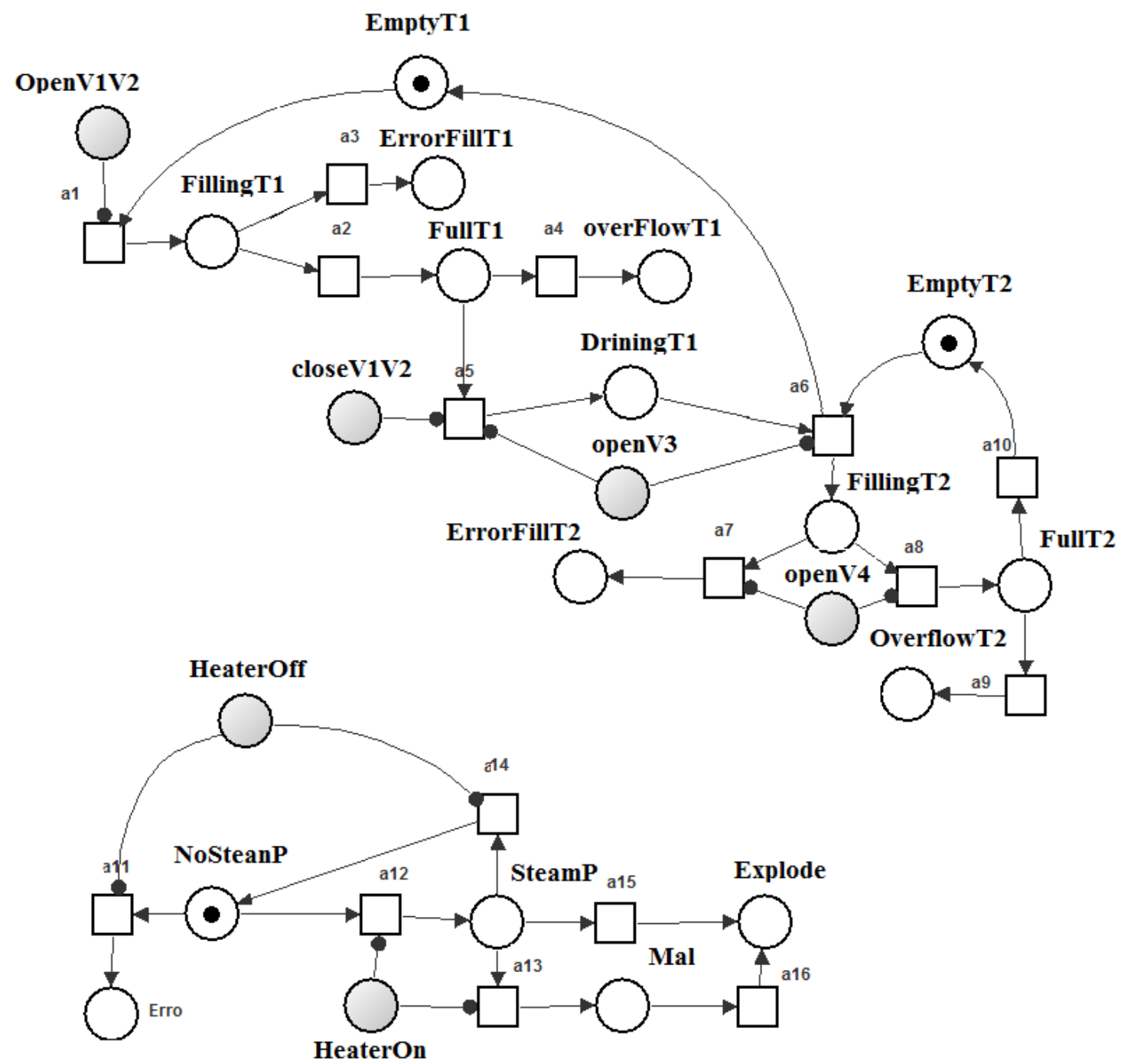

Fonte: Elaborada pela autora. 
Figura 34 - Modelagem em rede de Petri do controlador

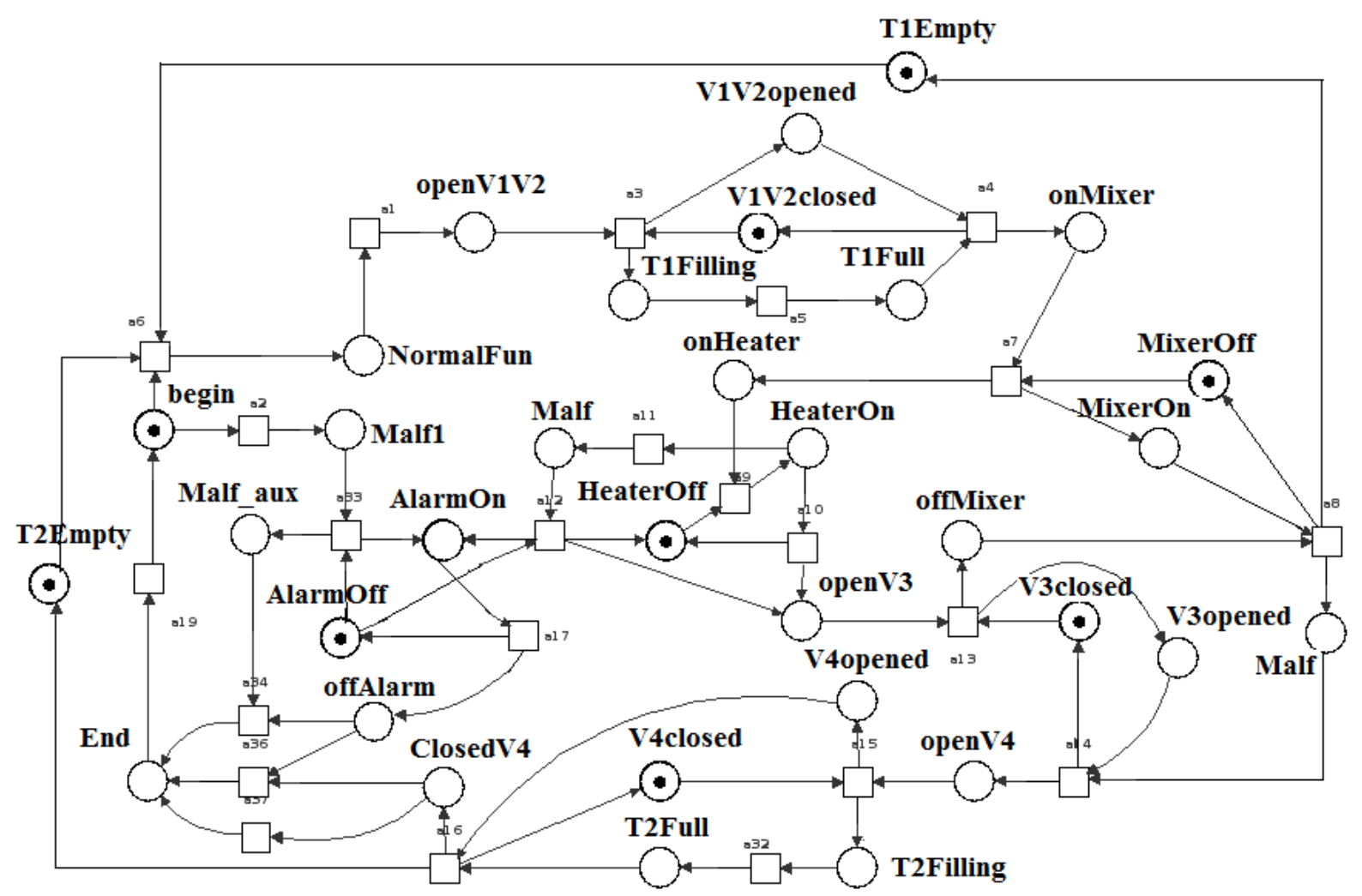

Fonte: Elaborada pela autora.

\subsubsection{Definindo os invariantes}

Os invariantes serão usados tanto na representação como na verificação de requisitos de sistemas. A seguir serão verificados alguns dos requisitos desejáveis no sistemas de evaporação mostrado na figura 27.

Partindo da informação apresentada nos diagramas de classes mostrados nas figuras 29 e 30, e das especificações descritas em OCL, serão definidos os requisitos do sistemas que serão verificados usando os invariantes das redes de Petri. Significa que as especificações feitas em OCL srão transformadas em um conjunto de inequações que representam invariantes de lugar na rede de Petri. 
As especificações do sistema que devem ser satisfeitas podem ser escritas como uma soma dos elementos do vetor de marcação, equação 3.8 .

A equação 3.8 significa que a suma dos tokens nos lugares $p_{1}, \ldots, p_{r}$ da rede de Petri nunca pode exceder o numero $k$. Este numero $k$ vai depender da marcação inicial da rede $\left(M_{0}\right)$, sendo que $k \leq M_{0}$.

A tabela 5 mostra as especificações em OCL da Planta, e na tabela 6 se definem os invariantes correspondentes a cada especificação representada na tabela 5.

Tabela 5 - Especificação em OCL correspondente ao funcionamento da Planta

\begin{tabular}{|c|c|}
\hline \multicolumn{2}{|r|}{ context CPalnt inv } \\
\hline Id & Especificações em OCL \\
\hline 1 & $\begin{array}{l}\text { (Tank1.Full) or (Tank1.Empty) or } \\
\text { (Tank1.Filling) or (Tank1.Overflow)) }\end{array}$ \\
\hline 2 & $\begin{array}{l}\text { (Tank2.Full) or (Tank2.Empty) or } \\
\text { (Tank2.Filling) or (Tank2.Overflow)) }\end{array}$ \\
\hline 3 & $\begin{array}{c}\text { (Condenser.SteamProd) implies not } \\
((\text { Condenser.NoSteamProd }) \text { and (Condenser.Error) })\end{array}$ \\
\hline
\end{tabular}

Tabela 6 - Definição das inequações que representam invariantes de lugar da Planta

\begin{tabular}{|l|c|}
\hline Id & Invariantes \\
\hline 1 & $M($ FullT 1$)+M($ EmtyT 1$)+M($ T1Filling $)$ \\
& $+M($ T1Overflow $) \leq 1$ \\
\hline 2 & $M($ FullT 2$)+M($ EmptyT 2$)+M($ T2Filling $)$ \\
& $+M($ T2Overflow $) \leq 1$ \\
\hline 3 & $M($ SteamProd $)+M($ NoSteamProd $)+M($ Erro $) \leq 1$ \\
\hline
\end{tabular}

A tabela 7, descreve os requisitos em OCL do controlador do sistema que serão verificados; e a tabela 8 mostra as definições das inequações correspondentes a cada especificação de OCL descrita na tabela 7, as quais representam o conjunto de lugares invariantes.

\subsubsection{Verificando os requisitos}

Para verificar a veracidade das equações descritas nas tabelas 6 e 8, é preciso calcular os invariantes da rede, e depois conferir que os conjuntos de lugares de cada inequação pertence a algum vetor do conjunto solução dos invariantes de lugar da rede de Petri.

Os resultados obtidos pelo sistema GHENeSys referentes ao calculo dos invariantes são mostrados nas figuras 35 e 36, as quais correspondem aos invariantes da planta e do controlador, 
Tabela 7 - Especificação em OCL correspondente ao funcionamento do Controlador

\begin{tabular}{|c|c|}
\hline \multicolumn{2}{|r|}{ context Controller inv } \\
\hline Id & Especificações em OCL \\
\hline 1 & $\begin{array}{c}((\text { Tank1.Empty) or (Tank2.Empty)) implies } \\
(\operatorname{not}(\mathrm{V} 1 \mathrm{~V} 2 . \text {.open }))\end{array}$ \\
\hline 2 & (Tank1.Full) implies (Mixer.On) \\
\hline 3 & (Tank1.full) implies (V1V2.close) \\
\hline 4 & (Mixer.off) implies ( (V3.close) and (Tank1.Empty)) \\
\hline 5 & (Tank2.full) implies (V4.open) \\
\hline 6 & $\begin{array}{c}\text { ( (Tank1.Empty) and (Tank2.Empty) and (malf.false)) } \\
\text { implies (alarm.off) }\end{array}$ \\
\hline 7 & ( V1V2.open ) implies (V3.close) \\
\hline 8 & (Heater.on) implies (not(Tank1.Empty)) \\
\hline 9 & ((Tank1.full) and (Heater.off)) implies (V3.open) \\
\hline 10 & (Tank1.Empty) implies ((V3.close) and (Mixer.off)) \\
\hline 11 & (Tank2.Full) implies (V4.open) \\
\hline
\end{tabular}

Tabela 8 - Definição das inequações que representam invariantes de lugar do Controlador

\begin{tabular}{|l|c|}
\hline Id & Invariantes \\
\hline 1 & $M($ T1Empty $)+M($ T2Empty $)+M($ V1V2opened $) \leq 2$ \\
\hline 2 & $M(T 1 F u l l)+M($ MixerOn $) \leq 1$ \\
\hline 3 & $M(T 1 F u l l)+M($ V 1 V 2 closed $) \leq 1$ \\
\hline 4 & $M(T 1$ Empty $)+M($ V 3 closed $)+M($ MixerOff $) \leq 3$ \\
\hline 5 & $M($ T $2 F u l l)+M($ V 4 opened $) \leq 1$ \\
\hline 6 & $M($ T1Empty $)+M($ T 2 Empty $)+M($ NormalFun $)+$ \\
& $M($ Alarmoff $) \leq 4$ \\
\hline 7 & $M($ V1V2opened $)+M($ V 3 close $) \leq 1$ \\
\hline 8 & $M($ Heateron $)+M($ T 1 Empty $) \leq 1$ \\
\hline 9 & $M($ T1Full $)+M($ HeaterOff $)+M($ Vopened $) \leq 2$ \\
\hline 10 & $M(T 1$ Empty $)+M($ V 3 closed $)+M($ MixerOff $) \leq 2$ \\
\hline 11 & $M($ T2Full $)+M($ V4opened $) \leq 2$ \\
\hline
\end{tabular}

respectivamente.Esse conjunto de invariantes coincide com as equações definidas nas tabelas 6 e 8, portanto, isso demonstra que as equações descritas nessas tabelas são verdadeiras. Assim, é possível verificar se o sistema atende aos requisitos desejados.

A equação 1 da tabela 6 é um subconjunto das equações que formam os invariantes 1 da figura 35, e assim respectivamente o resto dos invariantes. Da mesma forma para as equações da tabela 8 e figura 36

Os lugares invariantes que são verificados estão na cor laranja e amarela nas figuras 35 e 36 respectivamente. 
Figura 35 - Invariantes da rede de Petri da Planta

\begin{tabular}{|l|c|c|c|}
\hline \multirow{2}{*}{} & \multicolumn{3}{|c|}{ lace Invariants } \\
\cline { 2 - 4 } & $\mathbf{1}$ & 2 & 3 \\
\hline EmtyT1 & 1 & 0 & 0 \\
\hline FillingT1 & 1 & 0 & 0 \\
\hline ErrorFillT1 & 1 & 0 & 0 \\
\hline FullT1 & 1 & 0 & 0 \\
\hline OrerflowT1 & 1 & 0 & 0 \\
\hline EmptyT2 & 0 & 1 & 0 \\
\hline DriningT1 & 1 & 0 & 0 \\
\hline FillingT2 & 0 & 1 & 0 \\
\hline ErrorFillT2 & 0 & 1 & 0 \\
\hline FullT2 & 0 & 1 & 0 \\
\hline OrerflowT2 & 0 & 1 & 0 \\
\hline NoSteamP & 0 & 0 & 1 \\
\hline Erro & 0 & 0 & 1 \\
\hline SteamP & 0 & 0 & 1 \\
\hline Explode & 0 & 0 & 1 \\
\hline Mal & 0 & 0 & 1 \\
\hline
\end{tabular}

Fonte: Elaborada pela autora.

Figura 36 - Invariantes da rede de Petri do controlador

\begin{tabular}{|l|c|c|c|c|c|c|c|c|c|c|c|}
\hline & \multicolumn{1}{|c|}{ Place Invariants } \\
\cline { 2 - 14 } & $\mathbf{1}$ & 2 & 3 & 4 & 5 & 6 & 7 & 8 & 9 & 10 & 11 \\
\hline begin & 0 & 0 & 0 & 0 & 0 & 0 & 0 & 0 & 0 & 0 & 0 \\
\hline openV1V2 & 2 & 0 & 0 & 1 & 0 & 1 & 0 & 1 & 1 & 1 & 0 \\
\hline V1V2opened & 2 & 0 & 0 & 1 & 0 & 1 & 1 & 1 & 0 & 1 & 0 \\
\hline V1V2closed & 0 & 1 & 1 & 0 & 0 & 0 & 1 & 0 & 0 & 0 & 0 \\
\hline T1Filling & 0 & 1 & 1 & 0 & 0 & 0 & 0 & 0 & 1 & 0 & 0 \\
\hline T1Full & 0 & 1 & 1 & 0 & 0 & 0 & 0 & 0 & 1 & 0 & 0 \\
\hline NormalFun & 2 & 0 & 0 & 1 & 0 & 1 & 0 & 1 & 1 & 1 & 0 \\
\hline onMixer & 2 & 0 & 0 & 1 & 0 & 1 & 0 & 1 & 1 & 1 & 0 \\
\hline MixerOn & 1 & 1 & 0 & 2 & 0 & 1 & 0 & 1 & 1 & 2 & 0 \\
\hline MixerOff & 0 & 1 & 0 & 1 & 0 & 0 & 0 & 0 & 0 & 1 & 0 \\
\hline onHeater & 1 & 0 & 0 & 0 & 0 & 0 & 0 & 0 & 0 & 0 & 0 \\
\hline HeaterOn & 1 & 0 & 0 & 0 & 0 & 0 & 0 & 1 & 1 & 0 & 0 \\
\hline HeaterOff & 0 & 0 & 0 & 0 & 0 & 0 & 0 & 1 & 1 & 0 & 0 \\
\hline openV3 & 1 & 0 & 0 & 0 & 0 & 0 & 0 & 0 & 0 & 0 & 0 \\
\hline V3opened & 1 & 0 & 0 & 1 & 0 & 0 & 1 & 0 & 1 & 1 & 0 \\
\hline V3closed & 0 & 0 & 0 & 1 & 0 & 0 & 1 & 0 & 1 & 1 & 0 \\
\hline openV4 & 1 & 0 & 0 & 0 & 0 & 1 & 0 & 0 & 0 & 0 & 0 \\
\hline V4opened & 1 & 0 & 0 & 0 & 1 & 1 & 0 & 0 & 0 & 1 & 1 \\
\hline V4closed & 0 & 0 & 0 & 0 & 1 & 0 & 0 & 0 & 0 & 1 & 1 \\
\hline End & 0 & 0 & 0 & 0 & 0 & 0 & 0 & 0 & 0 & 0 & 0 \\
\hline T1Empty & 1 & 0 & 0 & 1 & 0 & 1 & 0 & 1 & 1 & 1 & 0 \\
\hline T2Empty & 1 & 0 & 0 & 0 & 0 & 1 & 0 & 0 & 0 & 0 & 0 \\
\hline offMixer & 0 & 0 & 0 & 0 & 0 & 0 & 0 & 0 & 0 & 0 & 0 \\
\hline Moff & 0 & 0 & 0 & 0 & 0 & 1 & 0 & 0 & 0 & 0 & 0 \\
\hline Malf & 1 & 0 & 0 & 0 & 0 & 0 & 0 & 1 & 1 & 0 & 0 \\
\hline AlarmaOn & 0 & 0 & 0 & 0 & 0 & 1 & 0 & 0 & 0 & 0 & 0 \\
\hline T2Filling & 0 & 0 & 0 & 0 & 1 & 0 & 0 & 0 & 0 & 0 & 1 \\
\hline T2Full & 0 & 0 & 0 & 0 & 1 & 0 & 0 & 0 & 0 & 0 & 1 \\
\hline Malf1 & 0 & 0 & 0 & 0 & 0 & 0 & 0 & 0 & 0 & 0 & 0 \\
\hline AlarmaOff & 0 & 0 & 0 & 0 & 0 & 1 & 0 & 0 & 0 & 0 & 0 \\
\hline offAlarm & 0 & 0 & 0 & 0 & 0 & 0 & 0 & 0 & 0 & 0 & 0 \\
\hline
\end{tabular}

Fonte: Elaborada pela autora. 


\subsection{Planejamento de operações de navios em platafor- mas e portos de petróleo}

Genericamente, o problema que se apresenta neste estudo de caso pode ser descrito como a necessidade de fornecer o transporte de mercadorias e de ferramentas entre portos e plataformas de exploração e/ou produção no oceano. Os portos estão localizados num raio de $200 \mathrm{Km}$ entre si e as plataformas localizados em faixas de $100 \mathrm{~km}$ a $300 \mathrm{~km}$ de distância a partir desses portos.

Para simplificar o problema, optou-se por colocar duas plataformas na faixa de Rio de Janeiro, e duas no Santos. Foram consideradas três embarcações, ou seja, grandes barcos que podem transportar várias toneladas de carga. O que realmente faz a diferença para o problema é que isso leva algum tempo para carregar/descargar a carga.

Estas faixas foram divididas em duas partes: de Rio de Janeiro e Santos, respectivamente, como se mostra na figura 37. Cada faixa tem um porto (porto $P 1$ no Rio de Janeiro e porto $P 2$ em Santos), onde as atividades de carga/descarga ocorrem para apoiar a extração de petróleo em águas profundas (pré-sal). Ambas faixas contem um conjunto de plataformas: duas plataformas $(F 1, F 2)$ na faixa de Rio de Janeiro, e duas $(\mathrm{G} 1, \mathrm{G} 2)$ na faixa de Santos. Existem também áreas de espera (uma área de espera em cada faixa): a do Rio de Janeiro (chamado Al) está localizada a $120 \mathrm{~km}$ (distância radial) do porto $P 1$ e o de Santos (chamado de A2) está localizado a $100 \mathrm{~km}$ do porto $P 2$ onde ficam ancoradas as embarcações para não ocupar lugar nos respectivos portos.

\subsubsection{Especificações do sistema}

O problema geral a ser resolvido baseia-se no transporte e entrega de uma lista de carga solicitada a diferentes locais, considerando uma série de restrições e elementos tais como: portos disponíveis, plataformas, capacidade dos navios, pesos dos itens de carga; consumo de combustível, estações de reabastecimento disponíveis no oceano, Duração diferente de operações e Custos.

Dado um conjunto de itens de carga, o problema consiste em encontrar um plano viável que garanta a sua entrega, respeitando as limitações e exigências da capacidade dos navios. $\mathrm{O}$ 
Figura 37 - Esquema das faixas e a posição dos portos na costa brasileira.

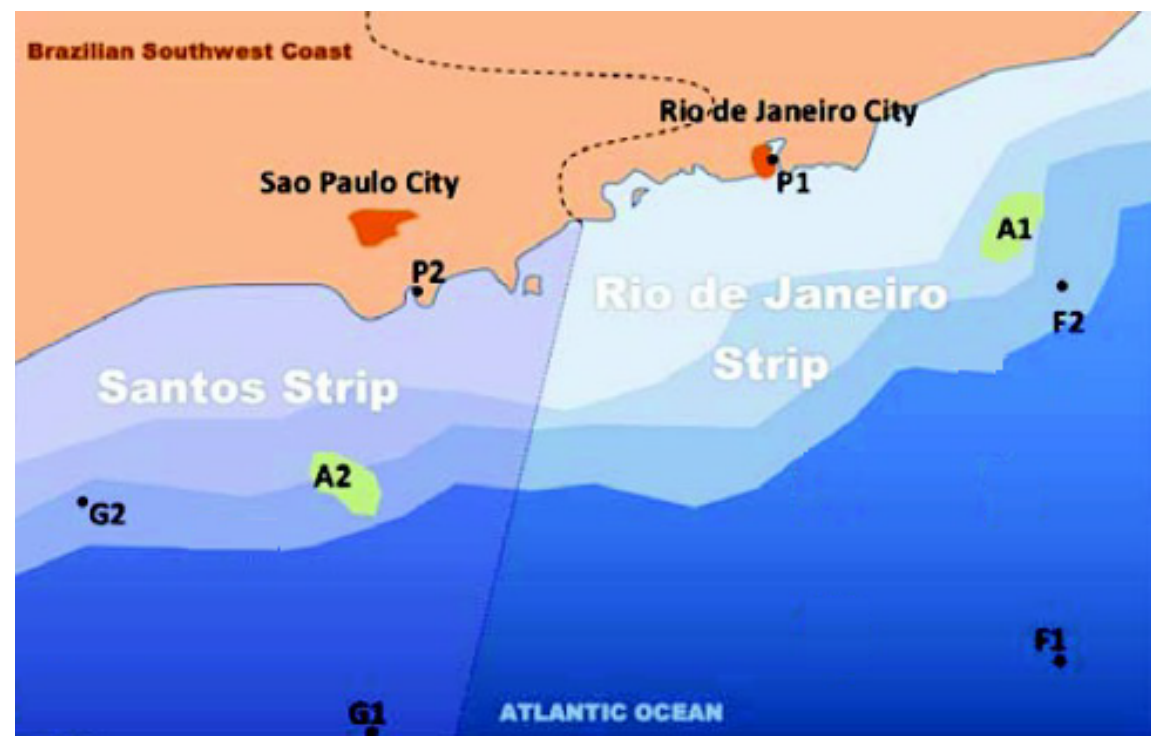

Fonte: Elaborada pela autora.

objetivo é minimizar a quantidade total de combustível consumido, o tamanho das filas de espera nos portos, o número de navios utilizados, e o custo de ancoragem. Um objetivo especial é reduzir a zero a fila de espera para ancoragem junto às plataformas.

\subsubsection{Restrições do sistema a ser consideradas neste trabalho}

- Somente um navio, por vez, pode ancorar na plataforma de reabastecimento.

- Não é possível carregar e descarregar o navio ao mesmo tempo: primeiro descarrega e depois carrega.

- O reabastecimento pode ser feito durante a ação de carga ou descarga.

- O tempo de ancoragem e desancoragem nos portos é de até uma hora, e nas plataformas de até 30 minutos.

- O tempo para carregar e descarregar os navios tanto nos portos como nas plataformas é até 5 horas.

- O reabastecimento de combustível nos portos pode demorar até 3 horas, e nas plataformas até 5 horas. 
Consideraremos como posição inicial dos navios as áreas de espera A1 e A2. F2 e G2 são as únicas plataformas capazes de realizar o reabastecimento, além dos portos.

\subsubsection{Modelagem do sistema de planejamento}

O primeiro passo na modelagem do sistema descrito é representar os requisitos usando UML. Primeiramente se representam os principais objetos do sistema e suas relações através do diagrama de classes da UML mostrado na figura 38.

Figura 38 - Diagrama de classes do sistema geral

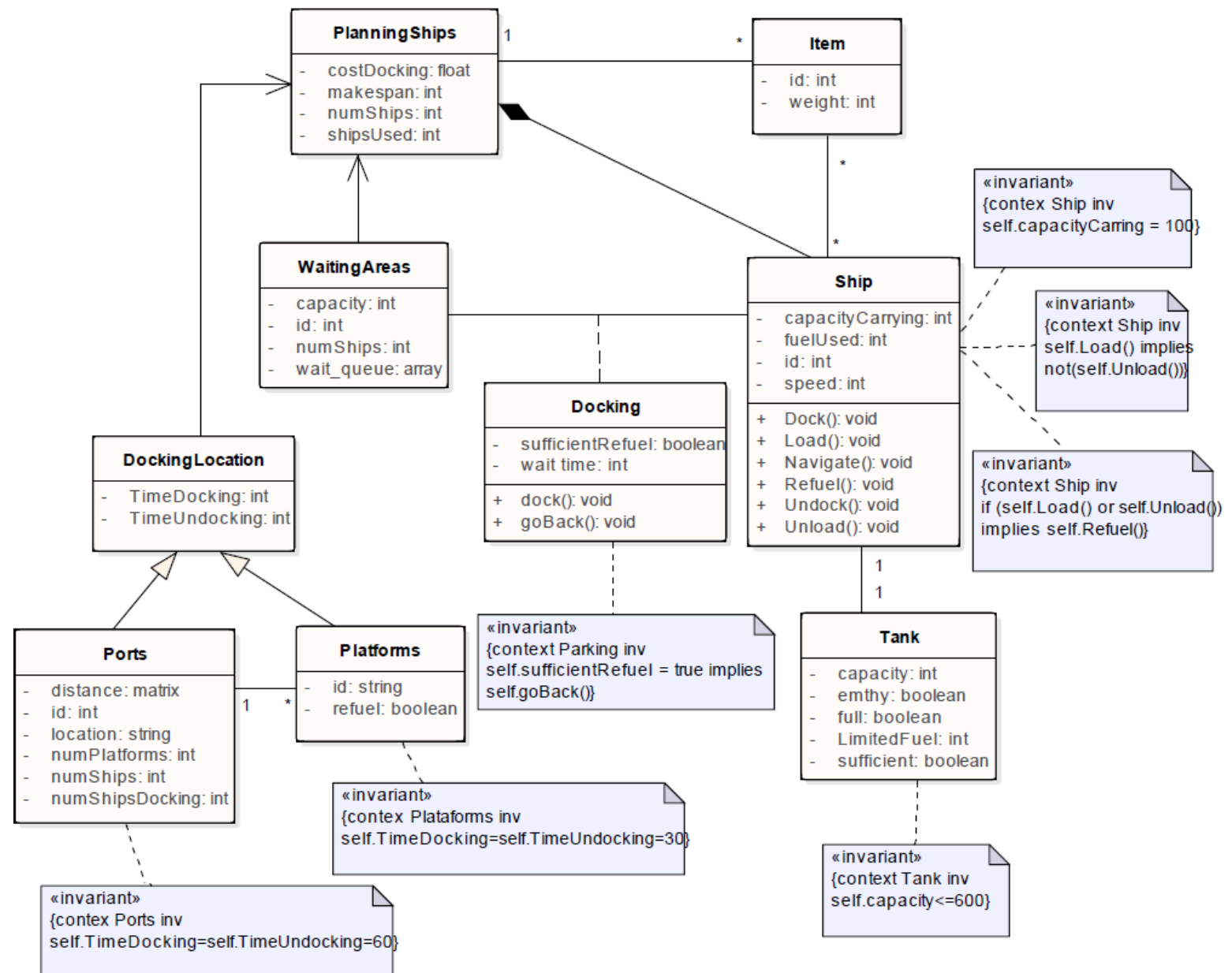

Fonte: Elaborada pela autora.

A figura 39 mostra o diagrama de objetos correspondente as classes: WaitingAreas, Ports, e Platforms respectivamente. 
Figura 39 - Diagrama de objetos correspondente as classes: (a) WaitingAreas, (b) Ports, (c) Platforms.
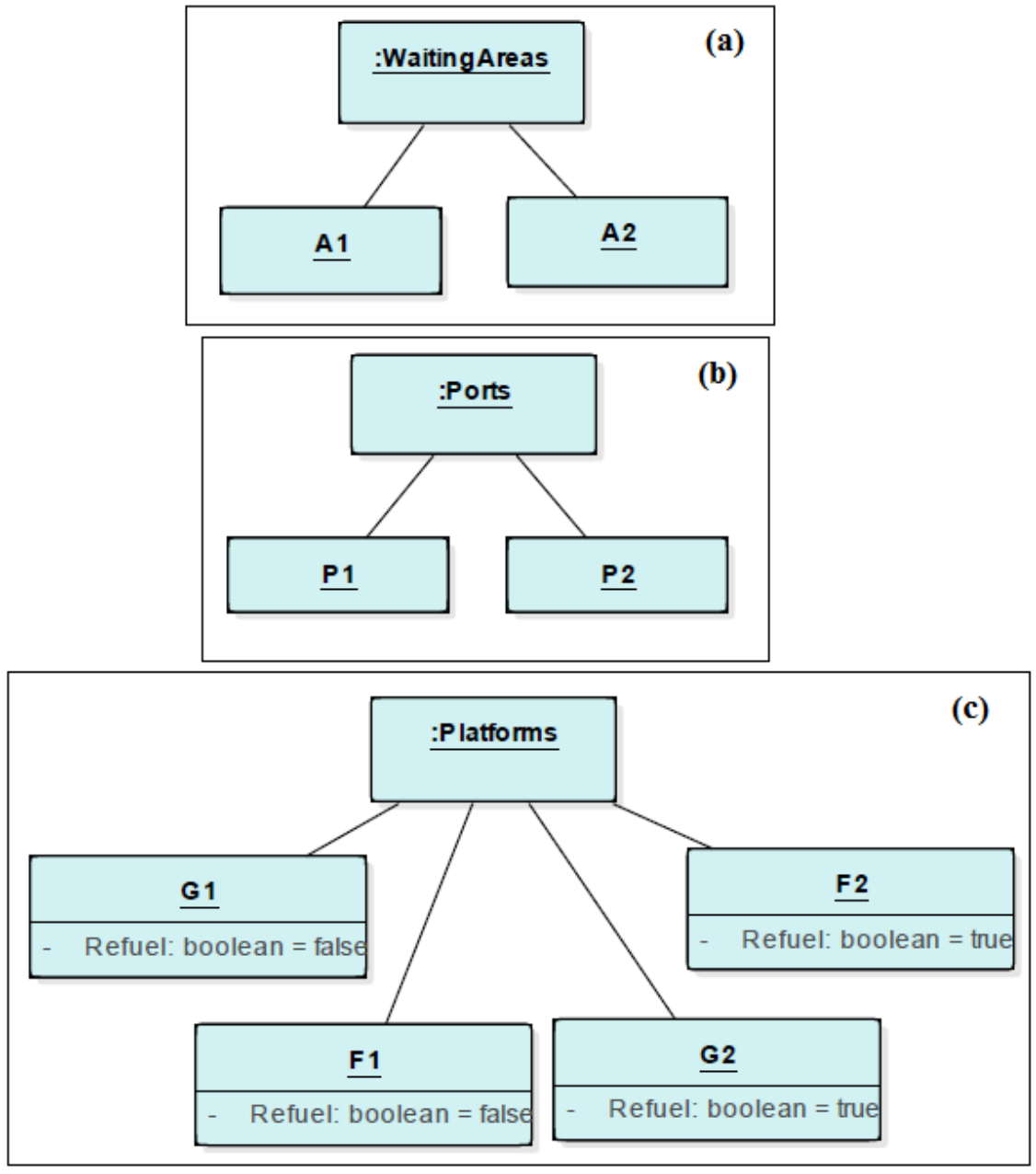

Fonte: Elaborada pela autora. 
Partindo do diagrama de classes da UML, e levando em consideração os diagramas de objetos, são construídos os diagrama de estados. A figura 40 mostra o diagrama de estados correspondente à classe Ship, representada no diagrama de classes da figura 38.

Figura 40 - Diagrama de estados da classe Ship

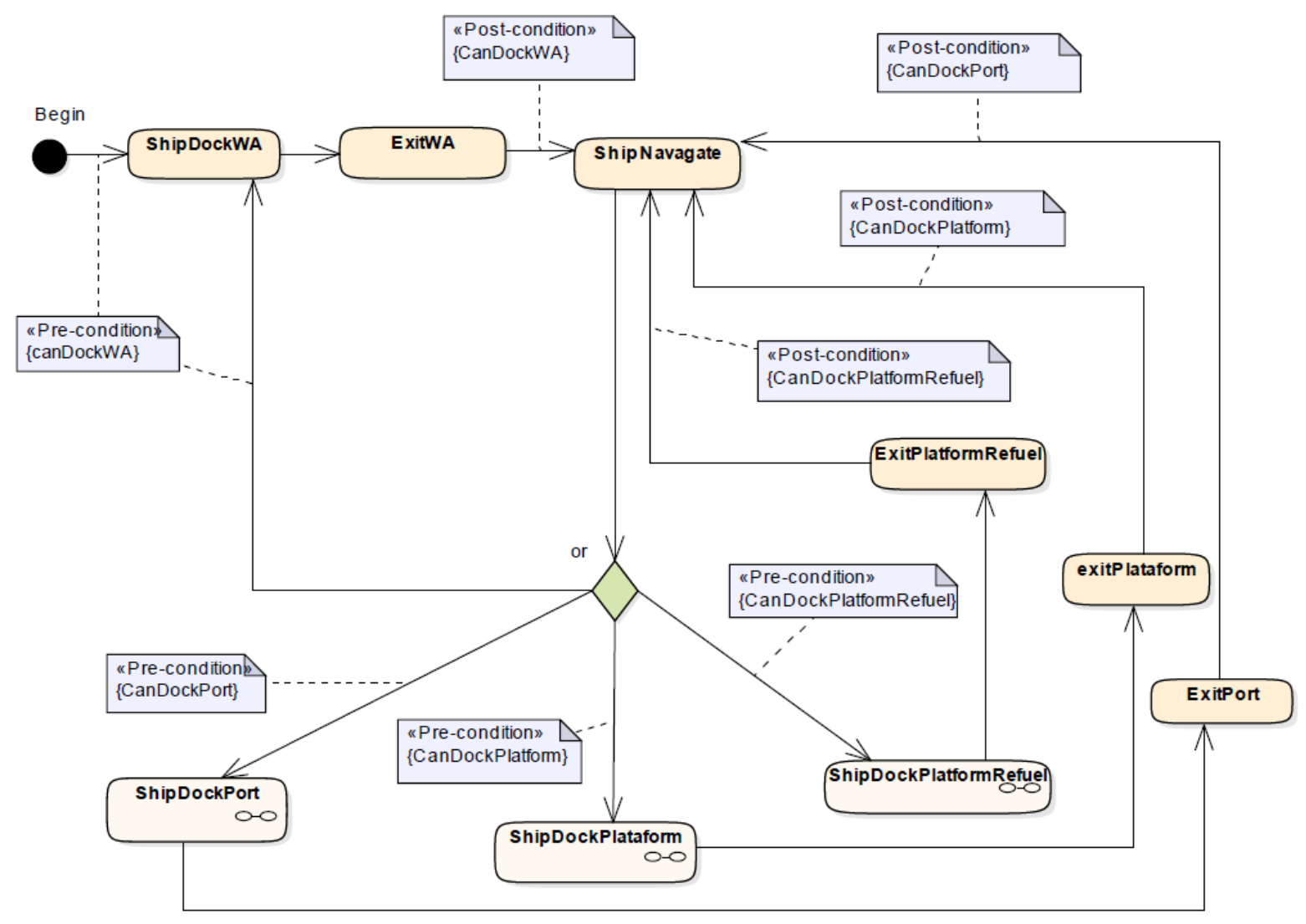

Fonte: Elaborada pela autora.

As ações dos navios nos portos e nas plataformas foram representadas através de três sub-diagramas de estados: o primeiro representa as ações do navio nos portos, enquanto as operações das plataformas foram representadas em outros dois diagramas de estados: um para as plataformas onde não é possível reabastecer os navios, e outro para representar o movimento relativo de navios e plataformas onde é possível o reabastecimento.

A figura 41 mostra a hierarquia destes diagramas de estados. 
Figura 41 - Hirarquía dos diagramas de estados:(a) Diagrama de estado Geral, (b) Diagrama de estado correspondentes aos portos, (c) Diagrama de estados correspondentes as plataformas, (d) Diagrama de estados correspondentes as plataformas de reabastecimento

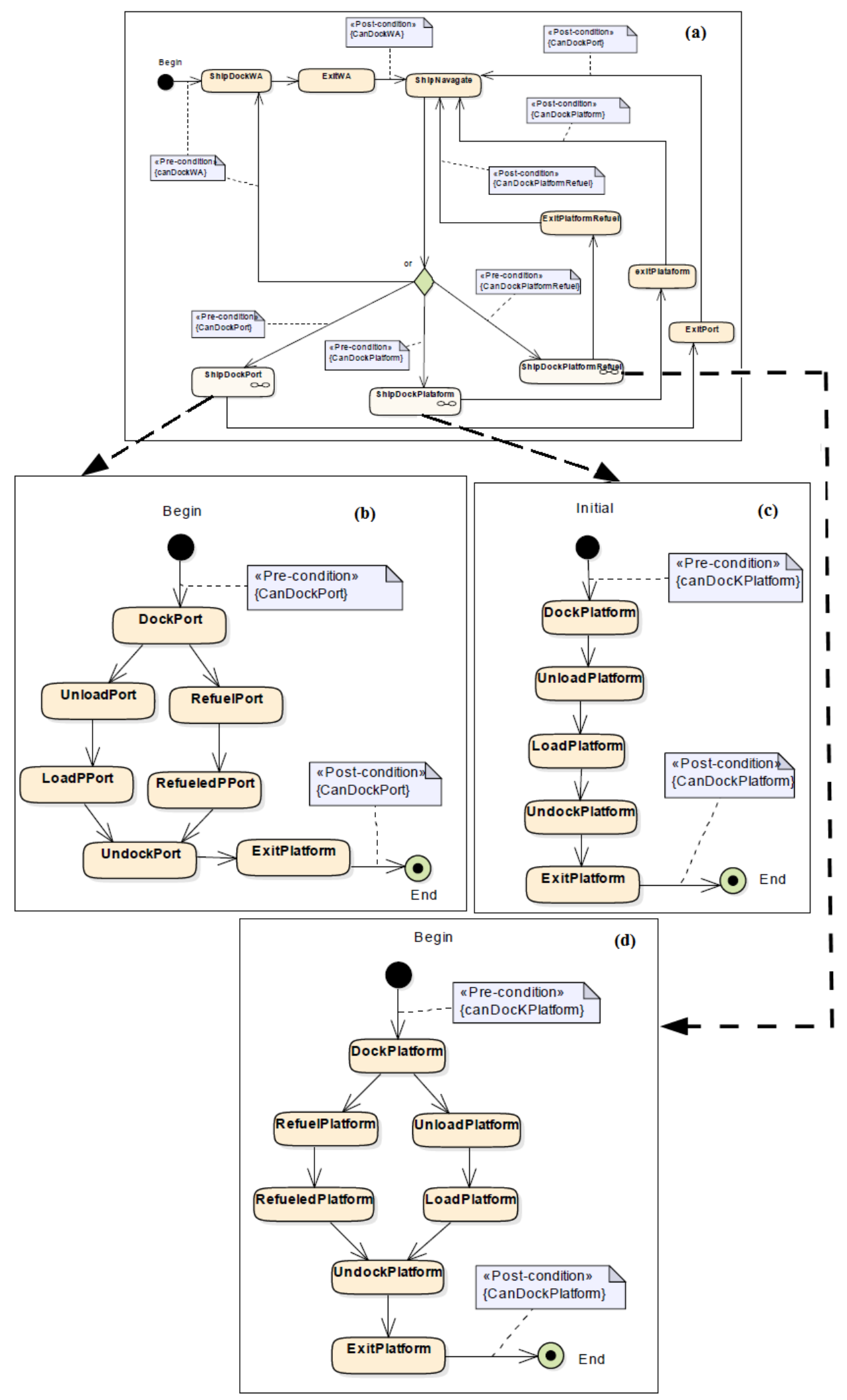

Fonte: Elaborada pela autora. 
Nos diagramas de estados mostrado na figura 41, não foi levado em consideração que existem dois portos, e quatro plataformas, como mostrado no diagrama de objetos da figura 39. As figuras 42 e 43 mostram os diagramas de estados correspondentes aos portos e às plataformas respectivamente, considerando o número de portos e plataformas representado na figura 39.

Figura 42 - Diagrama de estado correspondentes aos portos.

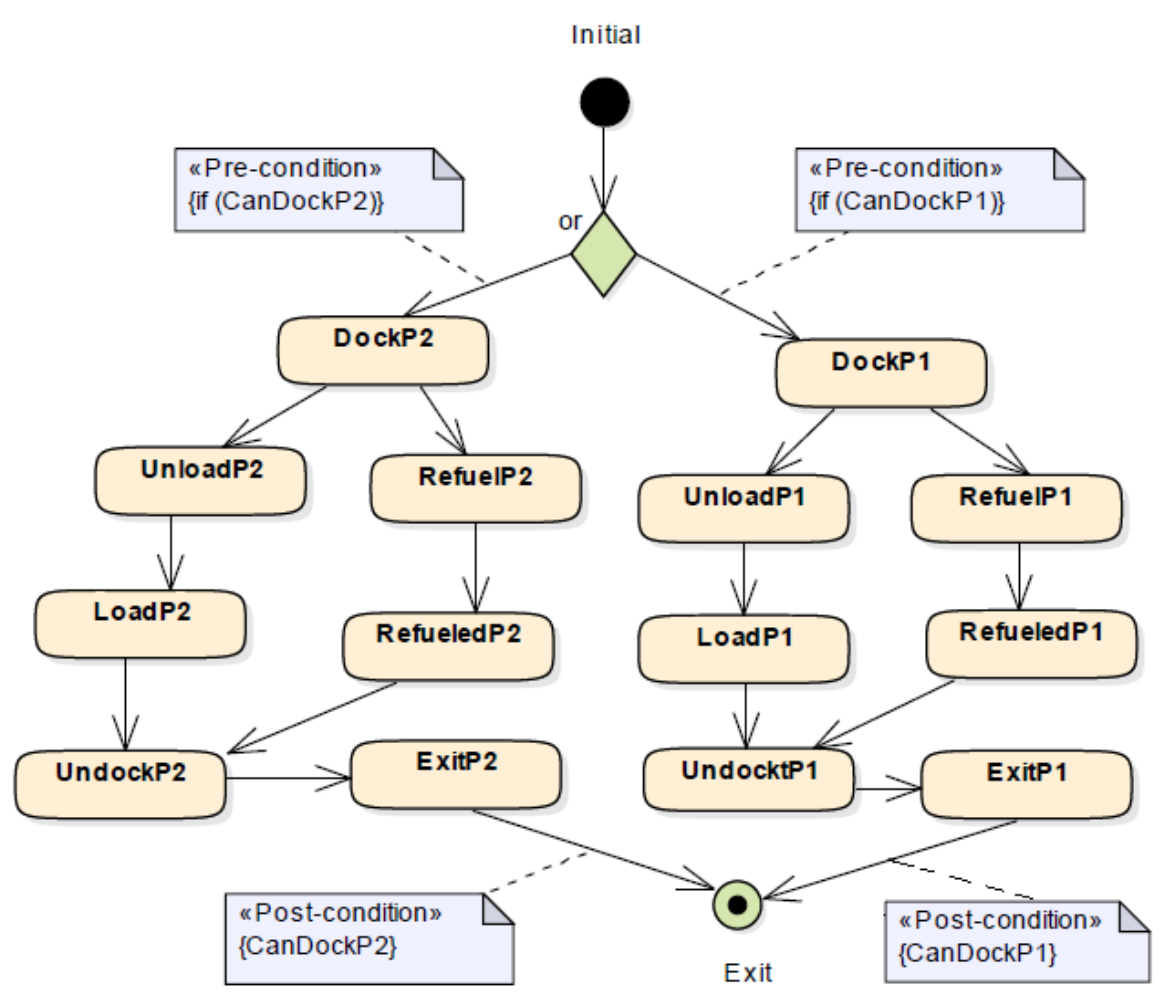

Fonte: Elaborada pela autora. 
Figura 43 - Diagrama de estado correspondentes as plataformas: (a) Plataformas sem abastacimento, (b) plataformas com abastecimiento

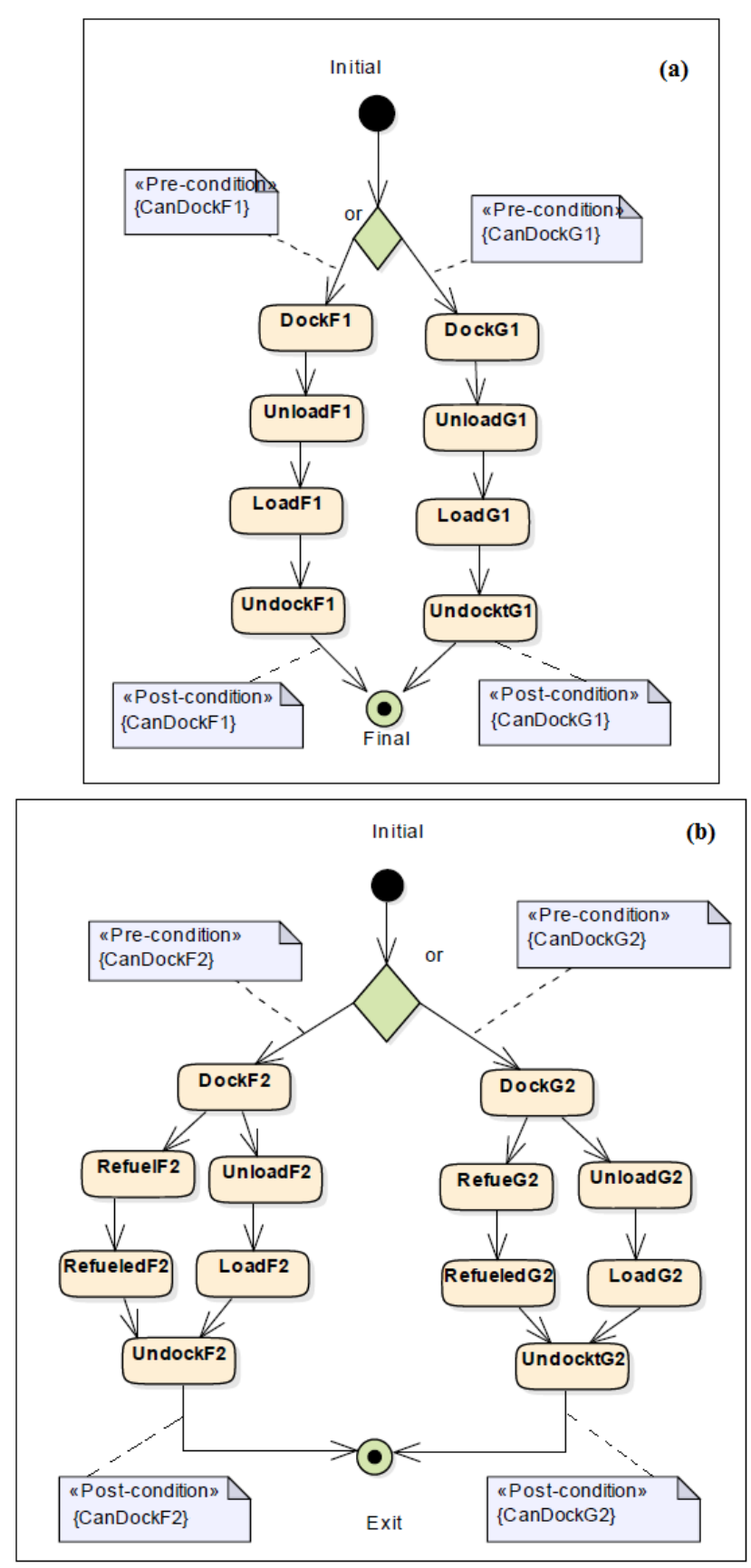

Fonte: Elaborada pela autora.

As restrições de tempo do sistema são representadas através dos diagramas de tempo. Para este trabalho somente foram consideraradas as restrições de tempo correspondente as ações de ancoragem/desancoragem, carregamento e descarregamentos dos navios, tanto nos portos como nas plataformas. As figuras 44 e 45 mostram as restrições de tempo para o navio nos portos e nas plataformas respectivamente. 
Figura 44 - Diagrama de tempo para operações do navio nos portos

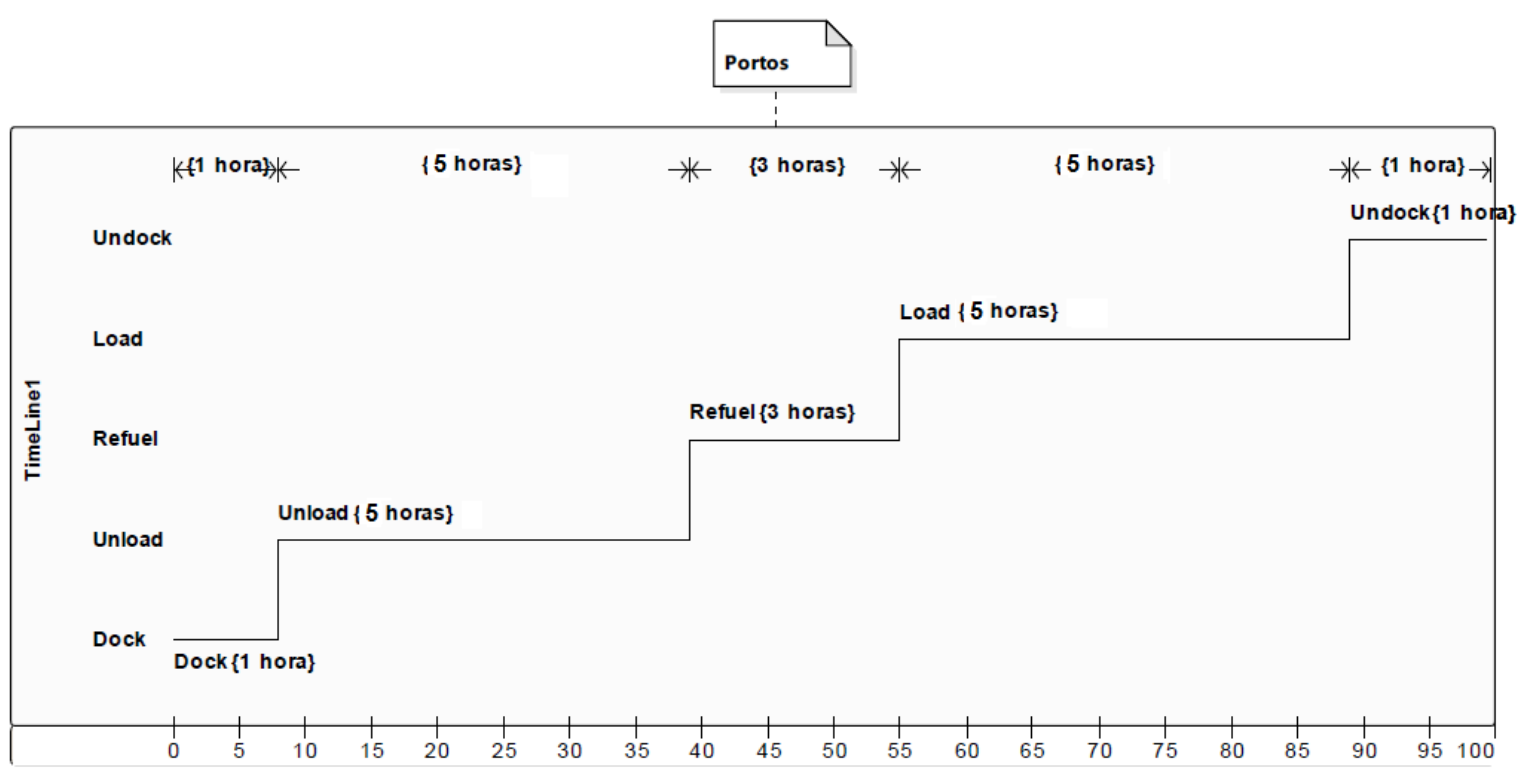

Fonte: Elaborada pela autora.

Figura 45 - Diagrama de tempo para operações do navio nas plataformas

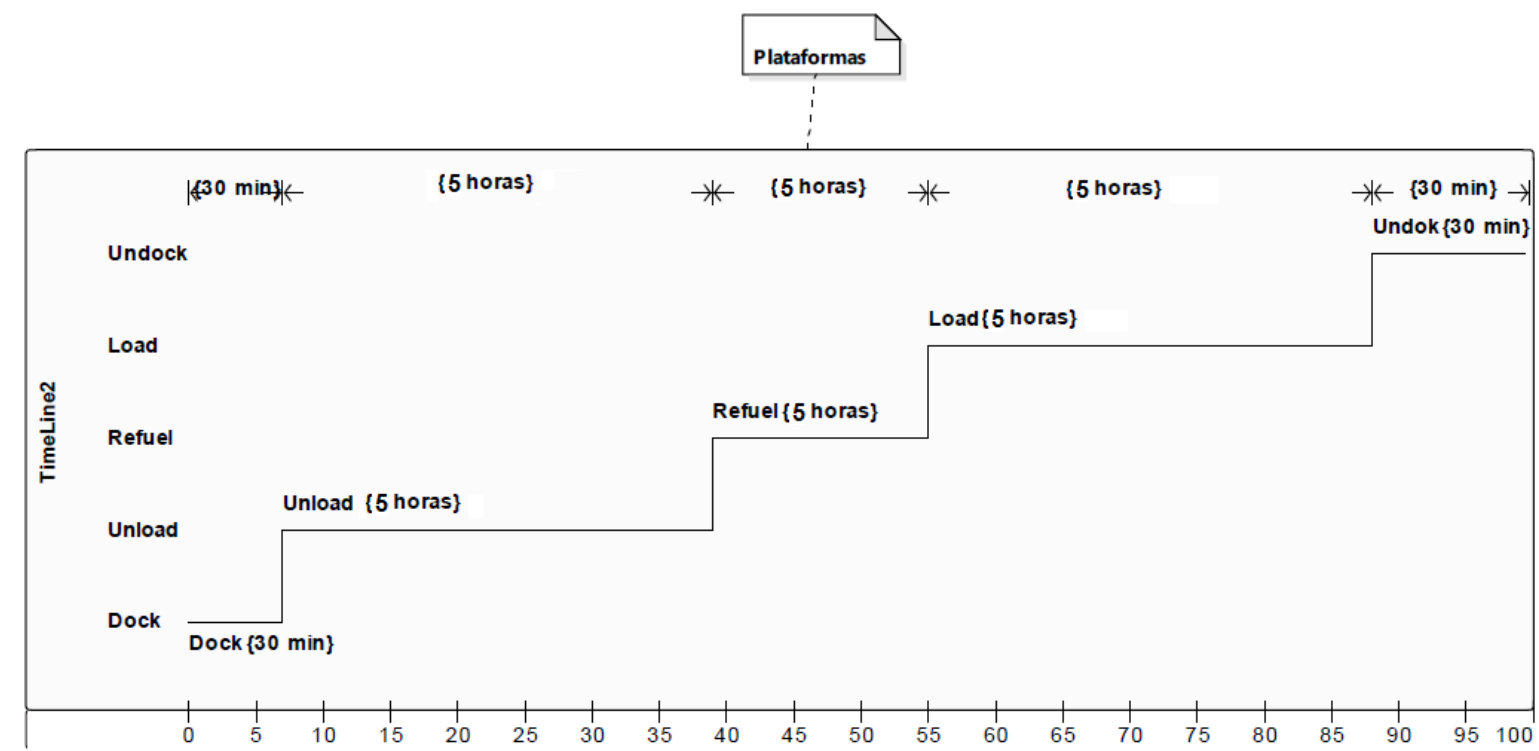

Fonte: Elaborada pela autora.

\subsubsection{Transformando os diagramas UML em rede de Petri}

Uma vez feita a modelagem em UML, os diagramas de estados são transformados numa rede GHENeSys como foi descrito no capítulo 3.

A figura 46 mostra a transformação do modelo hierárquico de diagramas de estados, mostrado na figura 41, em uma rede hierárquica GHENeSys. Porém esta rede não representa o problema real, uma vez que o sistema de planejamento que está sendo modelado possui 3 navios, 
2 portos, e 4 plataformas, duas delas com possibilidade de reabastecimento.

Figura 46 - Modelagem hierárquica do sistema na rede GHENeSys. (a) Rede geral do sistema, (b) Rede correspondentes aos portos, (c) Rede correspondentes as plataformas, (d) Rede correspondentes as plataformas de reabastecimento

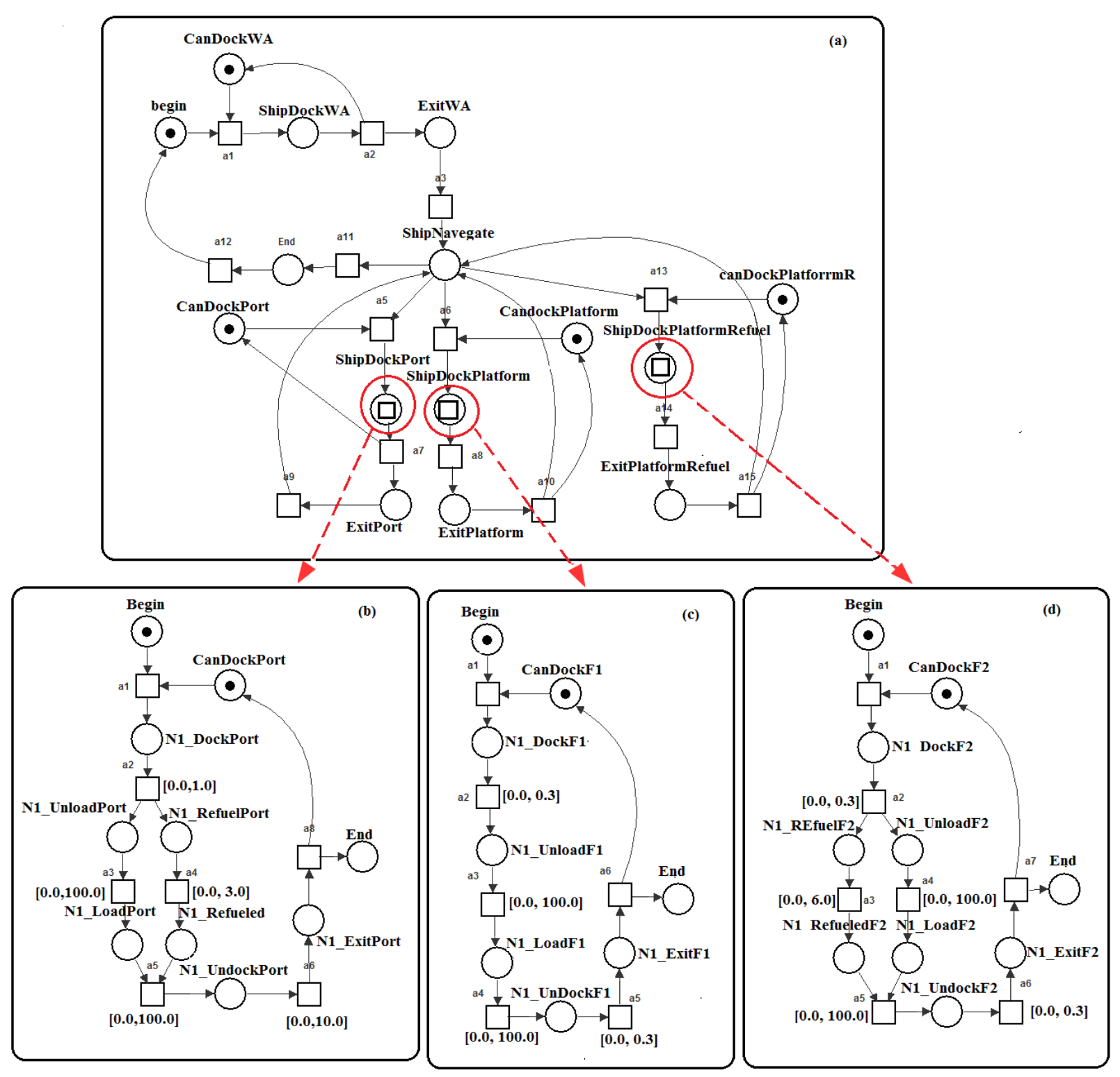

Fonte: Elaborada pela autora.

Sendo assim, é preciso modelar todas as instâncias do sistema. Numa rede de Petri, as instâncias são modeladas por marcas. Para o sistema que está sendo modelado, as marcas representam a presença ou não de um navio em cada estado (lugar da rede). Porém, neste sistema de planejamento os navios tem características diferentes, e portanto não seria adequado colocar várias marcas em um mesmo lugar para representar diferentes navios. Consequentemente, para cada estado do diagrama de estados principal do sistema figura 41 (a) devem ser representados por três lugares diferentes na rede GHENeSys, que representarão os três navios. No caso dos 
estados que representam as áreas de espera, e nos portos teremos seis lugares diferentes para cada um, devido a que existem duas áreas de espera e três navios. Para as plataformas serão considerados doze lugares. A tabela 9 mostra o mapeamento de alguns dos estados do diagrama de estados geral figura 41(a) e os lugares da rede mostrada na figura 46(a).

Tabela 9 - Equivalência entre os estados no diagrama de estados e os lugares na rede GHENeSys.

\begin{tabular}{|c|c|c|}
\hline \multicolumn{3}{|c|}{ Diagrama de estados geral } \\
\hline Estado & Lugar & Descrição \\
\hline ShipDockWA & $\begin{array}{l}N_{i} \text { DockWA1, } \\
N_{i} \text { DockWA2 } \\
i=1 \ldots 3\end{array}$ & $\begin{array}{l}\text { Navio (i) ancorado } \\
\text { na área de espera } 1 \\
\text { Navio (i) ancorado } \\
\text { na área de espera } 2\end{array}$ \\
\hline ShipDockPort & $\begin{array}{l}N_{i} \text { DockP1, } \\
N_{i} \text { DockP2 } \\
i=1 \ldots 3\end{array}$ & $\begin{array}{l}\text { Navio (i) ancorado } \\
\text { no porto } 1 \\
\text { Navio (i) ancorado } \\
\text { no porto } 2\end{array}$ \\
\hline ShipDockPlatform & $\begin{array}{l}N_{i} \text { DockF } 1, \\
N_{i} \text { Dock } G 1 \\
i=1 \ldots 3\end{array}$ & $\begin{array}{l}\text { Navio (i) ancorado } \\
\text { na plataforma F1 } \\
\text { Navio (i) ancorado } \\
\text { na plataforma G1 }\end{array}$ \\
\hline $\begin{array}{l}\text { ShipDockPlatform } \\
\text { Refuel }\end{array}$ & $\begin{array}{l}N_{i} \text { DockF } 2, \\
N_{i} \text { DockG2 } \\
i=1 \ldots 3\end{array}$ & $\begin{array}{l}\text { Navio (i) ancorado } \\
\text { na plataforma } \mathrm{F} 2 \\
\text { Navio (i) ancorado } \\
\text { na plataforma } \mathrm{G} 2\end{array}$ \\
\hline
\end{tabular}

A figura 47 mostra a rede hierárquica do sistema, já considerando todas suas instâncias.

\subsubsection{Verificação dos modelos}

Partindo da informação representada no diagrama de classes e das restrições formuladas em OCL, se definem alguns requisitos funcionais do sistema que precisam ser verificados. Os requisitos serão verificados usando os invariantes de lugar das redes de Petri.

A tabela 10 mostra as descrições em OCL correspondente às operações dos navios nos portos, e sua interpretação em termos de inequações que representam os invariantes de lugar.

A equação (1) da tabela 10 significa que enquanto os navios estão fazendo a operação de carregamento nos portos, não podem fazer o descarregamento. A equação (2) significa que enquanto o navio faz operações de carga ou descarga nos portos, é possível reabastecer o tanque.

A tabela 11 descreve os requisitos que devem ser verificados nas operações dos navios nas plataformas onde não é possível reabastecer. Neste caso só se verifica que as operações de 
Figura 47 - Rede GHENeSys do sistema geral

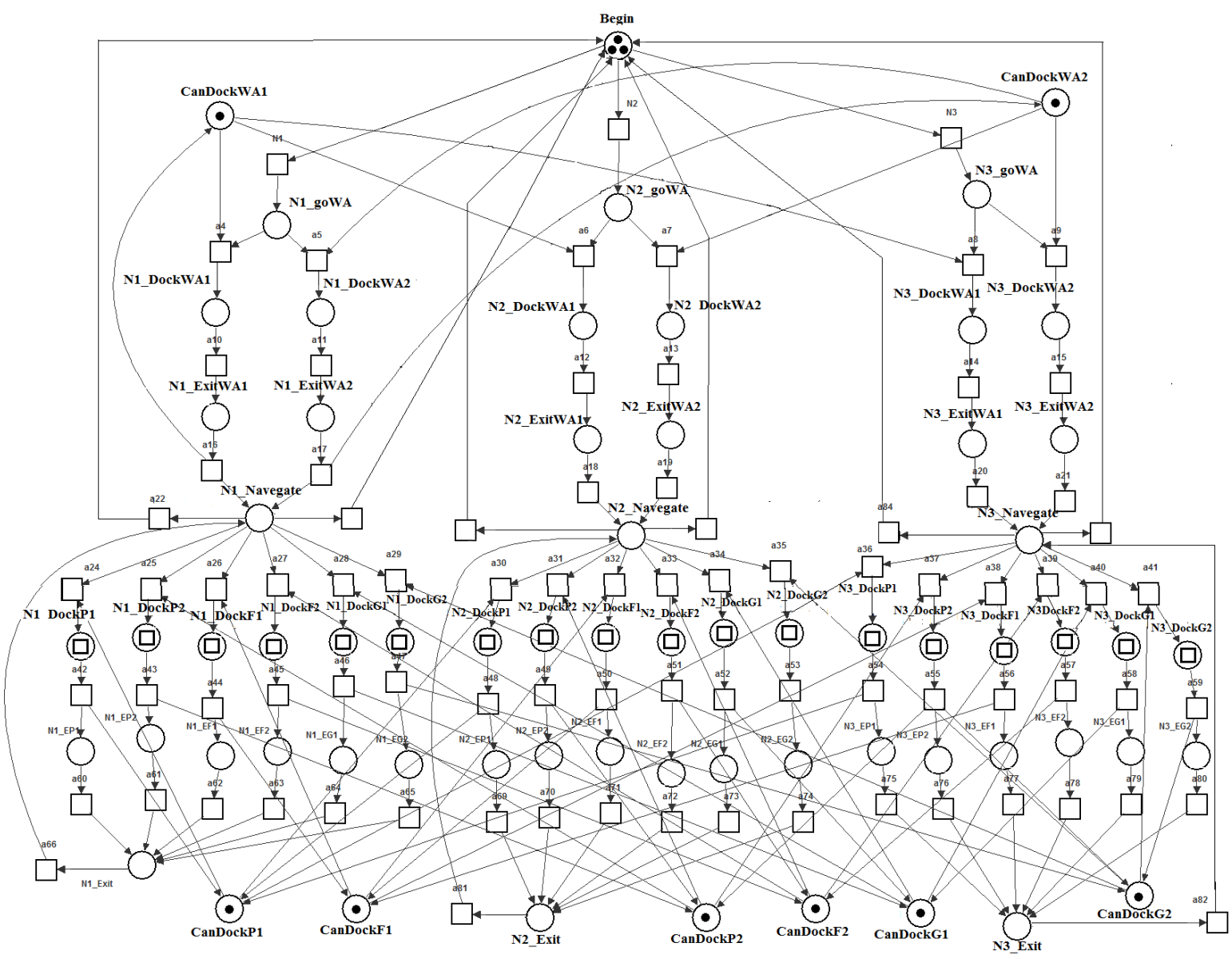

Fonte: Elaborada pela autora.

\begin{tabular}{|l|c|c|}
\hline Id & Especificações em OCL & Invariantes \\
\hline 1 & $($ self.Load()) implies & $M\left(N_{i}\right.$ LoadP $\left._{j}\right)+$ \\
& not ((self.Unload()) & $M\left(N_{i}\right.$ UnloadP $\left._{j}\right) \leq 1$ \\
& & $i=1 \ldots 3, j=1 \ldots 2$ \\
\hline 2 & if (self.Load() or & $M\left(N_{i}\right.$ LoadP $\left._{j}\right)+$ \\
& self.Unload()) & $M\left(N_{i}\right.$ UnloadP $\left._{j}\right)+M\left(N_{i}\right.$ Refuel $\left._{j}\right) \leq 1$ \\
& implies self.Refuel( $)$ & $i=1 \ldots 3, j=1 \ldots 2$ \\
\hline
\end{tabular}

Tabela 10 - Especificação descritas em OCL correspondente as operações dos navios nos portos.

carga e descarga não se realizem de forma simultânea.

\begin{tabular}{|l|c|c|}
\hline Id & Especificações em OCL & Invariantes \\
\hline 1 & $($ self.Load()) implies & $M\left(N_{i}\right.$ LoadF 1$)+$ \\
& not $((\operatorname{self.Unload}))$ & $M\left(N_{i}\right.$ Unload 1$) \leq 1$ \\
\hline 2 & & $M\left(N_{i}\right.$ Load $\left.G 1\right)+$ \\
& & $M\left(N_{i}\right.$ Unload $\left.G 2\right) \leq 1$ \\
\hline
\end{tabular}

Tabela 11 - Especificação descritas em OCL correspondente as operações dos navios nas plataformas.

A figura 48 mostra alguns dos invariantes de lugar, corresponde à rede dos Portos (figura 46 (b)), e à rede das Plataformas (figura 46 (c)), obtidos pelo sistema GHENeSys. A equação 1 da tabela 10 se verifica com a invariante número 1 da figura 48(a); e a equação 2 se verifica 
com o invariante número 5 . As equações da tabela 11 podem ser verificadas com a invariante número 1 da figura 48(b). A figura 48(b) mostra o cálculo dos invariante na rede correspondente a plataforma $F 1$, mas o cálculo dos invariantes na rede da plataforma $G 1$ é equivalente.

Figura 48 - (a): Invariantes de lugar da rede que modela as ações nos portos (figura 46(b)). (b): Invariantes de lugar da rede que modela as ações nas plataformas (figura 46(c)).

\begin{tabular}{|c|c|c|c|c|c|c|}
\hline & & \multicolumn{5}{|c|}{ Invariantes de lugar } \\
\hline & Lugares & 1 & 2 & 3 & 4 & 5 \\
\hline 1 & Begin & 0 & 0 & 1 & 1 & 1 \\
\hline 2 & N1 DockPort & 1 & 1 & 1 & 1 & 2 \\
\hline 3 & N1 UnloadPort & 1 & 0 & 1 & 0 & 1 \\
\hline 4 & N1 RefuelPort & 0 & 1 & 0 & 1 & 1 \\
\hline 5 & N1_LoadPort & 1 & 0 & 1 & 0 & 1 \\
\hline 6 & N1_Refueled & 0 & 1 & 0 & 1 & 1 \\
\hline 7 & N1_UndockPort & 1 & 1 & 1 & 1 & 2 \\
\hline 8 & CanDockPort & 1 & 1 & 0 & 0 & 1 \\
\hline 9 & N1ExitPort & 1 & 1 & 1 & 1 & 2 \\
\hline 10 & End & 0 & 0 & 1 & 1 & 1 \\
\hline
\end{tabular}

(a)

\begin{tabular}{|c|c|c|c|}
\cline { 3 - 4 } \multicolumn{1}{c|}{} & \multicolumn{2}{c|}{ Invariantes } \\
\cline { 2 - 4 } \multicolumn{1}{c|}{} & Lugares & 1 & 2 \\
\hline 1 & Begin & 1 & 0 \\
\hline 2 & N1_DockF1 & 1 & 1 \\
\hline 3 & N1_UnloadF1 & 1 & 1 \\
\hline 4 & N1_LoadF1 & 1 & 1 \\
\hline 5 & N1_UnDockF1 & 1 & 1 \\
\hline 6 & N1_ExitF1 & 1 & 1 \\
\hline 7 & End & 1 & 0 \\
\hline 8 & CanDockF1 & 0 & 1 \\
\hline
\end{tabular}

(b)

Fonte: Elaborada pela autora.

Além dos requisitos formulados em OCL e representados no diagrama de classes, existem outros requisitos do sistema que podem ser verificados usando o cálculo dos invariantes. A tabela 12 descreve os invariantes que devem ser verificados no sistema geral, representado na rede da figura 47.

Tabela 12 - Invariantes do sistema geral.

\begin{tabular}{|c|c|}
\hline Id & Invariantes \\
\hline 1 & $\begin{array}{c}M\left(N_{i} \text { DockWA } 1\right)+M\left(N_{i} \text { DockWA2 }\right)+ \\
M\left(N_{i} \text { DockP1 }\right)+M\left(N_{i} \text { DockP } 2\right)+\mathrm{m} \\
M\left(N_{i} \text { DockF } 1\right)+M\left(N_{i} \text { DockF } 2\right)+ \\
M\left(N_{i} \text { DockG } 1\right)+M\left(N_{i} 1 \text { Dock } 2\right)+ \\
M\left(N_{i} \text { Navegate }\right) \leq 1, i=1 \ldots 3\end{array}$ \\
\hline 2 & $\begin{array}{c}M\left(N_{1} \text { DockF } 1\right)+M\left(N_{2} \text { DockWF } 1\right)+ \\
M\left(N_{3} \text { DockF } 1\right) \leq 1\end{array}$ \\
\hline 3 & $\begin{array}{c}M\left(N_{1} \text { DockF } 2\right)+M\left(N_{2} \text { DockWF } 2\right)+ \\
M\left(N_{3} \text { DockF } 2\right) \leq 1\end{array}$ \\
\hline 4 & $\begin{array}{c}M\left(N_{1} \text { Dock } G 1\right)+M\left(N_{2} \text { DockWG1 }\right)+ \\
M\left(N_{3} \text { Dock } G 1\right) \leq 1\end{array}$ \\
\hline
\end{tabular}

As equações da tabela 12 representam os seguintes requisitos do sistema: a equação 1 significa que os navios podem estar em apenas um dos seguintes lugares: áreas de espera, portos, plataformas, ou navegando; a equação 2, 3 e 4 significa nas plataformas só pode ter um navio de cada vez.

A figura 49 mostra os resultados do cálculo dos invariantes de lugar, obtidos pelo sistema GHENeSys, na rede correspondente ao sistema geral, mostrada na figura 47. A equação numero 
1 da tabela 12 se verifica com o invariante 4 da figura 49 (a cor laranja pertence ao navio N1, a cor azul ao navio N2, e a cor vermelha ao navio N3). As restantes equações $(2,3,4)$ são verificadas pelas invariantes $(1,2,3)$ da figura 49 , respectivamente.

Figura 49 - Invariantes de lugar da rede principal (figura 47). A cor laranja pertence ao navio N1, a cor azul ao navio N2, e a cor vermelha ao navio N3.

\begin{tabular}{|c|c|c|c|c|c|c|c|c|c|c|c|}
\hline & \multicolumn{5}{|c|}{ Invariantes de lugar } & & & & & & \\
\hline & Lugares & 1 & 2 & 3 & 4 & & & \multicolumn{4}{|c|}{ Invariantes de lugar } \\
\hline 1 & canDockWA1 & 1 & 1 & 1 & 0 & & Lugares & 1 & 2 & 3 & 4 \\
\hline 2 & CanDockWA2 & 1 & 1 & 1 & 0 & 42 & N1_EP1 & 0 & 0 & 0 & 1 \\
\hline 3 & N1_DockWA1 & 1 & 1 & 1 & $\overline{1}$ & 43 & N1_EP2 & 0 & 0 & 0 & 1 \\
\hline 4 & N1_DockWA2 & 1 & 1 & 1 & 1 & 44 & N1_EF1 & 0 & 0 & 0 & 1 \\
\hline 5 & N2 DockWA1 & 1 & 1 & 1 & 1 & 45 & N1_EF2 & 0 & 0 & 0 & 1 \\
\hline 6 & N2 DockWA2 & 1 & 1 & 1 & 1 & 46 & N1_EG1 & 0 & 0 & 0 & 1 \\
\hline 7 & N3 DockWA1 & 1 & 1 & 1 & $\frac{1}{1}$ & 47 & N1_EG2 & 0 & 0 & 0 & 1 \\
\hline 8 & N3 DockWA2 & 1 & 1 & 1 & $\frac{1}{1}$ & 48 & N1_Exit & 0 & 0 & 0 & 1 \\
\hline 9 & N1 ExitWA1 & 1 & 1 & 1 & 1 & 49 & N2_EP1 & 0 & 0 & 0 & 1 \\
\hline 10 & N1 ExitWA2 & 1 & 1 & 1 & $\frac{1}{1}$ & 50 & N2_EP2 & 0 & 0 & 0 & 1 \\
\hline 11 & N2 ExitWA1 & 1 & 1 & 1 & $\frac{1}{1}$ & 51 & N2_EF1 & 0 & 0 & 0 & 1 \\
\hline 12 & N2 ExitWA2 & 1 & 1 & 1 & & 52 & $\mathrm{~N} 2$ EF 2 & 0 & 0 & 0 & 1 \\
\hline 13 & N3 ExitWA1 & 1 & 1 & 1 & & 53 & N2_EG1 & 0 & 0 & 0 & 1 \\
\hline 14 & N3 ExitWA2 & 1 & 1 & 1 & & 54 & $\mathrm{~N} 2 \_\mathrm{EG} 2$ & 0 & 0 & 0 & 1 \\
\hline 15 & N1 Navegate & 0 & 0 & 0 & & 55 & N3_EP1 & 0 & 0 & 0 & 1 \\
\hline 16 & N2 Navegate & 0 & 0 & 0 & & 56 & N3_EP2 & 0 & 0 & 0 & 1 \\
\hline 17 & N3 Navegate & 0 & 0 & 0 & & 57 & N3_EF1 & 0 & 0 & 0 & 1 \\
\hline 18 & CanDockP1 & 1 & 1 & 1 & & 58 & N3_EF2 & 0 & 0 & 0 & 1 \\
\hline 19 & CanDockP2 & 1 & 1 & 1 & & 59 & N3_EG1 & 0 & 0 & 0 & 1 \\
\hline 20 & CanDockF1 & 1 & 1 & 1 & & 60 & N3_EG2 & 0 & 0 & 0 & 1 \\
\hline 21 & CanDockF2 & 0 & 1 & 1 & & 61 & N2_Exit & 0 & 0 & 0 & 1 \\
\hline 22 & CanDockG1 & 0 & 0 & 1 & & 62 & N3_Exit & 0 & 0 & 0 & 1 \\
\hline 23 & CanDockG2 & 0 & 0 & 0 & & 63 & Begin & 0 & 0 & 0 & 0 \\
\hline 24 & N1 DockP1 & 1 & 1 & 1 & & 64 & $\mathrm{~N} 1$ & 0 & 0 & 0 & 1 \\
\hline 25 & N1 DockP2 & 1 & 1 & 1 & 1 & 65 & $\mathrm{~N} 2$ & 0 & 0 & 0 & 1 \\
\hline 26 & N1_DockF1 & 1 & 1 & 1 & $\frac{1}{1}$ & 66 & $\mathrm{~N} 3$ & 0 & 0 & 0 & 1 \\
\hline 27 & N1_DockF2 & 0 & 1 & 1 & 1 & & & & & & \\
\hline 28 & N1_DockG1 & 0 & 0 & 1 & 1 & & & & & & \\
\hline 29 & N1_DockG2 & 0 & 0 & 0 & 1 & & & & & & \\
\hline 30 & N2_DockP1 & 1 & 1 & 1 & 1 & & & & & & \\
\hline 31 & N2_DockP2 & 1 & 1 & 1 & 1 & & & & & & \\
\hline 32 & N2_DockF1 & 1 & 1 & 1 & 1 & & & & & & \\
\hline 33 & N2_DockF2 & 0 & 1 & 1 & 1 & & & & & & \\
\hline 34 & N2_DockG1 & 0 & 0 & 1 & 1 & & & & & & \\
\hline 35 & N2_DockG2 & 0 & 0 & 0 & 1 & & & & & & \\
\hline 36 & N3_DockP1 & 1 & 1 & 1 & 1 & & & & & & \\
\hline 37 & N3_DockP2 & 1 & 1 & 1 & 1 & & & & & & \\
\hline 38 & N3_DockF1 & 1 & 1 & 1 & 1 & & & & & & \\
\hline 39 & N3_DockF2 & 0 & 1 & 1 & 1 & & & & & & \\
\hline 40 & N3_DockG2 & 0 & 0 & 0 & 1 & & & & & & \\
\hline 41 & N3_DockG1 & 0 & 0 & 1 & 1 & & & & & & \\
\hline
\end{tabular}

Fonte:Elaborada pela autora.

Um método mais adequado para modelar este tipo de problema, seria usar uma rede de alto nível, na qual é possível diferenciar os tokens e por conseguinte reduzir o número de lugares da rede. Neste trabalho o problema foi reduzido para dois portos e quatro plataformas, mas o problema real tem um número bem maior. Portanto, a modelagem do sistema real usando uma rede lugar/transição seria muito grande, dificultando seu entendimento. A figura 50 mostra a 
modelagem no sistema CPNTools da rede de alto nível equivalante à rede da figura 47. Embora não exista uma abordagem analítica para calcular invariantes em redes coloridas, é importante chamar a atenção de que as ventagens de modelagem, que eventualmente poderiam ser obtidas pelo dobramento da rede, ainda podem ser mantidas se forem utilizados invariantes durante a análise de requisitos (SALMON et al., 2016).

Figura 50 - Rede de Petri alto nível.

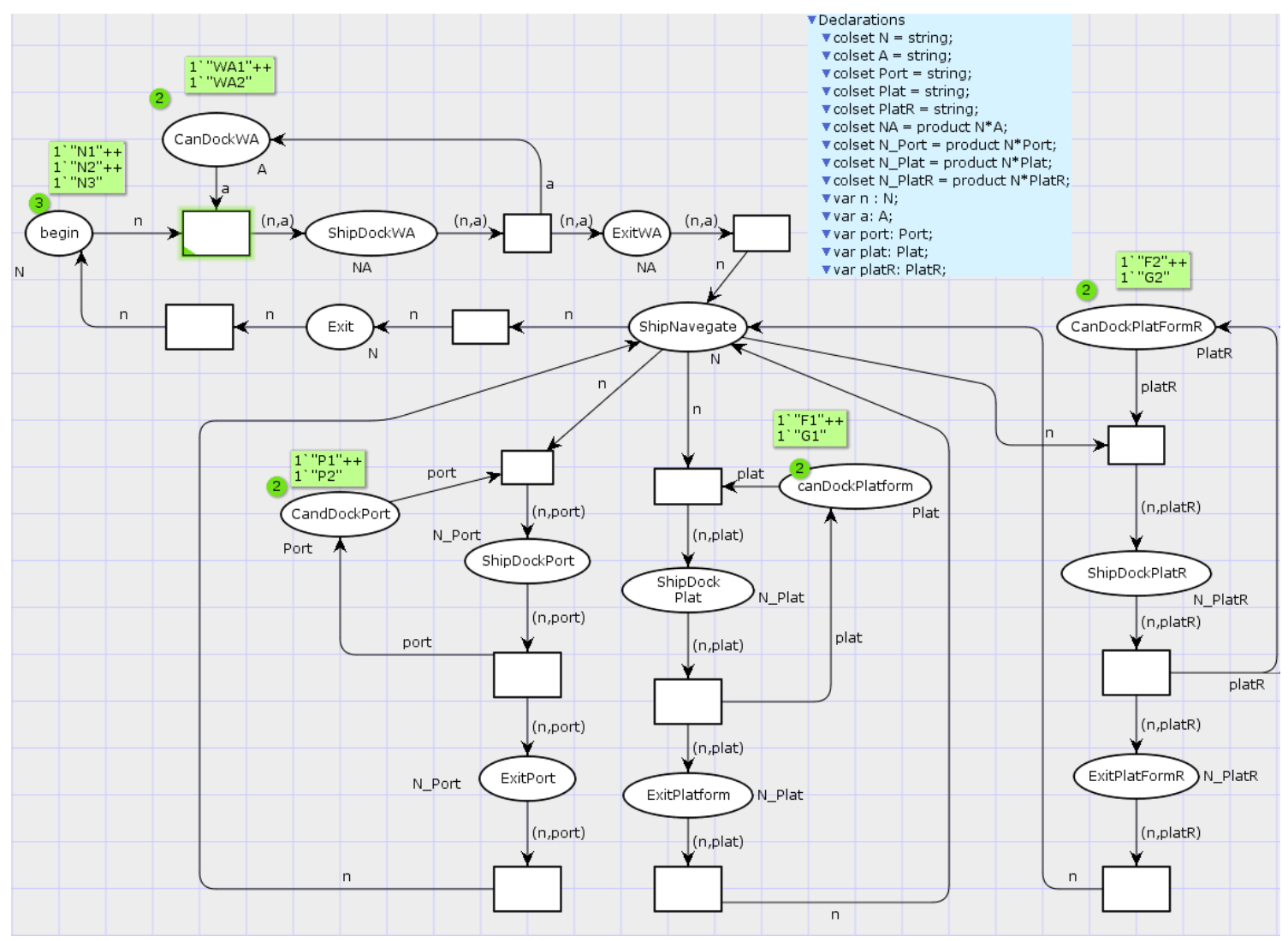

Fonte: Elaborada pela autora. 


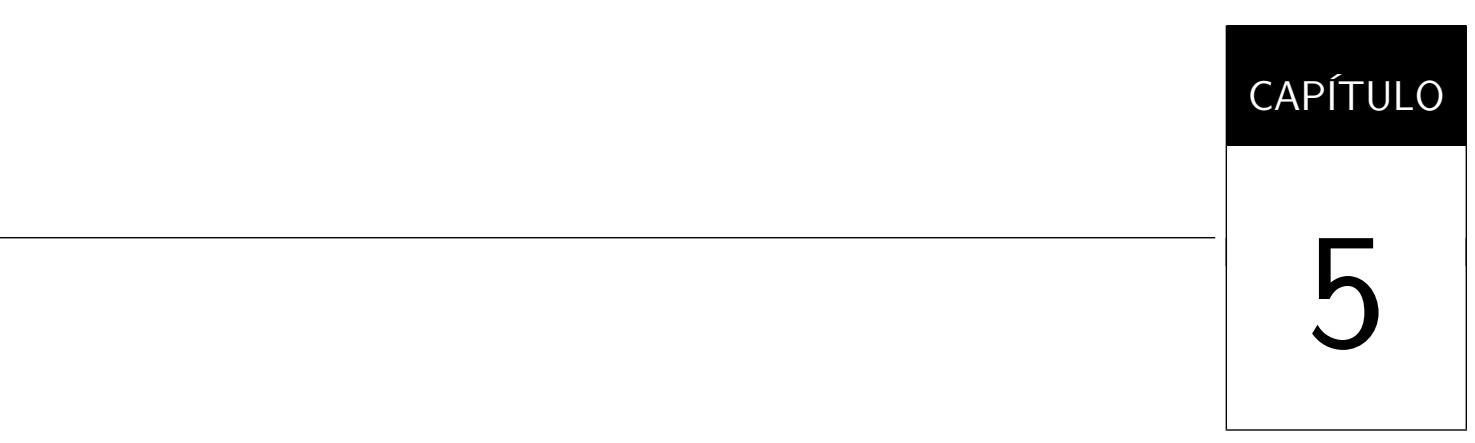

CONCLUSÕES E TRABALHOS FUTUROS

Neste capítulo são apresentadas as conclusões do trabalho, e as recomendações para dar continuidade à pesquisa neste assunto.

\subsection{Conclusões}

Neste trabalho foi proposta uma disciplina de projeto para sistemas automatizados, baseado em UML e redes de Petri. A abordagem apresentada propõe, partir da modelagem em UML, e passar para uma representação formal em redes de Petri, onde é possível realizar a análise e verificação formal dos requisitos usando invariantes definidos sobre estas redes.

Para capturar os requisitos do sistema foi proposto um conjunto mínimo de cinco diagramas: diagrama de classes, diagrama de objetos, diagrama de estados, diagrama de tempo, e diagrama de interação. Nos diagramas de classes e objetos são capturados os requisitos estáticos dos sistemas, e estes por sua vez serão representados formalmente usando OCL (que é usada para definir os requisitos do sistema que representem invariantes). Os diagramas de estado, tempo e interação representam o comportamento dinâmico dos sistemas modelados. A partir desta representação semi-formal, foi proposto um algoritmo de transformação que converte diagramas de UML em uma rede de Petri GHENeSys.

Uma vez sintetizado o modelo em uma, ou várias redes GHENeSys, é feita a verificação 
do modelo. Para este trabalho, a proposta foi usar a análise dos invariantes da rede de Petri na verificação formal dos requisitos funcionais e estruturais dos sistemas. Assim, uma vez construída a rede GHENeSys, os invariantes devem ser calculados para demonstrar a veracidade das propriedades verificadas.

Uma das vantagens do método é usar invariantes desde o início do processo, introduzindoos na análise de requisitos. Neste trabalho foi utilizada a representação canônica baseada em UML, complementada pela OCL. No entanto, o fato de que os invariantes foram inseridos na fase inicial (usando OCL) torna viável a introdução de redes de Petri de alto nível.

O método proposto neste trabalho preenche uma lacuna da maioria dos métodos similares que é ter um procedimento de análise dos requisitos baseado em uma representação formal. Permite ainda uma validação antecipada antes da formalização das especificações, tornando a fase de desing e provimento de soluções mais consistente.

A fase final do método proposto consiste na verificação do sistema modelado, que é feita através do cálculo de invariantes. Antes de construir a rede de Petri foram descritos em OCL as especificações do sistemas que iriam ser verificadas. Estas especificações foram transformadas em inequações que representavam invariantes do sistema. Assim, uma vez construída a rede de Petri, os invariantes são calculados para demostrar a veracidade ou não das propriedades verificadas.

Uma vez obtidos os invariantes, um dos grandes problemas é a sua interpretação. Por tanto, a proposta deste trabalho foi definir os invariantes antes de construir a rede de Petri. $\mathrm{Na}$ maioria dos métodos usados para a obtenção dos invariantes, geralmente só é possível obter um subconjunto deles. Portanto, neste trabalho foram propostos algoritmos para o cálculo de invariantes baseado em métodos de álgebra linear que oferecem um conjunto de vetores que representa um gerador mínimo de todos os invariantes possíveis, onde qualquer combinação linear deles é também um invariante. Com isto se garante a obtenção de todos os invariantes possíveis.

Este método de verificação baseado no cálculo dos invariantes tem algumas vantagens em relação a outras técnicas de verificação existentes. A principal vantagem está no baixo custo computacional para obter os resultados, comparado com outros métodos de verificação. Porém, 
outras técnicas de verificação como model checking, permitem a verificação de um conjunto mais amplo de propriedades; sendo esta a principal limitante da verificação usando os invariantes. Outra vantagem da verificação formal usando invariantes, é que pode ser feita em diferentes níveis de abstração usando hierarquia, como foi demostrado em (FOYO, 2001). Significa que, os invariantes obtidos nas sub-redes são mantidos na rede principal.

A grande vantagem desta proposta é que o processo de verificação é simplificado, por não existir mais o problema da interpreteção dos invariantes. Porém continua tendo a desvantagens da maioria dos métodos formais: o alto nível de conhecimento matemático requerido para seu uso. A forte base matemática necessária para representar os requisitos usando invariantes, torna seu uso muitas vezes ineficiente em muitos projetos comerciais.

Nos estudos de caso apresentados foram mostrados os principais resultados do trabalho quanto ao uso prático do método de desing proposto. A aplicação do método proposto mostrou que o uso dos invariantes é mais adequado para verificar requisitos funcionais, fundamentalmente aqueles que precisem ser preservados durante todo o funcionamento do sistema. Para outras propriedades dinâmicas, como por exemplo a presença de deadlocks, os invariantes são menos adequados, porque só oferecem condições necessárias mas não suficiente para sua verificação.

No terceiro estudo de caso apresentado, foi obtido como resultado da modelagem, uma rede hierárquica do sistema, que permite a verificação dos principais requisitos de forma prática, embora o tamanho da rede dificulte a interpretação física. Sendo assim, o mais adequado para modelar este tipo de problema, seria usar uma rede de alto nível. Para isto, seria mais conveniente partir das especificações em UML para uma rede alto nível. Entretanto, ainda não existem métodos eficientes computacionalmente que permitam a análise dos invariantes nas redes de alto nível.

\subsection{Trabalhos Futuros}

A abordagem de design proposta possui grandes vantagens; porém existem sistemas nos quais seria mais adequado uma modelagem em redes de alto nível. Embora a rede de Petri de alto nível possua a mesma expressividade que a rede de Petri Place/transition, podem ser mais adequadas para modelar sistemas com um número elevado de instancias. O principal problema 
destas redes reside na análise dos modelos através de invariantes, uma vez que ainda não existem métodos razoavelmente eficientes que permitam automatizar o cálculo de invariantes. Sendo assim, a melhor alternativa para usar o método proposto seria reduzir a rede de alto nível a uma rede P/T para calcular os invariantes. Por isso, neste trabalho, foi usada uma rede Place/transition para modelar, analisar e verificar sistemas.

Porém, devido às dificuldades encontradas para representar sistemas com muitas instâncias de um mesmo objeto, seria conveniente estender o método proposto para sintetizar os modelos em redes de alto nível e trabalhar ao mesmo tempo em novos métodos para o cálculo de invariantes sobre as redes de alto nível, ou construir os modelos em redes de alto nível, mas fazer a verificação usando os modelos das redes Lugar/Transição, explorando o teorema de Smith (SMITH, 1998) que garante a correspondência biunívoca entre passagem clássicas (Lugar/Transição) e HLPN (High Level Petri Nets) e de existência de um processo (algorítmo) reversível para transformar uma na outra. Portanto, é possível usar um método de síntese, primeiro gerando uma rede HLPN, e depois, com base no teorema de Smith, converter redes HLPN em redes P/T (SMITH, 1998), gerar uma rede de Petri GHENeSys que possa ser verificada usando as técnicas apresentadas neste trabalho, explorando as extensões. Assim, a proposta para o trabalho futuro pode ser dividida nas seguintes fases:

- Redefinição da rede GHENeSys para suportar a modelagem de redes de alto nível: existe já uma proposta apresentada na dissertação de mestrado de (MIRALLES, 2012), que inclui na definição de GHENeSys, a possibilidade de colocar marcas de diferentes tipos nos lugares. Com isto a rede GHENeSys incrementaria o seu pontecial de modelagem.

- Adaptação e implementação dos algoritmos de dobramento e desdobramento, para converter redes de Petri de alto nível em redes Petri clássicas, apresentados em (SMITH, 1998), para ser usados no sistema computacional GHENeSys

Outra proposta para o trabalho futuro é a integração entre o ambiente GHENeSys e o ambiente para projetos de sistemas de planejamento itSIMPLE (Integrated Tools and Software Interface for Modeling PLanning Environments) (VAQUERO et al., 2007), e assim possibilitar a implementação dos algoritmos de transformação UML-GHENeSys propostos neste trabalho. 


\section{REFERÊNCIAS}

ALLA, H.; LADET, P.; MARTINEZ, J.; SILVA-SUAREZ, M. Modelling and validation of complex systems by coloured petri nets application to a flexible manufacturing system. In: Advances in Petri Nets 1984. [S.1.]: Springer, 1985. p. 15-31. Citado 2 vezes nas páginas 53 e 57.

ANTÓN, A. I.; POTTS, C. The use of goals to surface requirements for evolving systems. In: IEEE. Software Engineering, 1998. Proceedings of the 1998 International Conference on. [S.1.], 1998. p. 157-166. Citado na página 71.

BARESI, L.; PEZZÈ, M. Improving uml with petri nets. Electronic Notes in Theoretical Computer Science, v. 44, p. 107-119, 2001. Citado 4 vezes nas páginas 28, 75, 93 e 94.

BILLINGTON, J. et al. High-level petri nets-concepts, definitions and graphical notation, version 4.7. 3. Final Draft International Standard ISO/IEC, v. 15909, 2002. Citado 2 vezes nas páginas 39 e 40 .

BJORNER, N.; BROWNE, A. Automatic generation of invariants and intermediate assertions. Theoretical Computer Science, v. 173, p. 49-87, 1997. Citado na página 52.

CABOT, J.; GOGOLLA, M. Object constraint language (ocl): a definitive guide. In: Formal methods for model-driven engineering. [S.1.]: Springer, 2012. p. 58-90. Citado na página 74.

CAMPOS, J. C. C.; SILVA, M. On liveness analysis through linear algebraic techniques. In: CITESEER. In Proceedings of the Annual General Meeting of ESPRIT Basic Research Action 3148 Design Methods Based on Nets (DEMON. [S.1.], 1990. Citado 2 vezes nas páginas 46 e 83.

CARDOSO, J.; VALETTE, R. Redes de Petri. [S.1.]: Editora da UFSC, 1997. Citado na página 59.

CHUNG, L.; NIXON, B. A.; YU, E.; MYLOPOULOS, J. Non-functional requirements in software engineering. [S.1.]: Springer Science \& Business Media, 2012. v. 5. Citado na página 69.

COUSOT, P.; HALBWACHS, N. Automatic discovery of linear restraints among variables of a program. In: Proceedings of the 5th ACM SIGACT-SIGPLAN Symposium on Principles of Programming Languages. New York, NY, USA: ACM, 1978. (POPL'78), p. 84-96. Disponível em: <http://doi.acm.org/10.1145/512760.512770>. Citado na página 52.

CRILLY, T. The rise of cayley's invariant theory (1841-1862). Historia mathematica, Elsevier, v. 13, n. 3, p. 241-254, 1986. Citado na página 50.

DARDENNE, A.; LAMSWEERDE, A. V. Goal-directed requirements acquisition. Science of computer programming, Elsevier, v. 20, n. 1, p. 3-50, 1993. Citado na página 88. 
DARDENNE, A.; LAMSWEERDE, A. V.; FICKAS, S. Goal-directed requirements acquisition. Science of computer programming, Elsevier, v. 20, n. 1-2, p. 3-50, 1993. Citado na página 71.

DENARO, G.; PEZZE, M. Petri nets and software engineering. In: Lectures on Concurrency and Petri Nets. [S.1.]: Springer, 2004. p. 439-466. Citado na página 78.

DESEL, W. R. J. Place/transition petri nets. Lecture Notes in Computer Science, v. 1491, p. 122-173, 1998. Citado na página 40.

DICESARE, F.; KULP, P. T.; GILE, M.; LIST, G. The application of petri nets to the modeling, analysis and control of intelligent urban traffic networks. In: VALETTE, R. (Ed.). Application and Theory of Petri Nets 1994. [S.1.]: Springer Berlin Heidelberg, 1994, (Lecture Notes in Computer Science, v. 815). p. 2-15. ISBN 978-3-540-58152-9. Citado na página 117.

DOBING, B.; PARSONS, J. How uml is used. Commun. ACM, ACM, New York, NY, USA, v. 49, n. 5, p. 109-113, maio 2006. ISSN 0001-0782. Disponível em: <http://doi.acm.org/10. 1145/1125944.1125949>. Citado na página 72.

DORFMAN, M.; THAYER, R. Guide to software requirements specification. IEEE Standards, Guidelines and Examples on System and Software Requirements Engineering, 1990. Citado na página 69 .

E., Y.; KANTOR, J. C. Modelling and optimal control of discrete- event chemical processing using petri nets. Computers \& Chemical Engineering, v. 15, p. 503-519, 1991. Citado na página 104.

FLOYD, R. W. Assigning meanings to programs. Mathematical aspects of computer science, v. 19, n. 19-32, p. 1, 1967. Citado na página 53.

FOYO, P. D. GHENeSys : Uma Rede Estendida Orientada a Objetos Para Projeto De Sistemas Discretos. Dissertação (Mestrado) - Departamento de Mecatrônica, Escola Politécnica da Universidade de São Paulo, Brasil, 2001. Citado 5 vezes nas páginas 49, 50, 110, 145 e 155.

FOYO, P. M. G. del. Verificação Formal de Sistemas Discretos Distribuídos. Tese (Doutorado) - Escola Politécnica da Universidade de São Paulo, 2009. Citado 3 vezes nas páginas 121, 156 e 158 .

FOYO, P. M. G. del; SALMON, A. O.; SILVA, J. R. Requirements analysis of automated projects using uml/petri nets. In: Proc. of Congresso Internacional de Engenharia Mecânica. [S.1.: s.n.], 2011. Citado na página 75.

FRAPPIER, M.; HABRIAS, H. Software specification methods: an overview using a case study. [S.1.]: Springer Science \& Business Media, 2012. Citado na página 75.

GE FUKUNAGA T., N. M. Q.-W. On generating elementary t-invariants of petri nets by linear programming. Circuits and Systems, 2005. ISCAS 2005. IEEE International Symposium on, Vol. 1, p. 168-171, 2005. Citado na página 54.

GENRICH, H. J. Predicate/transition nets. In: Petri Nets: Central Models and Their Properties. [S.1.]: Springer, 1987. p. 207-247. Citado na página 40. 
GOGUEN, J. A.; LINDE, C. Techniques for requirements elicitation. In: IEEE. Requirements Engineering, 1993., Proceedings of IEEE International Symposium on. [S.1.], 1993. p. 152164. Citado na página 28.

GUERRA, E.; LARA, J. de. A framework for the verification of uml models. examples using petri nets. In: JISBD 03: VIII Jornadas de Ingeniería del Software y Bases de Datos: actas. Alicante: Universidad de Alicante. [S.1.: s.n.], 2003. p. 325-334. Citado na página 28.

HADDAD, S.; COUVREUR, J. Towards a general and powerful computation of flows for parametrized coloured nets. In: Proceedings of the 9th European Workshop on Applications and Theory of Petri Nets. [S.1.: s.n.], 1988. Citado na página 57.

HOARE, C. A. R. An axiomatic basis for computer programming. Communications of the ACM, ACM, New York, NY, USA, v. 12, n. 10, p. 576-580, out. 1969. ISSN 0001-0782. Disponível em: <http://doi.acm.org/10.1145/363235.363259>. Citado na página 53.

HORKOFF, J.; AYDEMIR, F. B.; CARDOSO, E.; LI, T.; MATÉ, A.; PAJA, E.; SALNITRI, M.; MYLOPOULOS, J.; GIORGINI, P. Goal-oriented requirements engineering: A systematic literature map. In: IEEE. Requirements Engineering Conference (RE), 2016 IEEE 24th International. [S.1.], 2016. p. 106-115. Citado na página 71.

HORKOFF, J.; LI, T.; LI, F.-L.; SALNITRI, M.; CARDOSO, E.; GIORGINI, P.; MYLOPOULOS, J. Using goal models downstream: A systematic roadmap and literature review. International Journal of Information System Modeling and Design (IJISMD), IGI Global, v. 6, n. 2, p. 1-42, 2015. Citado na página 71.

IRWIN, G.; TURK, D. An ontological analysis of use case modeling grammar. Journal of the Association for Information Systems, v. 6, n. 1, p. 2, 2005. Citado na página 72.

JACKSON, M. Requirements and specifications: a lexicon of software practice, principles and prejudices. Addison Wesley, Wokingham., 1995. Citado na página 68.

JENSEN, K. . Coloured petri nets: A high level language for system design and analysis. In: SPRINGER. International Conference on Application and Theory of Petri Nets. [S.1.], 1989. p. 342-416. Citado na página 40.

JENSEN, K. . Coloured Petri nets: basic concepts, analysis methods and practical use. [S.l.]: Springer Science \& Business Media, 2013. v. 1. Citado 4 vezes nas páginas 53, 56, 59 e 66.

JENSEN, K. Coloured petri nets and the invariant-method. Theoretical computer science, Elsevier, v. 14, n. 3, p. 317-336, 1981. Citado na página 56.

JENSEN, K.; KRISTENSEN, L. M. Colored petri nets: modelling and validation of concurrent systems. Springer Verlag, ISBN, v. 978, n. 3, p. 642, 2009. Citado na página 66.

JENSEN, K.; KRISTENSEN, L. M.; WELLS, L. Coloured petri nets and cpn tools for modelling and validation of concurrent systems. International Journal on Software Tools for Technology Transfer, Springer, v. 9, n. 3-4, p. 213-254, 2007. Citado na página 59.

KAIYA, H.; HORAI, H.; SAEKI, M. Agora: Attributed goal-oriented requirements analysis method. In: IEEE. Requirements Engineering, 2002. Proceedings. IEEE Joint International Conference on. [S.1.], 2002. p. 13-22. Citado na página 71. 
KERKOUCHE, E.; CHAOUI, A.; BOURENNANE, E.-B.; LABBANI, O. A uml and colored petri nets integrated modeling and analysis approach using graph transformation. Journal of Object Technology, v. 9, n. 4, p. 25-43, 2010. Citado na página 75.

KINDLER, E. Software and systems engineering-high-level petri nets, part 2: Transfer format. International Standard ISO/IEC, p. 15909-2, 2005. Citado 2 vezes nas páginas 41 e 42.

KOTONYA, G.; SOMMERVILLE, I. Requirements engineering: processes and techniques. [S.1.]: Wiley Publishing, 1998. Citado na página 68.

KURT, J. How to find invariants for coloured petri nets. Mathematical Foundations of Computer Science 1981, Springer, p. 327-338, 1981. Citado 3 vezes nas páginas 55, 57 e 58.

LAMCH, D. Verification and analysis of properties of dynamic systems based on petri nets. In: IEEE COMPUTER SOCIETY. Parallel Computing in Electrical Engineering, 2004. International Conference on. [S.1.], 2002. p. 92-92. Citado na página 83.

LAMSWEERDE, A. V. Requirements engineering in the year 00: a research perspective. In: ACM. Proceedings of the 22nd international conference on Software engineering. [S.1.], 2000. p. 5-19. Citado 3 vezes nas páginas 67, 69 e 71.

LAMSWEERDE, A. van. Goal-oriented requirements enginering: a roundtrip from research to practice [enginering read engineering]. In: IEEE. Requirements Engineering Conference, 2004. Proceedings. 12th IEEE International. [S.1.], 2004. p. 4-7. Citado na página 67.

LAPOUCHNIAN, A. Goal-oriented requirements engineering: An overview of the current research. University of Toronto, p. 32, 2005. Citado na página 67.

LAUTENBACH, K. Linear algebraic techniques for place/transition nets. In: Petri nets: central models and their properties. [S.1.]: Springer, 1987. p. 142-167. Citado na página 44.

LEITE, J. C. S. d. P. Viewpoints on viewpoints. In: ACM. Joint proceedings of the second international software architecture workshop (ISAW-2) and international workshop on multiple perspectives in software development (Viewpoints' 96) on SIGSOFT'96 workshops. [S.1.], 1996. p. 285-288. Citado na página 92.

LIU, L.; YU, E.; MYLOPOULOS, J. Analyzing security requirements as relationships among strategic actors. In: Proceedings of the 3rd Symposium on Requirements Engineering for Information Security. West Lafayette, IN: CERIAS - Purdue University, 2002. (CERIAS '02), p. 4:1-4:14. Disponível em: <http://dl.acm.org/citation.cfm?id=2835417.2835421 >. Citado na página 27.

LIU, X. F.; YEN, J. An analytic framework for specifying and analyzing imprecise requirements. In: IEEE COMPUTER SOCIETY. Proceedings of the 18th international conference on Software engineering. [S.1.], 1996. p. 60-69. Citado na página 28.

MACAULAY, L. A. Requirements engineering. [S.1.]: Springer Science \& Business Media, 2012. Citado na página 68.

MACHADO, J. M.; CAMPOS, J. C.; SOARES, F.; LEãO, C. P.; SILVA, J. C. L. F. da. Simulation and formal verification of industrial systems controllers. In: Proceedings of the 19th International Congress of Mechanical Engineering. Brasilia, Brazil: ABCM, 2007. Citado 3 vezes nas páginas 107, 115 e 116. 
MERLIN, P. M. A Study of the Recoverability of Computing Systems. Tese (Doutorado) University of California, Irvine, 1974. Citado na página 43.

MERLIN, P. M.; FARBER, D. J. Recoverability of communication protocols-implications of a theoretical study. Communications, IEEE Transactions on, IEEE, v. 24, n. 9, p. 1036-1043, 1976. Citado na página 157.

MIRALLES, J. A. S. P. GHENeSys, uma rede unificada e de alto nível. Dissertação (Mestrado) — Departamento de Mecatrônica, Escola Politécnica da Universidade de São Paulo, Brasil, 2012. Citado na página 146.

MURATA, T. Petri nets: properties, analysis, and applications. IEEE, v. 77, p. 541-580, 1989. Citado 7 vezes nas páginas 36, 43, 44, 45, 47, 48 e 83.

OLVER, P. J. Classical invariant theory. [S.1.]: Cambridge University Press, 1999. v. 44. Citado na página 50.

OMG. OMG Unified Modeling Language, versão 2.5. [s.n.], 2015. Disponível em: <http: //www.omg.org/spec/UML/2.5/PDF>. Citado 2 vezes nas páginas 73 e 91.

PARSHALL, K. H. The british development of the theory of invariants (1841-1895). BSHM Bulletin, Taylor \& Francis, v. 21, n. 3, p. 186-199, 2006. Citado na página 50.

PARVEEN, S.; IMAM, A. Analysis of different techniques of gore (goal oriented requirement engineering). Global Sci-Tech, Al-falah School of Engineering and Technology, v. 9, n. 1, p. 22-36, 2017. Citado na página 71.

PETERS, G.; WILKINSON, J. H. On the stability of gauss-jordan elimination with pivoting. ACM New York, NY, USA, v. 18, p. 20 - 24, 1975. Citado na página 79.

R., B.; A.E., M. On the analysis of some structural properties of petri nets. IEEE Transactions on Systems, Man and Cybernetics, Part A, v. 35, p. 784- 794, 2005. Citado 2 vezes nas páginas 54 e 55.

RAMCHANDANI, C. Analysis of asynchronous concurrent systems by timed petri nets. Massachusetts Institute of Technology, 1974. Citado na página 43.

REISIG, W. Petri nets computer science modeling. Systems Biology Computational Biology, v. 16, p. 37-56, 2011. Citado na página 55.

ROBINSON WILLIAM N; PAWLOWSKI, S. D. V. V. Requirements interaction management. ACM Computing Surveys (CSUR), ACM, v. 35, n. 2, p. 132-190, 2003. Citado na página 78.

ROZENBERG, J. E. G. Elementary net systems. In: Lectures on Petri Nets I: Basic Models, Advances in Petri Nets, the volumes are based on the Advanced Course on Petri Nets. London, UK: Springer-Verlag, 1998. p. 12-121. ISBN 3-540-65306-6. Citado na página 40.

RUMBAUGH, J.; JACOBSON, I.; BOOCH, G. Unified modeling language reference manual. [S.1.]: Pearson Higher Education, 2004. Citado na página 72.

SALDHANA, J.; SHATZ, S. M. Uml diagrams to object petri net models: An approach for modeling and analysis. In: CITESEER. International Conference on Software Engineering and Knowledge Engineering. [S.1.], 2000. p. 103-110. Citado na página 75. 
SALMON, A. Z. O.; FOYO, D.; GONZÁLEZ, P. M.; SILVA, J. R. et al. Verification of automated systems using invariants. In: SBA. Congresso Brasileiro de Automática-CBA. Belo Horizonte. [S.1.], 2014. Citado 2 vezes nas páginas 32 e 58.

SALMON, A. Z. O.; MIRALlES, J.; FOYO, P. M. G. del; SILVA, R. Towards a unified view of modeling and design with ghenesys. In: 21st International Congress of Mechanical Engineering. [S.1.: s.n.], 2011. Citado 4 vezes nas páginas 32, 50, 64 e 83.

SALMON, A. Z. O.; SILVA, J. R. Usando invariantes na analise de requisitos. In: CBA Congresso Brasileiro de Automática. Campina Grande/PB-Brasil. [S.1.: s.n.], 2012. Citado 2 vezes nas páginas 32 e 58 .

SALMON, O. A. Z.; FOYO, D.; GONZÁLEZ, P. M.; SILVA, J. R. et al. Planejamento de ações em sistemas hierárquicos temporizados usando ghenesys. In: SBA. Congresso Brasileiro de Automática-CBA. Vitória, ES. [S.1.], 2016. Citado 3 vezes nas páginas 32, 58 e 142.

SANTOS, E.; SILVA, J. R. Applying petri nets to requirements validation. ABCM Symposium Series in Mechatronics, v. 1, p. 508-517, 2005. Citado na página 28.

SIAU, K.; LEE, L. Are use case and class diagrams complementary in requirements analysis? an experimental study on use case and class diagrams in uml. Requirements engineering, Springer, v. 9, n. 4, p. 229-237, 2004. Citado na página 72.

SILVA J. MARTINEZ, P. H. M. Generalized inverses and the calculation invariants for coluored petri nets. Tecnique et science informatique, v. 4, p. 113-126, 1985. Citado 2 vezes nas páginas 56 e 57.

SILVA J. R. ; DEL FOYO, P. M. G. Timed petri nets. Petri Nets Manufacturing and Computer Science, v. 1, p. 359-378, 2012. Citado na página 42.

SILVA JOSE REINALDO ; DEL FOYO, P. M. G. J. S. A. O. Introducing object-orientation in unified petri net approach. In: Proceedings of the 20th International Congress of Mechanical Engineering. [S.1.: s.n.], 2009. Citado na página 155.

SILVA JOSÉ REINALDO; SANTOS, E. A. . V. T. S. Specification and analysis for automated flexible manufacturing. In: Proceedings of the International Congress of Mechanical Engineering. [S.1.: s.n.], 2005. Citado na página 92.

SILVA, M. Half a century after carl adam petri s ph. d. thesis: A perspective on the field. Annual Reviews in Control, Elsevier, v. 37, n. 2, p. 191-219, 2013. Citado 3 vezes nas páginas 35, 43 e 44 .

SILVA, M.; TERUE, E. Linear algebraic and linear programming techniques for the analysis of place/transition net systems. In: Lectures on Petri Nets I: Basic Models. [S.1.]: Springer, 1998. p. 309-373. Citado 2 vezes nas páginas 53 e 54.

SMITH, E. Principles of high-level net theory. In: Lectures on Petri Nets I: Basic Models, Advances in Petri Nets, the volumes are based on the Advanced Course on Petri Nets. London, UK: Springer-Verlag, 1998. v. 1491, p. 174-210. ISBN 3-540-65306-6. Citado 3 vezes nas páginas 56, 64 e 146 . 
SOLNON, C.; CUNG, V. D.; Nguyen, A.; Artigues, C. The car sequencing problem: overview of state-of-the-art methods and industrial case-study of the ROADEF2005 challenge problem. European Journal of Operational Research (EJOR), Elsevier, v. 191, n. 3, p. 912-927, dez. 2008. Citado na página 107.

SOMMERVILLE. Software Engineering (7th Edition). [S.1.]: Pearson Addison Wesley, 2004. ISBN 0321210263 . Citado na página 67.

SOMMERVILLE, I. Engenharia de software, $8^{a}$ edição, tradução: Selma shin shimizu mel-nikoff, reginaldo arakaki, edilson de andrade barbosa. São Paulo: Pearson Addison-Wesley, v. 22, p. 103, 2007. Citado na página 69.

SOMMERVILLE, I.; SAWYER, P. Requirements engineering: a good practice guide. [S.l.]: John Wiley \& Sons, Inc., 1997. ISBN 0471974447. Citado na página 68.

SONG, S. W. Análise de invariantes na rede de Petri Ghenesys. Tese (Doutorado) - Universidade de São Paulo, 1997. Citado na página 50.

SULTAN, A.; BANO, J.; HUNDEWALE, N. Goal oriented requirements engineering-a review. In: CITESEER. 24th International Conference on Computer Applications in Industry and Engineering, Honolulu, Hawaii, USA, CAINE. [S.1.], 2011. p. 16-18. Citado na página 69.

TADAO, M. Temporal uncertainty and fuzzy-timing high-level petri nets. In: Application and Theory of Petri Nets 1996. [S.1.]: Springer, 1996. p. 11-28. Citado na página 43.

TIWARI, A.; RUESS, H.; SAÏDI, H.; SHANKAR, N. A technique for invariant generation. In: Tools and Algorithms for the Construction and Analysis of Systems. [S.1.]: Springer, 2001. p. 113-127. Citado na página 52.

VAQUERO, T. S.; ROMERO, V.; TONIDANDEL, F.; SILVA, J. R. itsimple 2.0: An integrated tool for designing planning domains. In: 18th International Conference on Automated Planning and Scheduling. Providence, Rhode Island: [s.n.], 2007. Citado na página 146.

VAQUERO, T. S.; SILVA, J. R. A brief review of tools and methods for knowledge engineering for planning \& scheduling. Knowledge Engineering for Planning and Scheduling 2011, v. 2, p. 7, 2011. Citado na página 28.

VAUTHERIN, G. M. J. Computation of flows for unary predicates transition nets. Advances in Petri nets, v. 4, n. 1, p. 113-126, 1985. Citado na página 57.

WAKUDA, M.; YAMAUCHI, M.; TAOKA, S.; WATANABE, T. A fast and space-saving algorithm fmsn for computing petri net invariants with supports containing all specified nodes. EIC Technical Report (Institute of Electronics, Information and Communication Engineers), v. 99, n. 204, p. 37-44, 1999. Citado na página 53.

YALAMOV, P. Y. On the backward stability of gauss-jordan elimination. In: Computing. [S.1.]: Springer Wien, 1991, (Mathematics and Statistics, v. 47). p. 193-197. Citado na página 79.

YAMALIDOU, K.; MOODY, J.; LEMMON, M.; ANTSAKLIS, P. Feedback control of petri nets based on place invariants. Automatica, Elsevier, v. 32, n. 1, p. 15-28, 1996. Citado na página 103. 
YU, E. S. Towards modelling and reasoning support for early-phase requirements engineering. In: IEEE. Requirements Engineering, 1997., Proceedings of the Third IEEE International Symposium on. [S.1.], 1997. p. 226-235. Citado na página 71.

ZEICHICK, A. Uml adoption making strong progress. Software development times, v. 15, 2004. Citado na página 78.

ZHAO, Y.; FAN, Y.; BAI, X.; WANG, Y.; CAI, H.; DING, W. Towards formal verification of UML diagrams based on graph transformation. In: IEEE COMPUTER SOCITY. Proceedings of the IEEE International Conference on E-Commerce Technology for Dynamic E-Business. [S.1.], 2004. Citado 2 vezes nas páginas 75 e 76. 


\section{REDE DE PETRI GHENESYS}

A rede GHENeSys foi desenvolvida para atender as fases 1 e 2 da norma e algumas extensões, como hierarquia, gates inibidores e habilitadores, e elementos de conexão externa, ou pseudoboxes, além da inclusão do tempo.

Assim é possível definir GHENeSys como uma rede de Petri (P/T ou HLPNG) hierárquica, orientada a objetos e com tempo (SILVA JOSE REINALDO ; DEL FOYO, 2009). A rede baseda em P/T tem uma equação de estado formalmente definida (FOYO, 2001), incluindo as extensões. Portanto os elementos básicos para analisar propriedades da rede são similares aos das redes clássicas coexistem com os elementos macro, os gates, lugares especiais para conexão entre o sistema estudado e o contexto (pseudo-lugares), a hierarquia e a versão temporizada e temporal. No caso da modelagem de sistemas de controle os pseudo-lugares representam eventos observáveis mas não-controláveis. O problema para a formalização destes pseudo-lugares é que estes têm marcação persistente e não podem ser afetados pela evolução das marcas.

Na rede GHENeSys, tanto os lugares (boxes) quanto as transições (atividades), podem representar subredes através da existência dos elementos "macros". Também se tem o fato de que a rede GHENeSys admite multiplicidade de marcas nos lugares o que nos leva à necessidade de diferenciar as marcas dependendo do tempo de criação ou permanência num determinado lugar.

Por esta razão, as marcas precisam do atributo tempo, de vital importância para a determinação das atividades habilitadas e as regras de disparo. 
Introduzindo multiplicidade nas marcas será necessário uma definição de multi-set que será usada na representação das marcações da rede GHENeSys.

Definição A.1 (Multi-set). Um multi-set $b$, sobre um conjunto $A$, é uma função de $A$ em $N$, $b: A \rightarrow N$. Se $a \in A$ então $b(a)$ é o número de vezes que o elemento $a$ aparece no multi-set $b$. $A_{M S}$ é o conjunto de todos os multi-sets sobre $A$. O multi-set vazio e denotado como $\varnothing$.

A seguir é mostrada a definição formal da rede GHENeSys (FOYO, 2009).

Definição A.2 (GHENeSys). GHENeSys é uma tupla $G=\left(L, A, F, K, \Pi, C_{0}, \tau\right)$ na qual $(L, A, F, K, \Pi)$ representa a estrutura da rede, $C_{0}$ é um conjunto de multisets representando a marcação inicial, e $\tau$ é uma função que mapeia os intervalos de tempo a cada elemento da rede.

- $L=B \cup P$, são os lugares os quais podem ser denominados Boxes e pseudo-boxes;

- A são as atividades;

- $F \subseteq(L \times A \rightarrow N) \cup(A \times L \rightarrow N)$ é a relação de fluxo;

- $K: L \rightarrow N^{+}$é a função de capacidade;

- $\Pi:(B \cup A) \rightarrow\{0,1\}$ é a função que identifica os elementos macro;

- $C_{0}=\left\{\left(l, \sigma_{j}\right)\left|l \in L, \sigma_{j} \in R^{+}\right| l \mid \leq K(l)\right\}$ é o conjunto das marcas no estado inicial;

- $\tau:(B \cup A) \longrightarrow\left\{Q^{+}, Q^{+} \cup\{\infty\}\right\}$ é uma função que mapeia os intervalos de tempo para cada elemento da rede.

O conjunto das marcas é composto pelos pares $\left(l, \sigma_{j}\right)$ onde $l \in L$ determina o lugar onde a marca se encontra e $\sigma_{j}$ é o relógio que mede o tempo que a marca permaneceu neste lugar. Os relógios estão sincronizados com um relógio global e são atualizados cada vez que uma transição acontece. Como podem existir várias marcas num mesmo lugar o conjunto das marcas é na realidade um multi-set.

O mapeamento $\tau$ associa um intervalo de tempo para cada elemento do tipo Box ou atividade. Carece de sentido associar um intervalo de tempo aos pseudo-boxes uma vez que estes são elementos com marcação permanente, isto é, a marcação dos pseudo-boxes não é modificada 
pela dinâmica da rede ${ }^{1}$. Os intervalos de tempo ligados aos elementos da rede seguem diferentes semânticas dependendo do tipo de elemento. Por exemplo, nos boxes, o intervalo de tempo representa o tempo mínimo ou máximo que uma marca pode permanecer neste elemento. Nas atividades, o intervalo de tempo possui a mesma semântica que as transições em redes TPN, como proposto por Merlin(MERLIN; FARBER, 1976).

Os intervalos de tempo são formados pelos extremos inferior e superior. Para cada elemento $e \in B \cup A$ da rede, o intervalo de tempo será denominado como $[\downarrow e, \uparrow e] \operatorname{com} \downarrow e \in Q^{+}$ $\mathrm{e} \uparrow e \in Q^{+} \cup\{\infty\}$.

\section{A.1 Diagrama de classes da rede GHENeSys}

A figura 51 mostra o diagrama de classes padrão usado no desenvolvimento do ambiente GHENeSys.

Como os pseudo-boxes podem representar elementos que são boxes em outras redes foi acrescentado na classe pseudo-box o metodo GetCurrentMarking o qual permite obter a marcação do elemento referenciado pelo atributo MasterElement. Este metodo e usado nas rotinas que determinam se uma determinada atividade esta habilitada ou não.

$\overline{1}$ Existem casos especiais onde a marcação dos pseudo-boxes é modificada, que serão discutidos mais adiante. 
Figura 51 - Novo Diagrama de Classes da rede GHENeSys

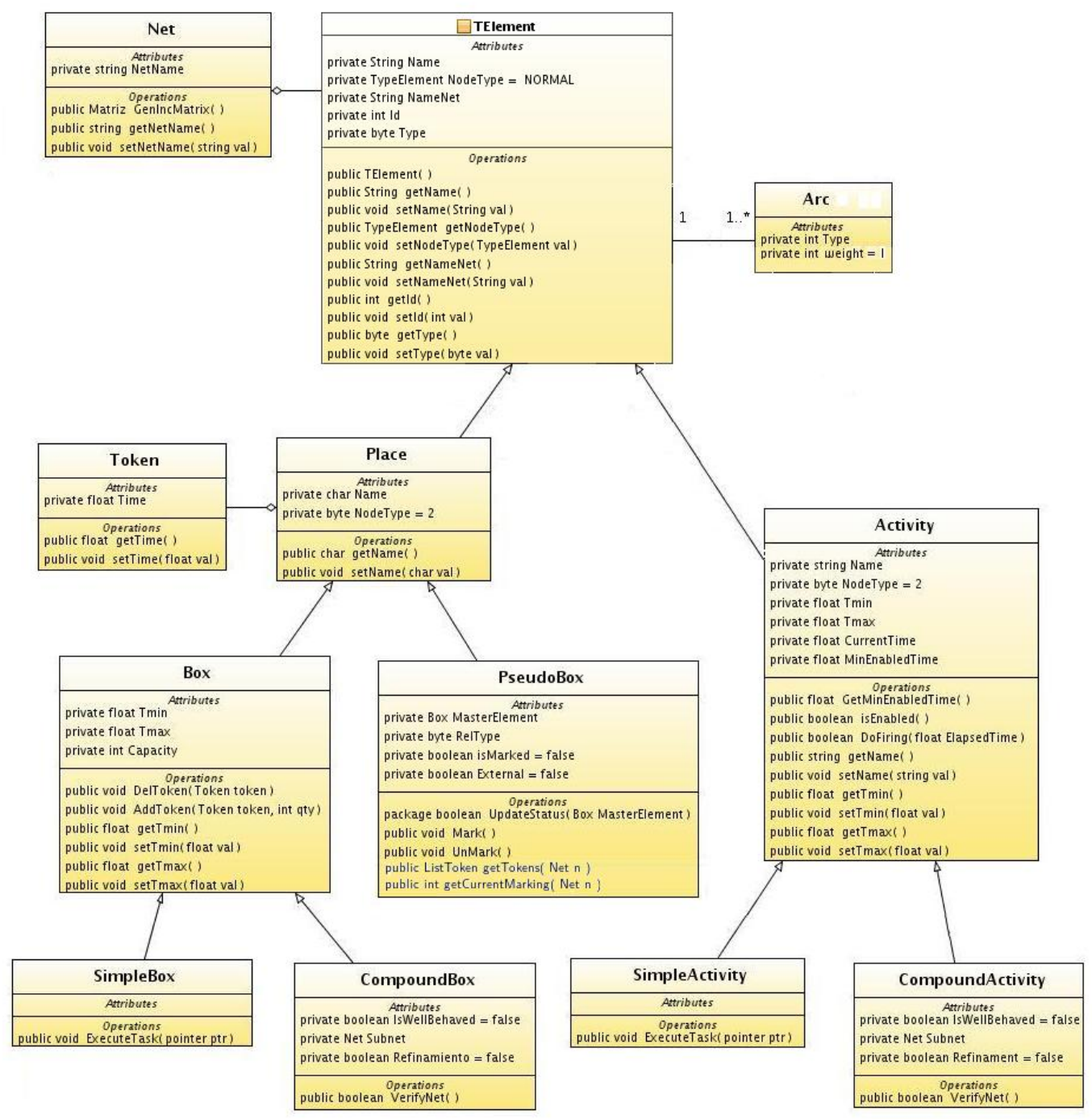

Fonte: (FOYO, 2009). 
Um sistema de equações lineares da forma:

$$
\left[\begin{array}{ccc}
a_{11} x_{1}+a_{12} x_{2}+\ldots+a_{1 n} x_{n} & = & b_{1} \\
a_{21} x_{1}+a_{22} x_{2}+\ldots+a_{2 n} x_{n} & & b_{2} \\
\vdots & & \vdots \\
a_{m 1} x_{1}+a_{m 2} x_{2}+\ldots+a_{1 m n} x_{n} & = & b_{m}
\end{array}\right]
$$

é chamado sistema de equações lineares com $m$ equações e $n$ incógnitas, onde os (coeficientes) $a_{i j}$ e os (termos independentes) $b_{i}$ são elementos conhecidos e os $x_{j}$ são elementos desconhecidos (incógnitas). O número $n$ de incógnitas pode ser maior, menor ou igual ao numero de equações $m$.

Os coeficientes $a_{i j}$ e os termos independentes $b_{i}$ pertencentes as equações (B.1) podem ser rearranjados de modo a compor duas matrizes, (B.2) e (B.3):

$$
\mathbf{A}=\left[\begin{array}{cccc}
a_{11} & a_{12} & \ldots & a_{1 n} \\
a_{21} & a_{22} & \ldots & a_{2 n} \\
\vdots & \vdots & \ddots & \vdots \\
a_{m 1} & a_{m 2} & \ldots & a_{m n}
\end{array}\right]
$$




$$
\mathbf{A}^{*}=\left[\begin{array}{ccccc}
a_{11} & a_{12} & \ldots & a_{1 n} & b_{1} \\
a_{21} & a_{22} & \ldots & a_{2 n} & b_{2} \\
\vdots & \vdots & \ddots & \vdots & \vdots \\
a_{m 1} & a_{m 2} & \ldots & a_{1 m n} & b_{m}
\end{array}\right]
$$

As matrizes $A$ e $A^{*}$ são denominadas respectivamente matriz principal e matriz ampliada do sistema de equações (B.1). Este sistema pode ser representado de forma matricial como segue:

$$
A \cdot x=b
$$

onde $b$ é a matriz coluna $\left(b_{1}, b_{2}, \ldots, b_{m}\right)$ dos termos independentes; $A$ é a matriz de coeficientes do sistema de equações lineares (B.1), e $x$ é o vetor das incógnitas.

Definição B.1 (Solução de um sistema de equações lineares). Se entende como solução do sistema de equações lineares (B.1) a um conjunto de $n$ números $k_{1}, k_{2}, \ldots, k_{n}$ que quando são substituídos por cada elemento desconhecido do sistema (incógnita), transforma as equações em identidades.

Definição B.2 (Posto de uma matriz). O posto (rank) das colunas de uma matriz $A$ é o número máximo de colunas linearmente independentes de $A$. Similarmente, o posto das linhas é o numero máximo de linhas linearmente independentes de $A$. Uma vez que o posto das linhas e das colunas é sempre o mesmo, se denomina simplesmente posto de $A$ ao número de componentes linearmente independentes (linha ou coluna) e se denota $R(A)$.

Teorema B.1. Teorema de Rouche-Frobenius Seja $A$ a matriz de coeficientes e $A^{*}$ a matriz aumentada de um sistema de equações lineares. Se $R(A)=R\left(A^{*}\right)$, então o sistema é dito compatível. $\operatorname{SeR}(A)=R\left(A^{*}\right)=$ numero de incógnitas, então o sistema é compatível determinado (significa que a solução é única). Se $R(A)=R\left(A^{*}\right)<$ numero de incógnitas, então o sistema é compatível indeterminado (significa que o sistema tem infinitas soluções). Se $R(A) \neq R\left(A^{*}\right)$, então o sistema é incompatível (significa que não tem soluções dentro do conjunto dos números reais).

A figura 52 mostra o resultado deste teorema. 
Figura 52 - Teorema de Rouche-Frobenius

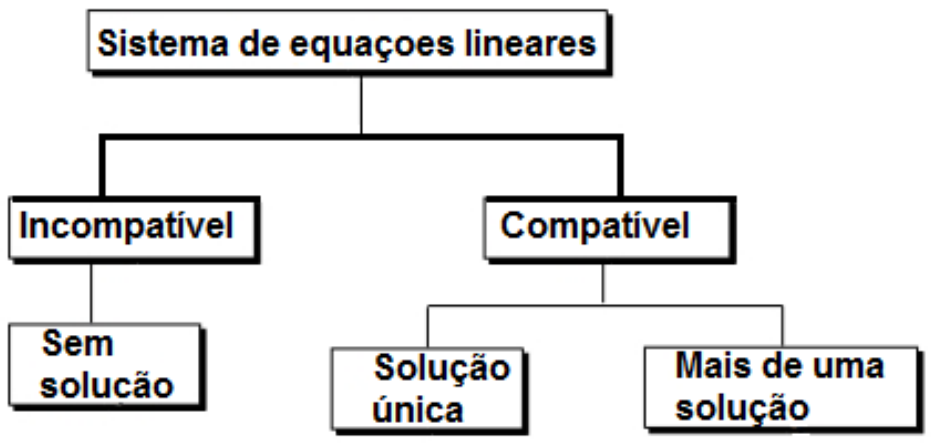

Fonte: Elaborada pela autora.

\section{B.1 Sistemas de equações lineares homogêneos}

Um sistema de equações lineares é homogêneo se todos os termos independentes são nulos, como se mostra na equação (B.5).

$$
\left[\begin{array}{cccccc}
a_{11} x_{1} & +a_{12} x_{2} & +\ldots & +a_{1 n} x_{n}= & 0 \\
a_{21} x_{1} & +a_{22} x_{2} & +\ldots & +a_{2 n} x_{n}= & 0 \\
\vdots & \vdots & \ddots & \vdots & \vdots \\
a_{m 1} x_{1} & +a_{m 2} x_{2} & +\ldots & +a_{m n} x_{n}= & 0
\end{array}\right]
$$

onde os $a_{i j}$ são os elementos conhecidos, enquanto os $x_{1}, x_{2}, \ldots, x_{n}$ são as incógnitas. O sistema (B.5) pode ser representado também em forma matricial, (B.6).

$$
A \cdot x=0
$$

Na equação (B.6) $A$ é uma matriz de dimensão $m x n$, onde a coluna $j$ está formada pelos coeficientes da equação $j$ do sistema. $x=\left(x_{1}, x_{2}, \ldots, x_{n}\right)$ é o vetor de incógnitas. $\mathrm{O}$ vetor nulo $(0, \ldots, 0)$ é sempre uma solução do sistema para qualquer valor dos coeficientes $a_{i j}$, e é denominada solução nula ou trivial. 


\section{B.2 Conjunto solução de um sistema de equações linea- res homogêneos}

Todo sistema de equações lineares homogêneos tem pelo menos uma solução, conhecida como a solução nula ou trivial. Em geral o conjunto solução dos sistemas lineares homogêneos cumpre as seguintes propriedades:

- Se $u$ e $v$ são dois vetores solução de um sistema homogêneo, então a soma destess vetores $u+v$ também é uma solução do sistema.

- Se $u$ é um vetor solução de um sistema homogêneo, e $r$ é um numero inteiro, então o produto $r u$ é também uma solução do sistema.

Os sistema homogêneos são um caso particular dos sistemas de equações lineares. Aplicando o teorema de Rouche-Frobenius aos sistemas homogêneos podemos obter o seguinte resultado:

Teorema B.2 (Sistemas de equações lineares homogêneos). A dimensão do espaço solução dos sistemas de equações homogêneos lineares com $n$ incógnitas é igual à diferença $n-r$, onde $r$ é o posto do sistema B.5.

Se $r=n$, pelo teorema de Rouche-Frobenius, o sistema deve ter uma solução única, que seria a solução trivial para os sistemas homogeneos.

Se $r<n$, o sistema de equações lineares homogêneos tem soluções diferentes da solução nula. 